\title{
Spinal cord stimulation in critical limb ischemia
}

Citation for published version (APA):

Spincemaille, G. H. J. J. (2001). Spinal cord stimulation in critical limb ischemia. [Doctoral Thesis, Maastricht University]. Datawyse / Universitaire Pers Maastricht. https://doi.org/10.26481/dis.20010704gs

Document status and date:

Published: 01/01/2001

DOI:

10.26481/dis.20010704gs

Document Version:

Publisher's PDF, also known as Version of record

\section{Please check the document version of this publication:}

- A submitted manuscript is the version of the article upon submission and before peer-review. There can be important differences between the submitted version and the official published version of record.

People interested in the research are advised to contact the author for the final version of the publication, or visit the DOI to the publisher's website.

- The final author version and the galley proof are versions of the publication after peer review.

- The final published version features the final layout of the paper including the volume, issue and page numbers.

Link to publication

\footnotetext{
General rights rights.

- You may freely distribute the URL identifying the publication in the public portal. please follow below link for the End User Agreement:

www.umlib.nl/taverne-license

Take down policy

If you believe that this document breaches copyright please contact us at:

repository@maastrichtuniversity.nl

providing details and we will investigate your claim.
}

Copyright and moral rights for the publications made accessible in the public portal are retained by the authors and/or other copyright owners and it is a condition of accessing publications that users recognise and abide by the legal requirements associated with these

- Users may download and print one copy of any publication from the public portal for the purpose of private study or research.

- You may not further distribute the material or use it for any profit-making activity or commercial gain

If the publication is distributed under the terms of Article $25 \mathrm{fa}$ of the Dutch Copyright Act, indicated by the "Taverne" license above, 
SPINAL CORD STIMULATION IN CRITICAL LIMB ISCHEMIA 
ISBN 9052783128

(C) GHJJ Spincemaille, Maastricht 2001

Vormgeving en druk: Datawyse / Universitaire Pers Maastricht 


\title{
Spinal cord stimulation in critical limb ischemia
}

\author{
Proefschrift \\ ter verkrijging van de graad van doctor \\ aan de Universiteit Maastricht, \\ op gezag van de Rector Magnificus, \\ Prof Dr A.C. Nieuwenhuijzen Kruseman \\ volgens het besluit van het College van Decanen \\ in het openbaar te verdedigen op 4 juli 2001 om 14.00 uur \\ door
}

Geert Helena Joris Jan Spincemaille

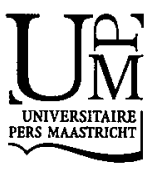


Promotores

Prof dr M.J.H.M. Jacobs

Prof dr D.A. Bosch (Universiteit van Amsterdam)

Co-promotor

Dr D.Th. Ubbink (Universiteit van Amsterdam)

Beoordelingscommissie

Prof dr P.J.E.H.M Kitslaar (voorzitter)

Prof dr C.G.M.I. Baeten

Prof dr E.J. Beuls

Prof dr M.E. Durieux

Prof dr J. Gybels (Katholieke Universiteit Leuven)

Prof dr M.A. van den Hout 


\section{Contents}

\section{CHAPTER 1}

Introduction 7

\section{CHAPTER 2}

Spinal cord stimulation in patients with critical limb ischaemia:

A preliminary evaluation of a multicenter trial. $\quad 19$

\section{CHAPTER 3}

Spinal cord stimulation in critical limb ischaemia:

A randomized trial. $\quad 29$

\section{CHAPTER 4}

Pain and quality of life in patients with critical limb ischaemia: Results of a randomized controlled multicenter study on the effect of spinal cord stimulation. $\quad 45$

\section{CHAPTER 5}

Technical data and complications of spinal cord stimulation: Data from a randomized trial on critical limb ischaemia. $\quad 65$

\section{CHAPTER 6}

Microcirculatory investigations to determine the effect of spinal cord stimulation for critical leg ischaemia: The Dutch Multicenter Randomized Controlled study. $\quad 77$

\section{CHAPTER 7}

Prediction of imminent amputation in patients with non-reconstructible leg ischemia by means of microcirculatory investigations. 93

\section{CHAPTER 8}

The Results of Spinal Cord Stimulation in Critical Limb Ischaemia:

A Review $\quad 107$ 
CHAPTER 9

General discussion $\quad 121$

CHAPTER 10

Summary 129

Samenvatting 131

DANKWOORD 135

CURRICULUM VITAE $\quad 139$ 


\section{Introduction}

\section{CRITICAL LIMB ISCHEMIA}

The second European consensus document (SECD) on chronic critical leg ischemia defines critical limb ischemia in non-diabetic patients as rest pain or tissue necrosis (ulceration or gangrene) with an ankle systolic pressure (ASP) of $\leq 50 \mathrm{~mm} \mathrm{Hg}$, or a toe pressure of $\leq 30 \mathrm{~mm} \mathrm{Hg}$. (European working group 1992) Ischemia is defined as a lower than normal supply of blood flow resulting in a deficit of $\mathrm{O}_{2}$ and nutritive substances delivered at the periphery. The disturbed metabolism causes pain when extra blood supply is required after exercise. If the disease progresses, pain is also present at rest. The best known symptom in the early stages is intermittent pain as in vascular claudication. Further progress of reduced blood flow results in under-perfusion of tissues. Endangered skin regions are subjected to ischemia leading to ulcerations and gangrene.

Critical limb ischemia as defined is comparable with patients classified as Fontaine III and IV in addition to the pressure parameters. None of the criteria of the consensus is evaluated for its prognostic value in predicting outcome of the threatened limb. This was clearly demonstrated by Thompson and Jacobs, who found in their series that only about $50 \%$ of the patients classified as severely ischemic fulfilled the criteria of the consensus document, simply because the other $50 \%$ had an ASP $>50 \mathrm{~mm} \mathrm{Hg}$ and an outcome similar to those with an ASP $\leq 50 \mathrm{~mm} \mathrm{Hg}$. (Thompson et al 1993, Jacobs et al 1988). There is some agreement as to the prognostic value of skin lesions. Limb salvage in patients with CLI and ulcerations larger than $3 \mathrm{~cm}^{3}$ or gangrene is much lower than it would be if these skin lesions were not present. (Broseta et al 1986, Tallis et al 1992)

Wolfe presented an overview of the different definitions of CLI. His suggestion to look for high and low risk patients is a step in the right direction, however, he does not mention the microcirculatory measurements. (Wolfe et al 1997) Carter and Bunt proposed modified haemodynamic definitions for critical and subcritical ischemia, which include measurements of pressures and indices of microcirculation.(Carter et al 1997, Bunt et al 1996) The debate which might lead to a better classification of patients with CLI belongs to the vascular surgeons. An important part of the discussion will 
certainly be the value of microcirculatory measurements. There are different ways to assess blood flow and there is no consensus on the best prognostic indicator. This means that further studies are needed to find out which method has the best prognostic value and can discriminate responders (limb salvage) from non-responders. Ubbink describes that adding a combination of toe blood pressure (TBP) and transcutaneous $\mathrm{pO}_{2}$ $\left(\mathrm{TcpO}_{2}\right)$ using cut-off values of $38 \mathrm{~mm} \mathrm{Hg}$ for TBP and $35 \mathrm{~mm} \mathrm{Hg}$ for $\mathrm{TcpO}_{2}$ in supine position has a better prognostic value. (Ubbink et al 2000) Gersbach uses the difference between sitting and supine $\mathrm{TcpO}_{2}$ as a better predictor of outcome. (Gersbach et al 1997) Fiume reported that pain relief was only obtained in patients who showed an improved $\mathrm{TcpO}_{2}$ during trial stimulation, an observation also made by Jacobs. Petrakis suggested that a trial period of two weeks should be considered before final implantation, because those who show a significant increase in $\mathrm{TcpO} 2$ in that period have a better outcome. (Petrakis et al 1999)

The criteria of the SECD concern patients with "chronic" CLI! This means, at least, pain persisting for more than 2 weeks as used in the Dutch trial. In his study, Kumar only included patients if they were treated conservatively for 6 months; this represents a different population.(Kumar et al 1997) Looking at the limb survival of patients with CLI it is obvious that the first two to three months after the diagnosis of CLI are very important as a large number of patients are amputated within this period.

Recently, in a consensus document on the definition of CLI, some recommendations have been proposed for the definition and the trials on CLI. It is clear from this document that there is no real consenus on inclusion criteria and investigation of patients at risk of an amputation within months after the diagnosis of CLI. (Chronic CLI 2000)

\section{Chronic pain}

Since the sixties it has become clear that the best modality for treating pain was not to destroy pain pathways, but to try to restore function. As knowledge on pain mechanisms accumulated, the idea of a more dynamic central nervous system working with balances of inhibition and excitation was introduced. An enormous step forward was the gate theory of Wall and Melzack.(Melzack et al 1965) This theory (hypothesis) is illustrated as a schematic interaction between primary, secondary neurones and interneurones at the level of the dorsal horn of the spinal cord. It gives a possible explanation of what happens when a peripheral painful stimulus arrives at the dorsal horn: Not a simple activation of the second neurone 
(spinothalamic tract), but a complex integrated response conducted to the central nervous system. The first idea on this dynamic balance was introduced by Noordenbos who certainly merits more credit than generally given. He is remembered in a recent article by Melzack entitled: "From the gate to the neuromatrix". Melzack wrote: "How the (gate) theory actually came into being involves an amusing sequence of events. Pat and I proposed a general theory of somesthesis in the form of eight propositions. We then toyed with the idea of using this general "theory" as the basis for a theory that dealt exclusively with pain but we made no headway and put the project aside. Then things unexpectedly and suddenly started to fall into place. It began in the fall of 1962, when I first stumbled onto William Noordenbos' 1959 book on pain. That brilliant little book led me to have a flash of insight. Fig 1A shows Noordenbos' concept of pain. He did not fill in the circle in the dorsal horns to show how large fibers inhibit small ones. He just said that they did, and showed a picture of the substantia gelatinosa to illustrate the complexity of the dorsal horn anatomy. He then went on to explain temporal and spatial summation, referred pain, and other properties of pain after nerve surgery. However Noordenbos' story stops at the thalamus- the $\mathrm{T}$ at the top. My idea was to put a cortex on Bill's thalamus, show the dorsal column projection as a rapid, precise feedforward system to activate psychological processes, with a feedback to the circle to modulate the input. Here, at last, was the beginning of a conceptual model in which brain processes can select, filter and modulate pain processes." (Melzack 1999)

Initially the gate theory was vigorously critized, but thereafter a slow and steady increase in the number of articles sustaining and refining the theory was published. There are numerous clinical and functional descriptions of modern pain processing all based on the concept of the gate theory and the supraspinal control. One thing is, however, clear; many clinical conditions are not explained by this theory alone.

Pain perception can be described as follows. A peripheral receptor (cold, heat, mechanoreceptor) is activated and transmits a signal to the central nervous system. This is perceived as painful if the content of the information is such that the spinal and supraspinal systems alert the cortical and subcortical areas and evoke a reaction which we define as pain. This is true inasmuch as the conduction system is not structurally disturbed by mechanical or other means. If such a disturbance exists somewhere in the nervous system, "spontaneous" pain may be present and is generally defined as neuropathic pain. This can be explained by a mismodulation of the brain in the interpretation of activity in nerves and neurones. Many people suffer from chronic spontaneous pain, while they cannot explain the 
cause of their pain and as a matter of fact they are frequently not believed. This leads to secondary reactions affecting the environment of the patient. These observations explain that if pain is primarily an unpleasant experience it may have far greater consequences for an individual. The effects may be difficult to measure and to compare between patients who perhaps suffer from the same problem. Comparison of chronic pain therapies is difficult if only pain is measured and not the other health-related quality of life components.

Ischemic pain, the main symptom in CLI, is most probably a combination of nociceptive and neuropathic pain. The simple clinical evidence that ischemic pain is at least for a major part nociceptive is the positive effect of drugs such as opioids. The use of spinal cord stimulation which was proposed to treat patients with lesions in the neuronal pathways (e.g. peripheral nerve lesions) is not expected to have much influence on ischemic pain unless peripheral nerve lesions are involved. One may consider that in the presence of skin lesions, the peripheral nerves and their endings may degenerate following ischemia and therefore ischemic pain may be partially due to neuropathy. If one accepts this hypothesis then the effect of SCS on ischemic pain is more easily understood.

\section{Spinal cord stimulation - neuromodulation}

The enormous efforts performed by the scientists to eludicate the enigma of central nervous system processing may help clinicians to understand the possible working mechanisms of neuromodulatory techniques. Generalizing, pain is due to an overexcitation of peripheral neurones or an abnormal excitation of second order neurones in the spinal cord. Spinal cord stimulation is in that perspective an excellent technique capable of inhibiting an abnormal excitatory status. This neurophysiological explanation was followed by a more basic approach indicating the possible role of neurotransmitters, e.g. GABA, and other excitatory and inhibitory compounds such as aspartate and glutamate. Specific receptors have been studied and drugs are available that have specific actions, although some are still too toxic to be widely used. Important progress has, however, been made in specific pain drugs which may shift therapy in the future more towards drug development than to electrical therapy. Currently, the major disadvantages of drugs are their side effects and the uncertainty of their impact on humans after longterm use. 
Spinal cord stimulation was introduced in clinical practice by Shealy (Shealy et al 1967). Initially invasive surgery using a limited laminectomy, was needed for the implantation of the lead. Percutaneous implantation became possible after changes in the design of the lead. The flat surface was made cylindrical and resulted in the possibility to introduce it into the epidural space via a Touhy needle. The percutaneous technique made the method accessible to nonsurgical disciplines.

A spinal cord stimulator consists of a cylindrical lead mostly with four electrodes, a connection cable and a pulse generator. The technical evolution to improve all components is an ongoing process which restricts the evaluation of the therapy to the actual technical state. The major drawback for wide implementation is still the rate of complications, such as lead fracture, dislocation and infection. Another reason for the slow increase in number of implementations is the need for an accurate selection of eligible patients, the not always easy implantation procedure and the desirability of longterm follow-up.

\section{Technique of SCS}

In most cases, local anaesthesia is used to position the lead in the epidural space. General anaesthesia makes a correct placement of the electrode nearly impossible, because patients cannot provide information on the exact area where paraesthesias are felt. An epidural or a good regional block with complementary sedation makes it possible to perform a laminectomy with a patient still able to provide information on stimulation. The paraesthesias are phantom sensations created by SCS which activates the dorsal column neurones. When treating patients with critical limb ischemia, it is essential to obtain paraesthesias in the painful region of the limb, but the same is true for several other chronic pain conditions.

The site of puncture of the epidural space with a Touhy needle is two or three levels below the area where the tip of the lead will finally be positioned. The best technique is an oblique ( 45 degrees to the surface) and paramedian route in order to avoid sharp angles of the lead when perforating the ligamentum flavum of the epidural space. The lead is always positioned medially or slightly lateral to the midline in the dorsal part of the epidural space. Fluoroscopic control during the procedure is mandatory. Positioning of the lead in the epidural canal is the most important part of the procedure. One should be careful to avoid migration of the lead during the subsequent stage of the procedure. Fixation of the lead at the level of the superficial fascial layer is necessary. The lead is connected to an extension cable, which in turn is connected to the pulse generator. The whole system is implanted subcu- 
taneously in the same way as a pacemaker. The patient obtains an external programmer which allows the generator to be switched on and off. Another feature is the possibility of changing amplitude, pulse width and pulse rate; usually only the option of changing amplitude is activated. The physician can, however, fully control and programme the pulse generator using a remote external programmer.

\section{Effects of SCS on ischemia}

Cook was the first to notice that spinal cord stimulation (SCS) in patients with a neurological disease such as multiple sclerosis, spinal cord lesions, resulted in autonomic changes. He assumed that a regional increase in blood flow might be the underlying mechanism. [1973] Three years later he published a small study of nine patients, with varying degrees of limb ischemia resulting from failure of sympathectomy or bypass procedures. He observed a striking pain relief, while infarcted tissue was not restored but healing of wounds was promoted after SCS. He concluded: "It is indeed probable that persistent spinal cord stimulation will avert the need for amputation in some patients. It certainly can be considered as another alternative before progression to amputation after failure of all other known therapeutic modalities". (Cook et al 1976) Dooley observed the same phenomenon of increased blood flow in patients stimulated for central nervous system disorders such as multiple sclerosis, olivopontocerebellar atrophy, amyotrophic lateral sclerosis and Friedreich's ataxia. (Dooley et al 1976) Trying to elucidate the phenomenon he used transcutaneous electrical stimulation in a patient with a cervical radiculitis. Electrodes were placed over the right side of the cervical spine. A one-channel impedance plethysmograph was connected to the right finger. Electrostimulation for $2^{1 / 2}$ minutes resulted in a fall in impedance that was interpreted as equivalent to a $154 \%$ increase in blood flow to the finger. He concluded: "Electrostimulation over the posterior spinal roots and the spinal cord, although not new, has not been used extensively for the treatment of patients with arterial disease. Electrostimulation of the nervous system is not designed to replace standard therapeutic measures of treatment of patients with vascular disease, but to supplement them."

Tallis suggested three possible mechanisms whereby SCS could influence blood flow.

1. Conventional pain relief might reverse the sympathetic vasoconstriction that occurs in response to pain. The observation that adequate pain relief correlates with improved capillary flow would be in keeping with this. 2 . SCS induces an electrical sympathetic paralysis (with or without concomitant 
stimulation of cholinergic vasodilators). 3 . The antidromic stimulation of dorsal root afferents causing sustained vasodilatation has been demonstrated both in man and animals. (Tallis et al 1992)

Ghajar found that depending on the level of stimulation there was a more pronounced increase in capillary blood flow and skin temperature if the stimulation electrode was placed below the vertebral level $T_{10}$ or preferably at $\mathrm{T}_{12}$. (Ghajar et al 1998)

In his thesis, Linderoth formulated the following general conclusions on the possible action of SCS. (Linderoth Thesis 1992):

1. In man dorsal column stimulation (DCS) induces increased CSF levels of substance $\mathrm{P}$ (SP), presumably of spinal origin.

2. Spinal microdialysis is suitable for studies of SP-release in the dorsal horn in response to noxious electrical stimulation of a peripheral nerve.

3. In response to peripheral noxious stimuli SP is released both in the ipsiand contralateral dorsal horn of the spinal cord.

4. In the cat DCS induces release of both serotonin and SP in the dorsal horn of the spinal cord as measured with microdialysis.

5. The activation of $S P$ release by DCS probably requires the involvement of supraspinal mechanisms. SP released in the dorsal horn by noxious stimulation and that released by DCS presumably originate from separate neuronal pools, possibly with different functional properties.

6. The alleviation of ischemic and other types of pain by DCS may involve at least partly different mechanisms.

7. The vasodilatation hypothetically underlying the suppression of the ischemic pain is not dependent on intact connections with the supraspinal centres or on antidromic activation of primary afferent fibres, whether of large or small diameter.

8. The vasodilatory effects of DCS involve spinal and segmental mechanisms and require intact transmission through the ventral roots and sympathetic paravertebral ganglia via postganglionic noradrenergic neurones.

9. DCS exerts its influence in the peripheral vascular bed predominantly via transitory suppression of sympathetic vasoconstrictor control.

Some of the biochemical aspects of pain have been described in greater detail in many review articles. In his thesis, Cui gives an extensive description of the history of SCS and the pathophysiological and biochemical background of neuropathic pain. (Cui thesis 1999) If spontaneous pain is due to a hyperexcitatory state of primary or secondary order neurones, SCS seems to be able to inhibit the excitatory status. Recent publications on the pathophysiological processes involved in the generation of different types of 
pain indicate that tremendous progress has been made in unravelling the biochemical processes involved. The rapid evolution in genetic manipulation also provides the opportunity in pain research to "turn genes on and off", producing specific alterations in animals and thus facilitating the study of specific characteristics of receptors and the related neurotransmitters.

\section{State of the art before the randomised Dutch trial (1991)}

In the second half of the eighties and the beginning of the nineties, epidural spinal cord stimulation was seen as a possible alternative treatment for patients with peripheral arterial occlusive disease (PAOD) who were no longer eligible for vascular reconstruction. Spinal cord stimulation seemed to be useful whatever the origin of pain. Relieving pain would result in improved mobilization of the patient, which in turn would enhance blood flow and heal ulcers. If this was indeed the case, then the need for amputation would decrease.

Over a period of 10-15 years, case reports and series of patients have been published demonstrating that SCS was a very effective pain treatment. As inclusion criteria were frequently ill-defined, many reports contained a highly inhomogeneous group of patients (arteriosclerosis, vasospastic disease and others) sometimes at different stages of the disease. The belief that an amputation could be avoided in at least in 40 to $50 \%$ of the patients, motivated an increasing number of physicians to use the technique.

The positive sentiment towards the therapy was further driven by the publication of Augustinsson, who stated that indeed almost all patients (90\%) conservatively treated were amputated, while in the case of SCS this was only $34 \%$ (Augustinsson et al 1985). Some reports mentioned a near normalization of the blood flow in larger vessels proven by a normalization of Doppler ankle pressure or even Doppler waves. Due to the growing evidence, but considering the different way these results were reported, vascular surgeons produced an European Consensus document to at least harmonize the patient population under treatment.

If SCS could avoid limb amputation in a substantial proportion of the patients with critical limb ischemia, this would be an important gain for patients in whom the mortality rate was already $45-75 \%$ within 5 years. (Bertele et al 1999, Dormandy et al 1988)

Apart from the clinical criteria to select people for treatment, there was no common opinion at that time on the measurement of blood flow. In a leading article Jacobs and Jorning stated: "systolic ankle/arm pressure measurements at rest and after treadmill exercise are generally accepted as 
the best non-invasive method to document arterial obstruction of lower extremities.... It should be emphasised, however, that in patients with Fontaine stage III and IV not only is the macrocirculation inadequate, but especially in patients with ulcerations and gangrene, the microcirculation is also threatened. Tissue oxygen pressure measurement, laser Doppler flowmetry and isotope clearance techniques can be performed to study cutaneous blood flow. Intravital skin capillary microscopy is a direct and non-invasive method of studying the morphological pattern of skin microcirculation and allows the measurement of red blood cell velocity in the skin capillaries, which specifically reflects nutritional blood flow" (Jacobs et al 1998)

At the start of the Dutch study there was no consensus on how to measure blood flow in patients with critical ischemia.

\section{Aim of the study}

The results of SCS in patients with critical limb ischemia with a nonreconstructable occlusive arterial disease were insufficient to prove the efficiency of SCS regarding limb salvage. Pain relief alone was not a sufficiently strong argument to convince the community to use SCS widely, as pain relief could be obtained simply by other means such as conservative foot care and pain killers. It is, therefore, not surprising that Tallis stated in an editorial: "Although the clinical benefits of SCS in PVD have been established beyond doubt, many unanswered questions surround its use." (Tallis et al 1992) A randomised controlled study was the next step necessary to prove the efficacy of SCS therapy compared to conservative therapies. At the time the Dutch study was conceived, no randomised studies had been published. As large numbers of patients were needed to prove a statistical difference in limb salvage, it was obvious that the study had to be multicentred. A working group was formed, committed to participating in the long year effort collecting data and treating patients in a standardized fashion. A pilot study was carried out and the results led to a grant obtained from the government to initiate the Dutch multicentre randomised study. (Chapter 2) The primary outcome measure of the study was limb salvage. Other outcome measures were pain, quality of life, and cost-effectiveness. We considered a $30 \%$ difference in limb salvage rate between groups as statistically important; this was only half the rate predicted and described in the literature and discussed at meetings. An independent trial office was responsible for the randomisation, while the University of Rotterdam, Department of Epidemiology was the central office where data were collected. Klomp published the design of the trial in 1995. (Klomp et al 1995) 


\section{REFERENCES}

1. Augustinsson LE, Holm J, Carlsson CA et al. Epidural electrical stimulation of severe limb ischemia. Evidences of pain relief, increased blood flow and a possible limb saving effect. Ann Surg. 1985, 202:104-111.

2. Bertele V, Roncaglioni MC, Pangrazzi J, Terzian E, Tognoni. Clinical outcome and its predictors in 1560 patients with critical leg ischaemia. Eur I Vas Endovasc Surg. 1999,18:401-410.

3. Broseta J, Barbera J, de Vera JA. Spinal cord stimulation in peripheral arterial disease: a cooperative study. J Neurosurg 1986, 64:71-80.

4. Bunt TJ. TcpO 2 as an accurate predictor of therapy in limb salvage. Ann Vasc Surg 1996, 10:224

5. Carter SA.The challenge and importance of defining critical limb ischemia. Vasc Med 1997,2:126-131.

6. Chronic critical limb ischaemia. Eur J Vasc Endovasc Surg. 2000,19:S144-S243.

7. Cook AW, Oygar A, Baggentos P, Pacheco S, Kleriga E. Vascular disease of extremities: Electrical stimulation of spinal cord and posterior roots. NY State J Med. 1976,76: 366-368.

8. Cui JC. Spinal cord stimulation in neuropathy. Experimental studies of neurochemistry and behaviour. Thesis Stockholm 1999

9. Dooley D, Kasprak M. modifications of blood flow to the extremities by electrical stimulation of the nervous system. South Med J. 1976,69:1309-1311.

10. Dormandy JA, Thomas PRS. What is the natural history of a critical ischaemic patient with and without his leg? In: Greenhalgh RM, Jamieson CW, Nicolaides AN eds. Limb salvage and amputation for vascular disease. Philadelphia: Saunders 1988:11-26.

11. Duggan MM,Woodson J, Scott TE, Ortega AN, Menzoian JO. Functional outcomes in limb salvage vascular surgery. Am J Surg 1994, 168:188-191

12. European working group on critical leg ischemia: Second European consensus document on chronic critical leg ischemia. Eur J Vasc Surg 1992:6: (Suppl A), 1-32.

13. Fiume D, Palombi M, Sciassa V, Tamorri M. Spinal cord stimulation (SCS) in peripheral ischemic pain. Pacin Clin Electrophysiol 1989,12:698-704

14. Gersbach P, Hasdemir MG, Stevens RD, Nachbur B, Mahler F. Discriminative microcirculatory screening in patients with refractory limb ischaemia for dorsal column stimulation. Eur J Vas Endovasc Surg.1997,13:464-471.

15. Ghajar AW, Miles JB. The differential effect of the level of spinal cord stimulation on patients with advanced peripheral vascular disease in the lower limbs. Br J Neurosurg 1998,12:402-408.

16. Humphreys W, Evans F, Williams T. quality of life: Is it a pratical tool in patients with vascular disease? J Cardiovasc Pharmacol. 1994,23:S34-S36.

17. Humphreys W, Evans F, Williams T. Quality of life: Is it a practical tool in patients with vascular disease. J Cardiovasc Pharm. 23 suppl. 3:34-36,1994

18. Jacobs MJHM, Jorning PJG. Is epidural spinal cord stimulation indicated in patients with severe lower limb ischaemia? Eur J Vas Surg 2,207-208, 1988.

19. Klomp H.M., Spincemaille G.H., Steyerberg E.W., Berger MY, Habbema J.D.F., van Urk $\mathrm{H}$. Design issues of a randomised controlled clinical trial on spinal cord stimulation in critical limb ischemia. Eur J Vasc Endovasc Surg 1995; 10: 478-485.

20. Klomp HM, Spincemaille GHJJ, Steyerberg EW, Habbema JDF, van Urk H. Spinal cord stimulation in critical limb ischaemia: a randomised trial. Lancet 1999,353:1040-1044. 
21. Kumar K, Toth C, Nath RK, Verma AK, Burgess JJ. Improvement of limb circulation in peripheral vascular disease using epidural spinal cord stimulation: a prospective study. J Neurosurg 1997,86:662-669.

22. Linderoth B. dorsal column stimulation and pain. Experimental studies of putative neurochemical and neurophysiological mechanisms. Thesis Stockholm 1992.

23. Melzack R, Wall PD. Pain Mechanisms: a new theory. Science 1965,150:971-979.

24. Melzack R. From the gate to the neuromatrix. Pain suppl 6, 1999: S121-S126.

25. Noordenbos W. Pain. Problems pertaining to the transmission of nerve impulses which give rise to pain. Thesis 1959

26. Petrakis IE, Sciacca V. Does autonomic neuropathy influence spinal cord stimulation therapy success in diabetic patients with critical lower limb ischemia? Surg Neurol. 2000,53:182-188.

27. Petrakis IE, Sciacca V. epidural spinal cord stimulation in diabetic critical lower limb ischemia. J Diabetes Complications. 1999,13:293-299.

28. Shealy CN, Mortimer JT, Reswick JB. Electrical inhibition in pain by stimulation of the dorsal columns: Preliminary clinical report. Anest Analg. 1967,46:489-491.

29. Tallis R, Jacobs M, Miles J. Spinal cord stimulation in peripheral vascular disease. Editorial Br J Neurosurg 1992,6:101-105

30. Thompson MM, Sayers RD, Varty K, Reid A, London NJM, Bell PRF. Chronic critical leg ischaemia must be redefined. Eur J Vasc Surg 1993,7:420-426.

31. Ubbink DTh, Tulevski II, de Graaff JC, Legemate DA, Jacobs MJHM. Optimisation of the non-invasive assessment of critical limb ischaemia requiring invasive treatment. Eur J vas Endovasc Surg 2000, 19:131-137.

32. Wolfe JHN, Wyatt MG. Critical and subcritical ischaemia. Eur J Vasc Endovasc Surg 1997, 13:587-582 



\section{Spinal Cord Stimulation in Patients with Critical Limb Ischemia: A Preliminary Evaluation of a Multicentre Trial}

G. H. Spincemaille, H. M. Klomp*, E. W. Steyerberg**, and

J. D. F. Habbema** for the ESES study group

From the Department of Neurosurgery, University Hospital, Maastricht, The Netherlands, the *Department of Vascular Surgery, University Hospital Dijkzigt, Rotterdam, The Netherlands, and the ${ }^{* *}$ Department of Public Health, Erasmus University, Rotterdam, The Netherlands 


\section{SUMMARY}

Background: Spinal cord stimulation (SCS) is known to reduce chronic pain. The technique was offered to patients with critical limb ischemia due to atherosclerosis, in which vascular reconstruction was not possible.

Methods: 37 patients were randomized for standard treatment with analgesics and vasoactive drugs $(n=18)$ or electrical stimulation of the spinal cord in addition to the standard treatment $(n=19)$. The primary outcome measures were pain relief and limb salvage. Follow-up covered a period of 4 years.

Results: Amputation-free survival at 2 years was $39 \%$ for standard treatment and $61 \%$ for the stimulation plus standard treatment $(\mathrm{p}=0.08$, NS). Most amputations occurred within the first year after randomization. Pain relief was statistically significant in favour of the stimulation treatment $(p<0.001)$. None of the patients with good pain relief in the SCS-group was amputated. Limb salvage of this subgroup in the standard treatment was $75 \%$ at one year.

Conclusions: A larger multicenter randomized trial comparing SCS and conservative treatment is required to further establish the value of SCS in the treatment of critical limb ischemia. Follow-up of 2 years seems adequate to evaluate the effects of SCS. 


\section{INTRODUCTION}

Peripheral arterial ischemia due to atherosclerosis is a common disease in elderly. Intermittent claudication, a frequent manifestation of this disease, progresses to limb-threatening critical ischemia in a small number of patients. The progression is accompanied by pain at rest, skin ulcers, or both. About $30 \%$ to $40 \%$ of patients with peripheral arterial ischemia have diabetes mellitus (19). Healing of skin ulcers was described as an unexpected effect of spinal cord stimulation (SCS) and transcutaneous stimulation in patients treated for various neurological diseases $(5,13)$. Several authors confirmed an effect of SCS on pain and limb ischemia. (1, 2, 3, 7-12, $21,28)$. The hypothesis of a redistribution of blood flow was documented by Jacobs (11) using capillary microscopy. Linderoth (17) described inhibition of the sympathetic vasoconstriction in animal experiments. The effects on the macrocirculation are more conflicting and so far any effect is questionable $(1,2,21)$. Relief of chronic pain by SCS has been known for years and used in a number of neurological diseases $(14,15,18,22,23,24,27)$. Apart from the discussion on the underlying mechanism of SCS, clinicians are interested in a therapy that may increase limb salvage. Important to know is the accuracy of the difference in treatment outcome described in observational studies. Therefore, prospective randomized controlled studies are mandatory to prove the effects of SCS on ulcer healing, relief of ischemic pain and limb salvage.

\section{SUBJECTS AND METHODS}

The study was approved by the ethical committee of the hospitals involved and patients were enrolled after informed consent was obtained. Randomized blocks were used for treatment allocation in each center separately. Eligibility criteria are shown in Table 1 . Follow-up was scheduled at 1, 3, 6, 12,18 months and yearly thereafter. Standard treatment consisted of analgesics and vasoactive drugs together with optimal care in case of ulcerations or gangrene. The experimental treatment consisted of a spinal cord stimulator implantation (Itrel I - Medtronic - Minneapolis USA) in addition to the standard treatment (26). A spinal cord stimulation system included a lead, an extension cable and a pulse generator. The surgical procedure was performed under local anaesthesia with the patient in prone or lateral position under fluoroscopy. The lead was percutaneously placed in the epidural space, using a Touhy needle. In patients with pain in the lower limbs the lead was positioned between the thoracic vertebral level $11\left(\mathrm{Th}_{11}\right)$ and the 
Table 1. Inclusion and exclusion criteria: An upper limit for the ankle pressure of $50 \mathrm{~mm} \mathrm{Hg}$ was advised. It was left to the expertise of the vascular surgeon to decide if a patient was surgically non- reconstructible.

General condition: Surgically non-reconstructible atherosclerotic vessel disease of the lower limb.

Inclusion criteria: 1. Persisting pain at rest,

2. And / or skin lesions ( ulcerations or gangrene) in the region of the feet or toes, which surface may not exceed $3 \mathrm{~cm}^{2}$.

Exclusion criteria: 1. Arterial disease other than atherosclerotic.

2. Ulcerations or gangrene with a diameter larger than $3 \mathrm{~cm}^{2}$

3. Infections, which are difficult to treat and may cause septicemia.

4. Expected inadequate patient compliance.

5. Expected survival less than one year due to other diseases.

first lumbar $\left(\mathrm{L}_{1)}\right.$. Proper positioning of the lead was obtained when paresthesias were felt in the painful distal limb region following trial stimulation during implantation. The different parts of the system (lead, extension cable and pulse generator) were implanted subcutaneously and connected with each other. The pulse generator could be controlled from outside using an external programmer (Medtronic external programmer). Stimulation parameters were amplitude ( 0 to $10.5 \mathrm{~V}$ ), rate of stimulation (5 to $330 \mathrm{pps}$ ) and pulse width (60 to 450 ins). Limb survival was defined as patients alive without major amputations at last follow-up or dead without amputation. Minor amputations of the forefoot or toes were not considered as an end-point. Survival was defined as patients alive at the end of follow-up (censored observation). The Kaplan-Meier method was used to evaluate the limb survival. The Cox proportional hazard model was used to estimate the hazard ratio between the 2 treatment modalities. Descriptive analysis was performed for the evaluation of population characteristics and pain relief. Pain at intake was scored using the visual analogue scale (VAS) (4). The VAS is a simple method indicating intensity of pain on a scale from 0 to 10. During follow-up pain relief was classified as "excellent" = complete pain relief, "good" = equal or more than $50 \%$ pain relief, "moderate" = between 20 and $50 \%$ but still relevant to the patient, "none" less than $20 \%$ or worse. 
Table 2. Patient characteristics.

\begin{tabular}{lll}
\hline & Conservative (N=18) & SCS (N=19) \\
\hline age (range = 56-87) mean: & 69.5 & 72.2 \\
sex (m/f) & $14 / 4$ & $14 / 5$ \\
diabetes mellitus & 6 & 5 \\
& & \\
previous vascular surgery & 10 & 10 \\
Level A & 7 & 5 \\
Level B & 2 & 0 \\
Level C & 8 & 11 \\
previous sympathectomy & & \\
& 9 & 13 \\
other vascular risk factors & 3 & 11 \\
- hypertension & 8 & 14 \\
- coronary disease & 13 & 10 \\
- pulmonary disease & & 4 \\
- smoking & 7 & $37(22.7)$ \\
clinical examination skin lesions & 7 & $20(10.9)$ \\
- ulcerations & & $0.3(0.2)$ \\
- gangrene & $45(26.3)$ & \\
diagnostic evaluation (Doppler) mean (SD) & & \\
- ankle pressure (mm Hg) & $25(12.4)$ & \\
- toe pressure (mm Hg) & & \\
- index (brachial-ankle) & & \\
\hline
\end{tabular}

Population characteristics. Previous vascular surgery is divided into three levels. Level A refers to aorto-iliac, Level B refers to the femoro-popliteal region and Level $C$ refers to the crural region and the arch of the foot. Previous sympathectomy refers to surgical or chemical sympathectomy at the side of the involved limb. The Doppler measurements are restricted to 26 patients without diabetes. Toe pressure was measurable in only 15 ( 8 in the conservatively treated group and 7 in the SCS group) out of 21 patients.

\section{RESULTS}

At baseline, there were no statistically significant differences between patient characteristics of both groups (Table 2 ). 37 patients with surgically non-reconstructable peripheral arterial vessel disease and critical ischemia were randomized between 2 treatment modalities. 18 patients were assigned to standard treatment and 19 to spinal cord stimulation. The follow-up covered a period of 5.5 years. Median follow-up for amputation was 1690 days (CI: $25-75 \%=386-1834, n=19$ ). 


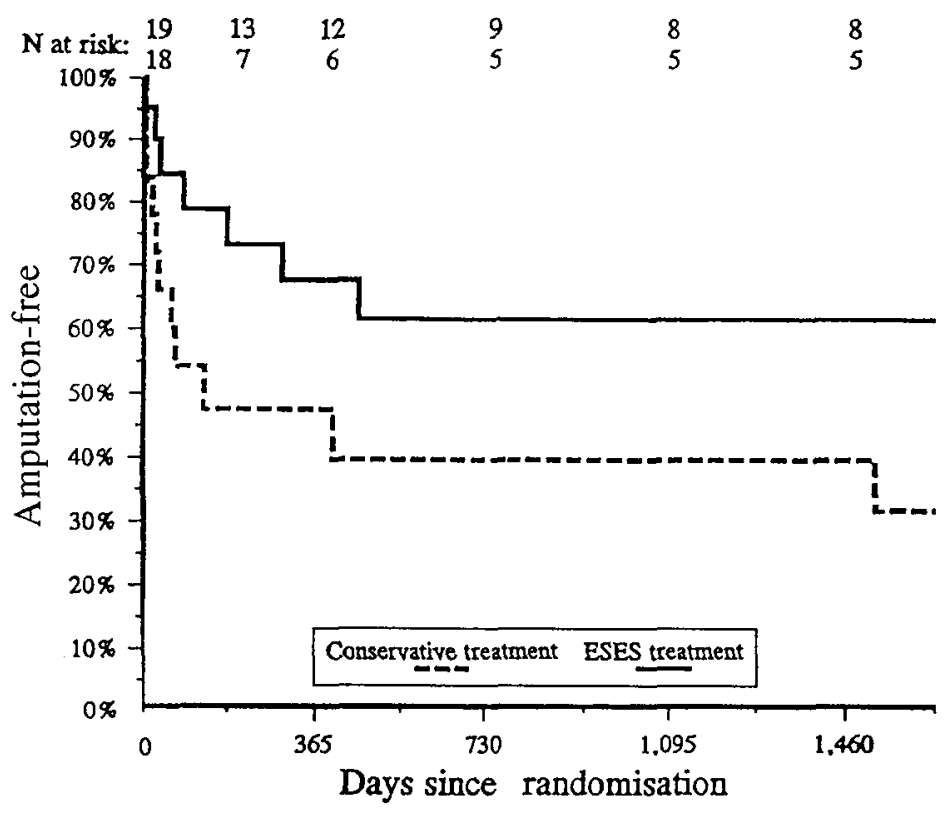

Figure 1. Limb salvage: The percentage of patients free of amputation is indicated in the ordinate. The follow-up covers a period of five years. Number of patients at risk indicated at the top of the figure

Limb survival at 2 years was $61 \%$ in the SCS group and $39 \%$ in the standard group ( $\mathrm{p}=0.08$ ) (Fig. 1). At 2 years follow-up patient survival was $68 \%$ in SCS and $61 \%$ in conservative treatment. At 5 years follow-up these percentages were 41 and 50. The hazard ratio for standard treatment was 2.3 (95\%-CI: 0.87-5.9), which means that the risk of amputation was 2.3 times higher in the standard treatment compared to SCS. The difference did however not reach the level of statistical significance (Cox proportional hazard model). At intake, pain intensity between the 2 groups was similar. The mean VAS score was $7.9(\mathrm{SD}=1.2)$ in SCS and 7.7 ( $\mathrm{SD}=1.4)$ in the standard group. Macrocirculatory data (ankle pressure, ankle/brachial index) were not significantly different between the 2 groups.

The mean VAS score at 3 months was $3.2(S D=2.4)$ for SCS and $6.2(S D=2.2)$ for the standard treatment $(\mathrm{p}=0.0004) .45 \%$ of the patients had good pain relief under SCS, $20 \%$ had moderate pain relief, $20 \%$ were unchanged and $15 \%$ were worse. In the standard treatment, $20 \%$ had a good pain relief, $5 \%$ had moderate pain relief, $35 \%$ no pain relief and $40 \%$ were worse. Most patients in the standard group continued to use major analgesics, especially 
morphine. The initial pain reduction in both groups persisted until a major complication occurred such as infection or progression of skin lesion. All patients with good pain relief in the SCS group survived without amputation compared to $75 \%$ in the standard group. Amputation in both groups occurred in all but one patient within the first 450 days after randomization. The technical problems encountered were mostly due to lead breakage or dislocation. The Sigma electrodes seemed to be quite vulnerable and in $15 \%$ $(n=3)$ lead fractures occurred at the point where the electrode left the fascial layers subcutaneously, making a sharp angle resulting in kinking and breakage of the wires in the silicone coating of the lead. No technical or infectious problems were encountered in our patients with regard to the pulse generator.

\section{DISCUSSION}

Our data indicate a significant reduction of pain in patients treated with SCS $(\mathrm{p}<0.001)$. The percentage of patients with good and moderate pain relief under SCS was $65 \%$. Life table analysis showed an amputation-free percentage at 2 years of $61 \%$ in the SCS group and $39 \%$ in the conservative group. This difference remained till the last follow-up at 5 years. There was a better limb survival in patients with good pain relief regarding both treatment modalities, compared to those with moderate or no pain relief. Pain relief as a result of SCS has been described in patients with ischemic pain due to peripheral atherosclerosis $(1,2,15,22,27)$. Some authors reported complete pain relief in 80 to $90 \%$ of the patients $(1,2,3)$. Others noted a decline over time in the number of patients with complete pain relief from $90 \%$ to $60 \%$ (11). Our results indicate a less pronounced effect of SCS on pain, but is in agreement with the observation that good or complete pain relief is a strong predictive factor regarding limb salvation. The difference in amputation-free survival between SCS and conservative treatment in our study was $22 \%$ after a follow-up of 2 years. Augustinsson found a $60 \%$ difference in favor of SCS, comparing a cohort of patients selected for stimulation with historical data of conservatively treated controls (1). Recently Jivegard reported a randomized trial on the effect of SCS in 51 patients with inoperable severe lower limb ischemia. The difference in amputation-free survival at 18 months between the 2 treatments was $17 \%$ in favor of SCS (12).

The high number of patients treated conservatively that survived without amputation was surprising. The amputation-free survival at 2 years in the conservatively treated group, was in the range of 39 to $45 \%$ (this study, 12). Augustinsson reported data of an amputation-free survival of only $10 \%$ after 
16 months of follow-up (1). This higher amputation frequency is difficult to explain as one would expect a similar outcome when patients are selected on the rigid criteria of "critical limb ischemia". However the reference group of patients (conservative treatment) in Augustinsson's study was a historical control group which may have differed from a group selected on the basis of the criteria of the European consensus on critical ischemia (6). In addition, a better care of ischemic ulcers and optimal adjustment of medical treatment is held responsible by some authors for a higher amputation-free survival (25).

The less pronounced effect on pain relief and limb salvage in our study may be due to the selection of patients with a more severe condition of limb ischemia. Randomization excluded preference of treatment by the referring physician. The small number of patients was responsible for a large variation in outcome.

The frequency of technical complications, dislocation and lead fracture, with monopolar leads is higher as with the actually used multipolar leads, which is still around $25 \%$ in the literature (26). Efforts to reduce these complications are made by developing new leads with different design and number of electrodes per lead.

\section{CONCLUSIONS}

SCS for patients with critical limb ischemia was less successful in our study than mentioned elsewhere. In order to determine more accurately the value of SCS in critical limb ischemia as defined in the European consensus document (6) a larger multicenter study is needed, which includes cost analysis (19) and quality of life measurement to determine the effectiveness of the treatment.

If 120 patients are enrolled the proposed study has a statistical power (1-ß) of more than $80 \%$ to detect an increase in median limb survival from 3 to 6 months with a $\alpha$-level of $5 \%$.

A follow-up period of 2 years seems adequate to evaluate the effect of treatment regarding the amputation frequency occurring within that period. Because circulation measurement did not reveal any effect on the macrocirculation, microcirculatory measurements as transcutaneous $\mathrm{PO}_{2}$, laser Doppler fluxmetry and capillary microscopy may be worthwhile to be studied as prognostic variables $(10,11)$. Such a study has been set up (14). 


\section{REFERENCES}

1. Augustinsson LE, Holm J, Carlsson CA, et al: Epidural electrical stimulation of severe limb ischemia. Evidences of pain relief, increased blood flow and a possible limb-saving effect. Ann Surg 1985; 202: 104-111.

2. Broseta J, Barbera J, de Vera JA, et al: Spinal cord stimulation in peripheral arterial disease. A cooperative study. J Neurosurg 1986; 64: 7l-80.

3. Bunt TJ, Holloway GA, Lawrence P, et al: Experience with epidural spinal stimulation in the treatment of end-stage peripheral vascular disease. Sem Vasc Surg 1991; 4:216-220.

4. Carlsson AM: Assessment of chronic pain. I. Aspects of the reliability and validity of the visual analogue score. Pain 1983; 16: 87-101.

5. Cook AW, Oygar A, Baggenstos P, et al: Vascular Disease of extremities: Electrical stimulation of spinal cord and posterior roots. N Y State J Med 1976; 76: 365-368.

6. European working group on critical leg ischemia: Second European consensus document on chronic critical leg ischemia. Eur J Vasc Surg 1992; 5 (suppl A): 1-32.

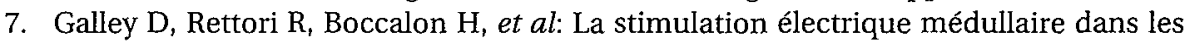
artériopathies des membres inférieurs: une étude multicentrique chez 244 patients. J Mal Vasc 1992; 17: 208-213.

8. Graber JN, Lifson A: The use of spinal cord stimulation for severe limb threatening ischemia: a preliminary report. Ann Vasc Surg 1987; 1: 578-581.

9. Groth KE: Spinal cord stimulation for the treatment of peripheral vascular diseaseEuropean Multi-center Study. In Fields (ed): Advances in Pain Research and Therapy. New York, Raven Press, 1985, pp 861-870.

10. Horsch S, Claeys L: Epidural spinal cord stimulation in the treatment of severe peripheral arterial occlusive disease. Ann Vasc Surg 1994; 8: 468-474.

11. Jacobs MJ, Jörning PJ, Joshi SR, et al: Epidural spinal cord electrical stimulation improves microvascular blood flow in severe limb ischemia. Ann Surg 1988; 207: 129-133.

12. Jivegard LEH, Augustinsson LE, Holm J, Risberg B, Ortenwall P: Effects of spinal cord stimulation (SCS) in patients with inoperable severe lower limb Ischaemia: a prospective randomized controlled study. Eur J Vasc Endovasc Surg 1995 9:421-425.

13. Kaada B: Promoted healing of chronic ulceration by transcutaneous nerve stimulation. VASA $1983 ; 12: 262-269$.

14. Klomp HM, Spincemaille GH, Steyerberg EW, Berger MY, Habbema JD, van Urk H: Design issues of a randomised controlled clinical trial on spinal cord stimulation in critical limb ischaemia. ESES study group. Eur J Vasc Endovasc Surg 1995; 10: 478.

15. Kraineck J, Thoden U, Reichert T: Pain reduction in amputees by long term spinal cord stimulation: Long term follow up study over 5 years. J Neurosurg 1980; 52: 346-360.

16. LaPorte C, Siegfried J: Lumbosacral spinal fibrosis (spinal arachnoiditis): Its diagnosis and treatment by spinal cord stimulation. Spine 1983; 8: 593-603.

17. Linderoth B, Fedorcsak I, Meyerson BA: Peripheral vasodilatation after spinal cord stimulation: Animal studies of putative effector mechanisms. Neurosurg 1991; 28:187-195.

18. Long DM: Patient selection and the result of spinal cord stimulation for chronic pain. In Hosobuchi H, Corbin T (ed): Indications for spinal cord stimulation. Proceedings of a Symposium, Amsterdam: Excerpta Medica 1981, pp 76-80. 
19. Mackel R: Properties of cutaneous afferents in diabetic neuropathy. Brain 1989; 112: 1359-1376.

20. Malone JM: Therapeutic and economic impact of a modern amputation program. Ann Surg 1979: 189: 798-802.

21. Meglio M, Cioni B, Lago $\mathrm{AD}$, et al: Pain control and improvement of peripheral blood flow following epidural spinal cord stimulation. Case report. J Neurosurg 1981; 54: 821-823.

22. Meglio M, Cioni B: Personal experience with spinal cord stimulation in chronic pain management. Appl Neurophysiol 1982; 45: 195-200.

23. Ray CD, Burton CV, Fifson A: Neurostimulation as used in a large clinical practice. Appl Neurophysiol 1982; 45: 160-166.

24. Richardson RR, Siqueira EB, Cerullo LJ: Spinal epidural neurostimulation for the treatment of acute and chronic intractable pain: initial and long term results. Neurosurg 1979; 5: 344-348.

25. Rivers SP: Successful conservative therapy of severe limb-threatening ischemia: The value of nonsympathectomy. Surgery 1986; 99: 759-762.

26. Shatin D, Mullett K, Hults G: Totally implantable spinal cord stimulation for chronic pain. Design and efficacy. Pace 1986; 9: 577-583.

27. Siegfried J, Lazorthes Y: Long term follow up of dorsal cord stimulation for chronic pain syndromes after multiple lumbar operations. Appl Neurophysiol 1982; 45: 201-204.

28. Tallis RC, Illis LS, Sedgwick EM, et al: Spinal cord stimulation in peripheral vascular disease. J Neurol Neurosurg Psych 1983; 46: 478-484. 


\section{Spinal-cord stimulation in critical limb ischaemia: A randomised trial}

Houke M Klomp, Geert H J J Spincemaille, Ewout W Steyerberg, J Dik F Habbema, Hero van Urk, for the ESES study group*

* Other group members given at end of the manuscript

Department of Surgery, University Hospital Rotterdam-Dijkzigt, Rotterdam (Prof H van Urk PhD, H M Klomp MD); Department of Neurosurgery, Atrium Medisch Centrum De Wever Hospital, Heerlen (G H J J Spincemaille MD); and Department of Public Health, Center for Clinical Decision Sciences, Erasmus University Rotterdam, Rotterdam, Netherlands (E W Steyerberg PhD, J D F Habbema PhD) 


\section{SUMMARY}

Background: For patients with critical limb ischaemia, spinal-cord stimulation has been advocated for the treatment of ischaemic pain and the prevention of amputation. We compared the efficacy of the addition of spinal-cord stimulation to best medical treatment in a randomised controlled trial.

Methods: 120 patients with critical limb ischaemia not suitable for vascular reconstruction were randomly assigned either spinal-cord stimulation in addition to best medical treatment or best medical treatment alone. Primary outcome measures were mortality and amputation. The primary endpoint was limb survival at 2 years.

Findings: The mean (SD) age of the patients was 72.6 years (10.3). Median (IQR) follow-up was 605 days (244-1171). 40 (67\%) of 60 patients in the spinal-cord stimulator group and $41(68 \%)$ of 60 patients in the standard group were alive at the end of the study, $(p=0.96)$. There were 25 major amputations in the spinal cord-stimulator group and 29 in the standard group, $(\mathrm{p}=0.47)$. The hazard ratio for survival at 2 years without major amputation in the spinal-cord stimulation group compared with the standard group was 0.96 (95\% CI 0.61-1.51).

Interpretation: Spinal-cord-stimulation in addition to best medical care does not prevent amputation in patients with critical limb ischaemia. 


\section{INTRODUCTION}

Critical lower-limb ischaemia occurs when resting blood flow does not meet the basic metabolic requirements of the tissues. Clinically, the patient has pain at rest or ischaemic skin lesions. Surgical revascularisation or endovascular angioplasty are the preferred treatments. Despite many technical and clinical advances, some patients have end-stage vascular disease i.e. limb threatening ischaemia that is not suitable for either primary intervention or reintervention.

The natural history of non-reconstructable critical limb ischaemia is not clear. Many groups suggest that amputation of the limb is necessary in $60-80 \%$ of patients within a year. ${ }^{1-6}$ Antithrombotic and vasoactive drugs are of little value in the management of critical limb ischaemia. Only prostanoids have shown some efficacy, but there is no evidence that in the long-term the limb is saved. . $^{3,9}$

Stimulation of the dorsal columns of the spinal cord causes paraesthesiae in corresponding dermatomes and suppression of nociceptive activity. In the past 15 years, spinal-cord stimulation has become an accepted technique to treat neurogenic pain disorders. The benefits of spinal-cord stimulation for ischaemic disorders-excellent pain relief and healing of ischaemic skin lesions-were reported in retrospective studies. ${ }^{10-20}$ Spinal-cord stimulation was thought to prevent or delay amputation and limb survival was reported to be $68-80 \%$ at 1 year and $56-71 \%$ at 2 years. ${ }^{10,13,21-24}$ However, efficacy has not been confirmed in randomised controlled studies. The only controlled study ( $n=51$ ) found no statistical difference in the proportion of limbs saved at 18 months between spinal-cord stimulation and control groups (62\% vs $45 \%) .{ }^{25}$ We carried out a multicentre, randomised clinical trial in the Netherlands that compared spinal cord stimulation and best medical treatment in 120 patients with critical limb ischaemia not suitable for further reconstruction.

\section{METHODS}

The design, randomisation, and other procedures have been described in detail elsewhere. ${ }^{26}$ The study took place between November, 1991, and January, 1996, in 17 hospitals in the Netherlands. The protocol was approved by the ethical committees at each centre, and patients gave written, informed consent.

Eligible patients had critical limb ischaemia and were not candidates for vascular intervention or reintervention, usually because of insufficient distal 
runoff or recurrent graft failure. Inclusion criteria were persistent pain at rest for more than 2 weeks or ischaemic skin lesions, ankle systolic pressure below $50 \mathrm{~mm} \mathrm{Hg}$ or, in patients with diabetes and incompressible vessels, absent palpable ankle pulses. Patients with extensive necrosis or infected gangrene and those who were terminally ill, dependent on a pacemaker, or unable to complete the patient questionnaire were excluded. Patients were stratified by diabetes, ankle pressure, and hospital. Randomisation was by a random numbers table and the list was held independently of the investigators. Patients were randomly assigned best medical treatment, which was the standard treatment, or spinal-cord stimulation treatment, which was in addition to the best medical treatment. Medical treatment included analgesics, antithrombotíc drugs such as aspirin or coumarins, vasoactive drugs such as pentoxifylline, buflomedil, or ketanserin, local wound care, and antibiotics, as needed. A list of recommended medication was provided, but there was no fixed treatment regimen. Chemical lumbar sympathectomy and prostanoids were not excluded, but were used in three patients only. The lead of the spinal-cord stimulator (Quadripolar, Medtronic, Minneapolis, MN, USA) was placed in the epidural space and manipulated until the patient experienced pleasant paraesthesiae that extended into the painful area of the limb. The pulse generator (Itrel II, Medtronic, Minneapolis, MN, USA) was implanted at the same time into the subcutaneous tissue of the flank. Patients with a spinal-cord stimulator were checked regularly by a neurosurgeon or anaesthetist.

If pain suppression was inadequate, medication, stimulation settings, or both were changed. Lead migration or infection of the stimulator was treated by repositioning the electrode, or treatment with antibiotics, but if these measures failed, the system was explanted.

All patients were assessed at months $1,3,6,12,18$, and at the end of the study. Between follow-up visits patients came to hospital as needed. The primary endpoint was limb survival at 2 years. When amputation was indicated, the level of amputation was recorded. Limb survival was defined as absence of major amputation. ${ }^{27}$ Major amputations were those at the level of the ankle or higher. Death from progressive gangrene, sepsis, complications, and 30-day perioperative mortality after amputation or implantation was classified as disease-specific mortality.

For assessment of pain, the McGill Pain Questionnaire 28 was used and the pain-rating index (PRI) was the measure of expressed pain. Analgesic use was recorded and quantified by the medication quantification scale (MQS). ${ }^{29}$ An MQS score was calculated from the dose and assigned values of the different analgesics. Major analgesics were narcotic analgesics and minor analgesics were aspirin, paracetamol, and non-steroidal anti-inflamma- 
tories. The Nottingham Health Profile ${ }^{30}$ (NHP) and EuroQol ${ }^{31}$ were used to assess quality of life.

Cost analysis was based on resources used by patients for 2 years after randomisation or until death, if it occurred within 2 years. Costs were classified into direct medical costs-those incurred inside and outside the hospital-direct non-medical costs, and indirect costs. ${ }^{32}$ The costs were calculated per patient as the product of volumes and market prices. Volumes of the cost items were collected for all patients. Market prices were estimated in smaller samples. All costs were expressed in 1993 Dutch guilders ( $1 \mathrm{fl} . \approx 0.35$ UK $£$ at the time of this study).

\section{STATISTICAL ANALYSIS}

Analysis was by intention to treat and included all patients who were randomised. Differences between groups were compared by t- tests, for continuous variables, and by $\chi^{2}$ tests for categorical data. Patient and limb survival was estimated with the Kaplan-Meier method and differences were evaluated by the log-rank test. In the analysis of limb survival, patients were censored at death. Healing of ischaemic skin lesions could only be assessed in intact legs and thus patients who died or had an amputation were censored. For the analysis of amputation level, patients were censored at death or at amputation on a higher level. Pain and quality-of-life measurements were assessed by ANCOVA and adjusted for baseline differences; $\mathrm{p}<0.05$ was deemed statistically significant. The study had $80 \%$ power to detect an increase in limb survival by 3 months (hazard ratio 1.8), based on a total sample size of 120 patients at the $95 \%$ level of significance.

\section{RESULTS}

141 patients were eligible and the flow of patients is shown in figure 1.120 patients were randomly assigned spinal-cord stimulation or standard treatment. The mean (SD) days in hospital for implantation of the stimulator was 4-9 days (2-3).

The characteristics of the patients at baseline are in table 1 . All patients took analgesics. Median follow-up was 605 days (244-1171). Kaplan-Meier estimates of patient survival were similar in the two groups (figure 2): the hazard ratio for the spinal-cord-stimulation group was 1.09 (95\% CI 0.59-2.03). Disease-specific mortality at 6 months was $5 \%$ in the spinal-cord stimulation group compared with $7 \%$ in the standard group; at 2 years these values 


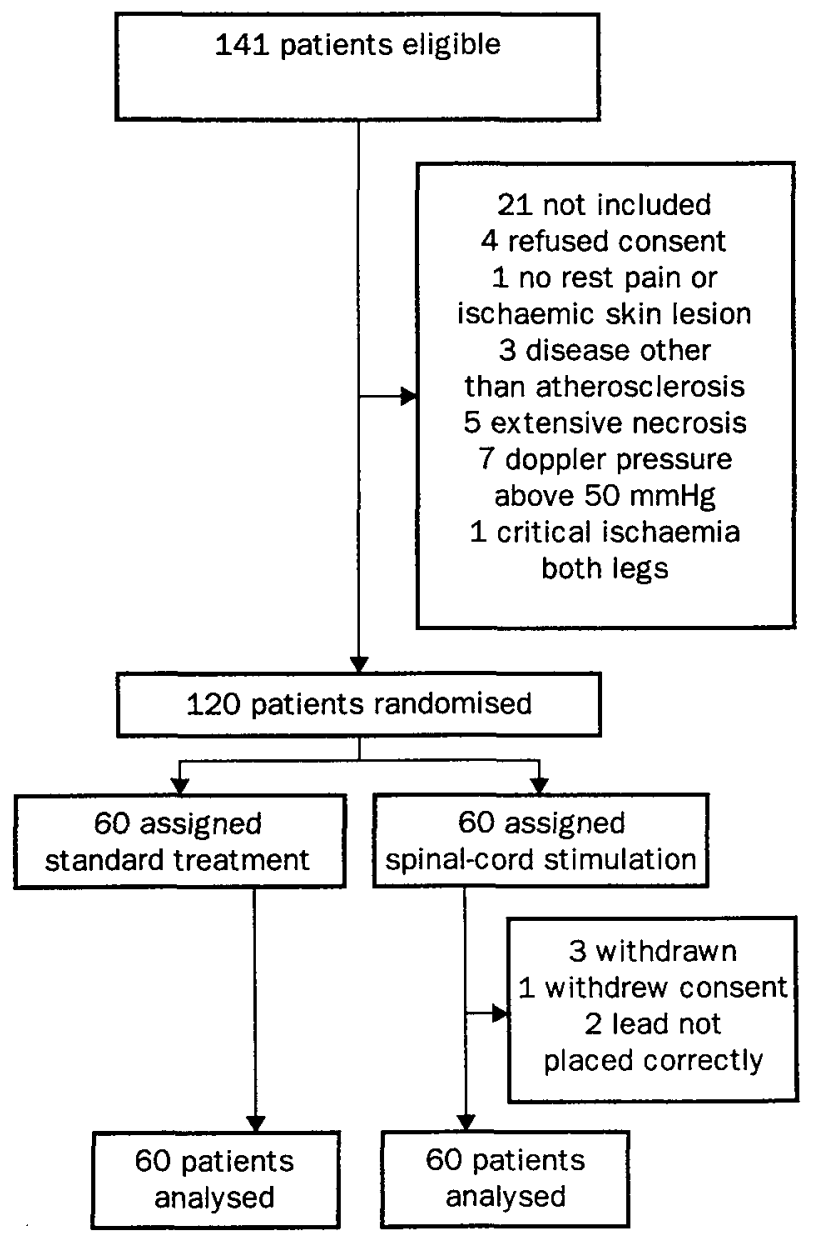

Figure 1. Trial profile

were $5 \%$ and $9 \%(\mathrm{p}=0.45)$, respectively. The amputation-free survival rates are shown in figure 3 . The areas between the curves show the proportion of patients alive without major or minor amputation. The hazard ratio for survival at 2 years without major amputation was 0.96 (0.61-1.51). Kaplan-Meier plots for limb survival are in figure 4. Most amputations occurred soon after randomisation. The hazard ratio for amputation in the spinal-cord stimulation group compared with the standard group was 0.81 (0.47-1.42). 
Table 1. Baseline clinical characteristics of patients

\begin{tabular}{|c|c|c|}
\hline & $\begin{array}{l}\text { Spinal-cord stimulation } \\
(\mathrm{n}=60)\end{array}$ & $\begin{array}{l}\text { Standard } \\
(\mathrm{n}=60)\end{array}$ \\
\hline \multicolumn{3}{|l|}{ Demographic } \\
\hline Age (years)* & $73-1(9-8)$ & $72.1(10.6)$ \\
\hline $\mathrm{M} / \mathrm{F}$ & $33 / 27$ & $37 / 23$ \\
\hline \multicolumn{3}{|l|}{ Other disorders } \\
\hline Diabetes & $22(37 \%)$ & $23(38 \%)$ \\
\hline Cerebrovascular accident or TIA & $13(22 \%)$ & $16(27 \%)$ \\
\hline Myocardial infarction & $23(38 \%)$ & $22(37 \%)$ \\
\hline Angina pectoris & $12(20 \%)$ & $15(25 \%)$ \\
\hline \multicolumn{3}{|l|}{ Vascular } \\
\hline \multicolumn{3}{|l|}{ Smoking } \\
\hline Stopped for more than 1 year & $22(37 \%)$ & $16(27 \%)$ \\
\hline Current & $18(30 \%)$ & $26(44 \%)$ \\
\hline \multicolumn{3}{|l|}{ Contralateral limb } \\
\hline Symptomatic & $19(32 \%)$ & $29(48 \%)$ \\
\hline Amputated & $9(15 \%)$ & $7(12 \%)$ \\
\hline Ischaemic skin lesions & $38(63 \%)$ & $41(68 \%)$ \\
\hline Ulceration & $23(38 \%)$ & $27(45 \%)$ \\
\hline Gangrene & $15(25 \%)$ & $14(23 \%)$ \\
\hline \multicolumn{3}{|l|}{ Previous vascular reconstructions } \\
\hline 1 or 2 & $25(42 \%)$ & $29(48 \%)$ \\
\hline$\geq 3$ & $19(32 \%)$ & $20(33 \%)$ \\
\hline Sympathectomy & $21(35 \%)$ & $19(32 \%)$ \\
\hline Ankle systolic pressure $(\mathrm{mm} \mathrm{Hg})^{*}$ & $35.2(24.8)$ & $41.6(21.8)$ \\
\hline Ankle-to-brachial pressure index * & $0.23(0.16)$ & $0.28(0.13)$ \\
\hline \multicolumn{3}{|l|}{ Pain and quality of life } \\
\hline Minor analgetic & $54(90 \%)$ & $50(83 \%)$ \\
\hline Major analgetic & $18(30 \%)$ & $21(35 \%)$ \\
\hline MQS score* & $7.0(5.1)$ & $7.4(5.2)$ \\
\hline Pain rating index score* & $22.6(11.4)$ & $21.6(11.4)$ \\
\hline \multicolumn{3}{|l|}{ Quality of life scores } \\
\hline NHP* & $47.7(19.4)$ & $47.2(20.0)$ \\
\hline EuroQol & $54.0(21.0)$ & $50.7(20.4)$ \\
\hline
\end{tabular}

Data are number (\%) or * mean (SD). TIA=transient ischaemic attack. MQS-Medication quantification scale score. $\mathrm{NHP}=$ Nottingham health profile. 


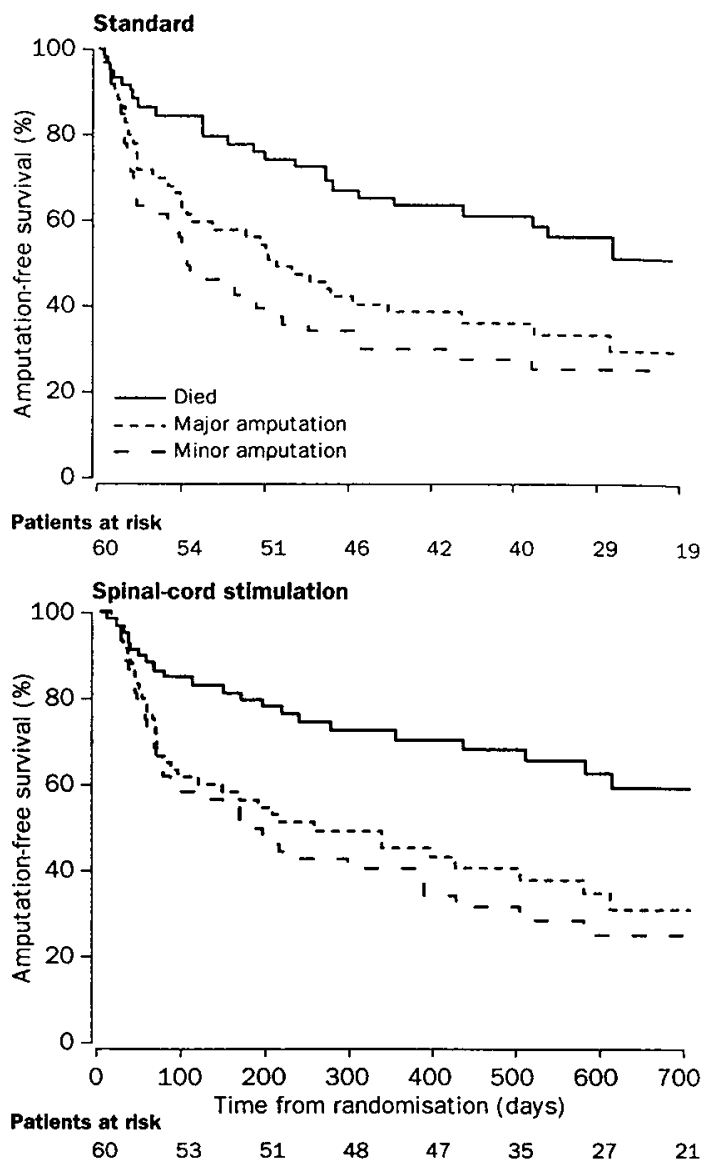

Figure 3. Amputation-free survival by type of amputation

In patients without amputations the cumulative percentage of ulcers healed at 1 year were $45 \%$ in the spinal-cord stimulation group vs $54 \%$ in the standard group ( $\mathrm{p}=0.21)$; the proportions of patients with gangrene were similar ( $53 \%$ vs $50 \%$, respectively; $\mathrm{p}=0.56$ ).

Table 2 shows the percentages of patients with amputations at toe, transmetatarsal, foot, below-knee, and above-knee levels. Overall, at 2 years only $27 \%$ of all patients were alive without any amputation; $37 \%$ had died. Reasons for amputation were progressive tissue loss (71\%), unbearable pain $(67 \%)$, infection $(15 \%)$, or combinations of these factors. 


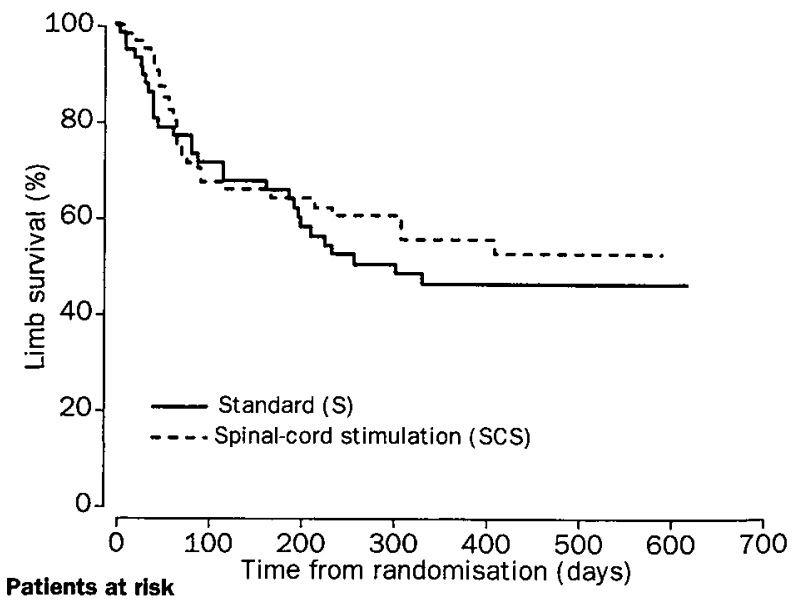

$\begin{array}{lllllllll}\text { SCS } & 60 & 39 & 37 & 30 & 25 & 25 & 22 & 20 \\ \mathrm{~S} & 60 & 40 & 32 & 25 & 23 & 22 & 20 & 17\end{array}$

Figure 4. Limb survival

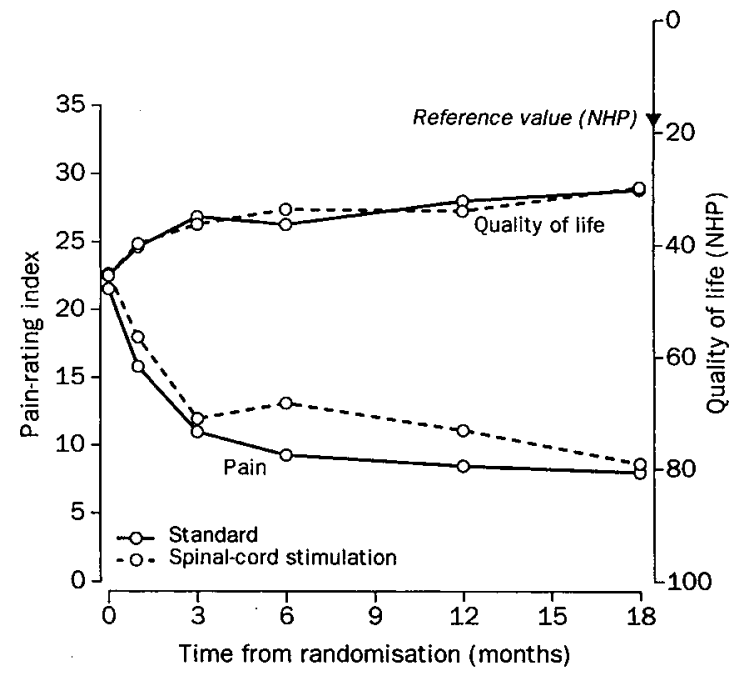

Figure 5. Pain-rating index and quality-of-life index 


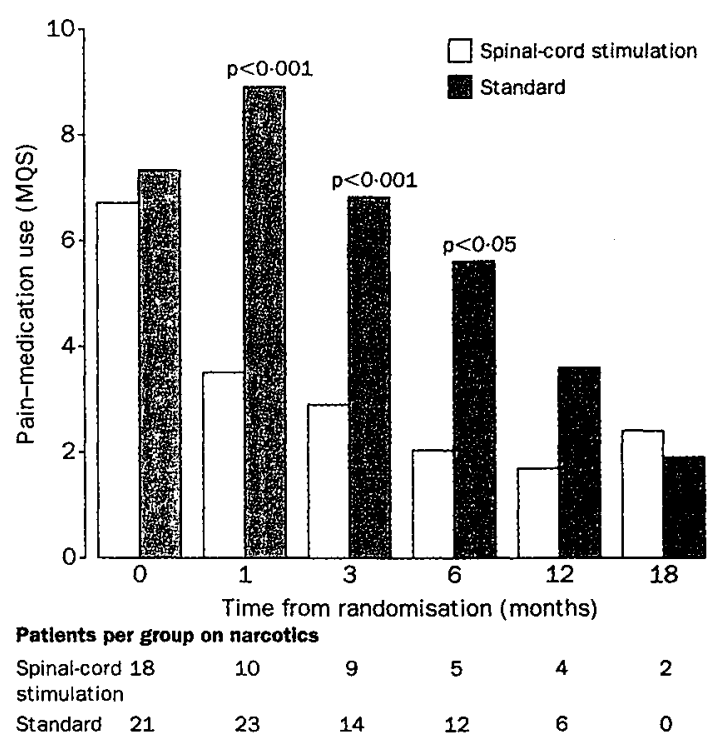

Figure 6. Pain medication use

Figure 5 shows the pain- rating index. Pain was decreased significantly in both treatment groups at 1 month and 3 months $(p<0.001$ ) and did not differ between groups. The NHP and Euroqol showed poor quality of life compared with matched reference values of the general population: the two groups did not differ.

Pain medication use is summarised in figure 6 .

In the spinal-cord-stimulation group, three patients needed lead repositioning within 30 days. During follow-up, 13 lead displacements occurred, and 11 reposition and one reimplantation procedures were done. Infection was reported in three patients. Three batteries failed within 18 months. Because of these difficulties eight patients (13\%) had suboptimal stimulation. If only patients with adequate stimulation were analysed, limb survival at 6 months was $67 \%$ in the stimulation group and $68 \%$ in the standard group; at 2 years these values were $55 \%$ and $46 \%$, respectively (hazard ratio 0.78 [0.44-1.39, $\mathrm{p}=0.39$ ).

In the standard group side-effects were reported in ten patients: upper gastrointestinal bleeding (3), nausea (7), dizziness (2). In the spinal-cord- 
stimulation group side effects occurred in four patients: duodenal perforation (1), nausea (2), and pruritus (1).

Most of the costs were from staying in hospital and in rehabilitation facilities. These costs were similar for both groups: mean fl. 25,957 and fl. 14,870 per patient in the spinal-cord-stimulation group vs fl. 27,153 and fl. 16,465 in the standard group. The mean cost for operative procedures per patient was fl. 18,428 in the stimulator group and fl. 918 in the standard group. The cost of implanting the stimulator was fl. 15,900. Costs for professional care at home and in homes for the elderly, were similar. Outpatient cost, medications, medical supplies, and non-medical costs were a small part of the cost. Total cost at 2 years was fl. 80,439 per patient in the spinal-cord stimulator group, fl. 17,376 (28\%) higher than in the standard group ( $\mathrm{p}=0.009)$. Adjusted for mortality, the mean cost per patient was fl. 69,066 in the stimulator group and fl. 52,407 in the standard group, $\mathrm{p}=0.002$.

\section{DISCUSSION}

In 1991, LoGerfa ${ }^{33}$ warned in an editorial about undue clinical acceptance of spinal-cord stimulation for management of lower extremity ischaemia and stressed the need for randomised clinical trials.

In this trial, we compared two treatment regimens and aimed to answer the question about which mode of therapy works best-rather than how it works. ${ }^{34}$ The primary measure of efficacy was limb survival. We did not find that spinal-cord stimulation was of benefit above that of best medical treatment. Amputation-free survival was not improved nor was the risk of major amputation significantly reduced. The rates of amputation were similar in both groups and were particularly high during the first 3 months, which shows both the nature of critical ischaemia and the limited potential of current treatments. However, a surprisingly high number of patients with critical limb ischaemia can, temporarily, be stable or improve with conservative methods: ${ }^{4,5,9}$ in the standard group, limb survival was $46 \%$ after 1 year.

Studies of new treatment modalities involve more medical care (hospital visits and general attention) in the selected patient population, which can improve outcomes. Therefore, efficacy can only be verified in controlled, preferably randomised, trials.

Patients with a spinal-cord stimulator used significantly less pain medication, which suggests substantial pain relief from this treatment. Nevertheless, similar pain reduction was seen in the standard group. Although spinal-cord stimulation may be of great benefit for ischaemic pain, the effect 
is not stronger than adequate conservative pain treatment. Amputation also reduces pain, on average by $40 \%$. The high frequency of amputations during the first 3 months thus accounts for at least $22 \%$ of the observed pain reduction in this period.

Spinal-cord stimulation was associated with a substantial number of complications in our patients. In other similar patient groups, such as those with peripheral vascular disease, patients have had complications from spinal-cord stimulation: failure (3-4\%), infection (3-5\%), lead dislocation and breaks (11-36\%), cerebrospinal-fluid leak (1\%), and meningitis (0.5\%). ${ }^{10,21-24}$ Most complications could be adequately corrected. Additional analysis did not show that the treatment effect of spinal-cord stimulation increased in patients with adequate stimulation.

Conservative treatment probably was the cause of potentially life-threatening gastrointestinal problems in four patients (three in the standard treatment group). Although these events may not be exclusively attributed to medication, elderly patients who use combinations of aspirin, non-steroidal anti-inflammatories, and anticoagulants are at risk of gastrointestinal complications. The calculated costs over 2 years were $28 \%$ higher in the spinal-cord-stimulator group than in the standard group: most of this was the cost of staying in hospital and rehabilitation. The initial costs in the spinal-cord stimulator group were high, all other costs evolved similarly in both treatment groups. We found that in patients with critical-limb ischaemia, a treatment regimen of best medical treatment and spinal-cordstimulation was no more effective than best medical treatment alone in preventing amputations and costs more. Medication can provide pain relief to that achieved with spinal-cord stimulation.

\section{References}

1. Dormandy JA, Mahir MS. The natural history of peripheral atheromatous disease of legs. In: Greenhalgh RM, ed. Vascular surgery issues in current practice, lst edn. London: Grune \& Stratton, 1986.

2. Dormandy J, Mahor M, Ascady G, et al. Fate of the patient with chronic leg ischaemia. J Cardiovasc Surg 1989; 30: 50-70.

3. European Working Group on Critical Leg Ischaemia. Second European consensus document on chronic critical leg ischemia. Circulation 1991; 84 (4 suppl): 1-26.

4. Rivers SP, Veith FI, Ascer E. Gupta SK. Successful conservative therapy of severe limb-threatening ischemia: the value of non-sympathectomy. Surgery 1986; 99 : 759-62.

5. Troeng $\mathrm{T}$, Bergquivst D, Janszon $\mathrm{L}$, Jendteg S, Liendgren $\mathrm{B}$. The choice of strategy in the treatment of critical leg ischaemia. 77reor Surg 1993; 8: 115-21.

6. Kempczinski RF. Management of chronic ischemia of the lower extremities. In: Rutherford RB, ed. Vascular surgery. 4th edn. Philadelphia: WB Saunders, 1995. 
7. Norgren L. Non-surgical treatment of critical limb ischemia. Eur J Vasc Surg 1990; 4: 449-54.

8. Belch JF, McCollum P. Pharmacotherapy of critical limb ischaemia. In: Horsh S, ed. Spinal cord stimulation. 1st edn. Darmstadt: Steinkopff, 1994.

9. Norgren L, Alwmark A, Angqvist KA, et al. A stable prostacyclin analogue (iloprost) in the treatmem of ischaemic ulcers of the lower limb. Eur J Vasc Surg 1990; 4: 463-67.

10. Augustinsson L, Carlsson CA, Holm J, Jivegard L. Epidural electrical stimulation in severe limb ischemia. Ann Surg 1985; 202: 104-10.

11. Bracale GC, Selvetella L, Mirabile F. Our experience with spinal cord stimulation (SCS) in peripheral vascular disease. Pacing Clin Electrophysiol 1989; 12: 695-97.

12. Broseta J, Barbara J, de Vera JA, et al. Spinal cord stimulation in peripheral arterial disease. J Neurosurg 1986; 64: 71-80.

13. Bunt TJ, Hollaway GA, Lawrence P, Cherney D. Experience in epidural spinal stimulation in the treatment of end-stage peripheral vascular disease. Semin Vasc Surg 1991; 4: $216-20$.

14. Cook AW, Oygar A, Gabbenstos P, Pacheco S, Kleriga E. Vascular disease of extremities. NY State J Med 1976; 76: 366-68.

15. Tallis RC, Illis LS, Sedgwick EM, Hardwidge C, Garfield JS. Spinal cord stimulation in peripheral vascular disease. J Neurol Neurosurg Psychiatry 1983; 46: 478-84.

16. Sampere CT, Guasch JA, Paladino CM, Casalongue S, Elencwajg B. Spinal cord stimulation for severely ischemic limbs. Pacing Clin Electrophysiol 1989; 12: 273-79.

17. Nachbur B, Gersbach P, Hasdemir M. Spinal cord stimulation for unreconstructible chronic limb ischemia. Eur J Vasc Surg 1994; 8: 383-88.

18. Meglio M, Cioni B, Dal Lago A, De Santis M, Pola P, Serricchio M. Pain control and improvement of peripheral blond flow following epidural spinal cord stimulation: case report. J Neurosurg 1981; 54: 821-23.

19. Jacobs MJHM, Slaaf DW, Reneman RS. Dorsal column stimulation in critical limb ischemia. Vasc Med Rev 1990; 1: 215

20. Fiume D, Palombi M, Sciassa V, Tamorri M. Spinal cord stimulation (SCS) in peripheraischemic pain. Paring Clin Electrophysiol 1989; 12: 698-704.

21. Jivegard L, Augustinsson L, Carlsson C, Holm J. Long-term results by epidural spinal electrical stimulation (ESES) in patients with inoperable severe lower limb ischaemia. Eur J Vasc Surg 1987; 1: 345-49.

22. Jacobs MJHM, Jörning PJG, Beckers RCY, et al. Foot salvage and improvement of microvascular blood flow as a result of epidural spinal cord electrical stimulation. J Vasc Surg 1990; 12: 354-60.

23. Steude U, Abenroth D, Sunder-Plassmann L. Treatment of severe arterial occlusive disease by epidural spinal electrical stimulation. Vasc Surg 1991; 25: 569-72.

24. Zucca F, Allaria B, Vaghi M, et al. Spinal cord stimulation in peripheral vascular disease. In: Horsch S, Claeys L, eds. Spinal cord stimulation. Darmstadt: Steinkopff, 1994: 183-89.

25. Jivegard LEH, Augustinsson LE, Holm J, Risberg B, Ortenwall P. Effects of spinal cord stimulation (SCS) in patients with inoperable severe lower limb ischaemia: a prospective randomised controlled study. Eur J Vasc Endovasc Surg 1995; 9: 421-25.

26. Klomp HM, Spincemaille GHJJ, Steyerberg EW, Berger MY, Habbema JDF, Van Urk H. Design issues of a randomised controlled clinical trial on spinal cord stimulation in critical limb ischemia. Eur J Vasc Endovasc Surg 1995; 10: 478-85. 
27. Rutherford RB. Standards for evaluating results of interventional therapy for peripheral vascular disease. Circulation 1991; 83 (suppl I): 6-11.

28. Van der Kloot WA, Vertommen H. De MPQ-DLV, een standaard Nederlandstalige versie van de McGill pain questionnaire: achtergronden en handleiding. 1st edn. Lisse: Swets \& Zeitlinger, 1989.

29. Masters-Steedman S, Middaugh SI, Kee WG, Larson DS, Harden RN, Miller MC. Chronic pain medications: equivalence levels and methods of quantifying usage. Clin J Pain 1992; 8: 204-14.

30. Essink-Bot ML, Krabbé PFM, Van Agt HME, Bonsel GJ. NHP or SIP-a comparative study in renal insufficiency associated anaemia. Qual Life Res 1996; 5: 91-100.

31. Brooks with the EuroQol Group. EuroQol: the current state of play. Health Policy 1996; 37: 53-72.

32. Drummond MF, Stoddart GL, Torrance GW. In: Methods for the economic evaluation of health care programmes. I st edn. Oxford: Oxford University Press, 1992.

33. LoGerfo FW. Epidural spinal cord electrical stimulation: an unproven methodology for management of lower extremity ischemia. J Vasc Surg 1991; 13: 518-19.

34. Schwartz D, Lellouch J. Explanatory and pragmatic attitudes in therapeutic trials. J Chron Dis 1967; 20: 637-48. 


\title{
Pain and quality of life in patients with critical limb ischaemia: Results of a randomized controlled multicentre study on the effect of spinal cord stimulation.
}

\author{
G. H. Spincemaille a, H. M. Klomp ${ }^{\text {b }}$, E. W. Steyerberg c, \\ J. D. F. Habbema ${ }^{c}$ for the ESES study group \\ a Dept. of Neurosurgery, Academic Hospital Maastricht, ${ }^{b}$ Dept. of Vascular Surgery, \\ Dijkzigt Academic Hospital Rotterdam, ${ }^{\mathrm{C}}$ Dept. of Public Health, Erasmus University \\ Rotterdam, The Netherlands
}




\section{SUMMARY}

We carried out an assessment of pain and quality of life in patients with critical limb ischaemia during the follow-up of a multicentre randomized trial. In a multicentre clinical trial 120 patients were randomized between medical treatment and medical treatment plus spinal cord stimulation. Patients were selected on the basis of clinical symptoms and macrocirculatory data as described in the European consensus document on critical limb ischaemia. Data were collected at intake and then 1, 3, 6, 12 and 18 months later. Primary outcome measures were limb salvage, pain relief and quality of life. Patient and limb survival was estimated with the Kaplan-Meier method. Pain was evaluated using the visual analogue scale (VAS), the McGill pain questionnaire, the pain score of the Nottingham Health Profile (NHP) and the use of analgesics. Quality of life was evaluated using the NHP, the EuroQol and mobility subscore of the Sickness Impact Profile.

The 2-year limb survival was $52 \%$ for SCS treatment and $46 \%$ for standard treatment $(\mathrm{p}=0.47)$. Pain relief was considerable in both treatment strategies $(\mathrm{p}<0.005)$ with no significant differences between the strategies. The improvement occurred within the first few months and remained stable during further follow-up. Patients with SCS used fewer non-narcotic and narcotic drugs $(p<0.001$ at $t=1$ and $t=3, p<0.002$ at $t=6)$. The overall scores of quality of life improved significantly $(p<0.05)$, with no difference in score between treatments. The subscores of mobility and energy of the NHP in non-amputated patients was significantly better in the SCS group $(\mathrm{p}<0.005)$. Amputation had a negative effect on mobility, resulting in a difficult rehabilitation but relieved pain substantially $(\mathrm{p}<0.05)$.

In contrast to the existing literature, the randomized trial revealed no major difference in overall pain and quality of life assessment between treatment groups. The effect on energy and mobility was significantly better in patients treated with SCS, who also used substantially fewer analgesics. 


\section{INTRODUCTION}

Morbidity and mortality are considerable in patients once critical limb ischaemia is diagnosed. The 5-year mortality in elderly patients with lower limb ischaemia exceeds $50 \%$. In a study with a slightly older group of patients, the 1-, 3-, and 5-year survival rates were $59 \%, 28 \%$ and $23 \%$, respectively, which were markedly poorer than the expected survival rates of the age- and sex-matched Japanese population at 1,3 and 5 years, which were $93 \%, 79 \%$ and $65 \%$, respectively (Ohta et al., 1998). An amputation of the ischaemic limb is performed in $50 \%$ of patients once critical limb ischaemia is diagnosed within 2 years independently of the therapy given (Dormandy et al., 1988). The major reasons for amputation are non-healing skin ulcers, gangrene and pain. The primary therapy is vascular reconstruction. In patients where vascular reconstruction is no longer a possibility, pain medication and vasoactive drugs are used to reduce pain and avoid limb amputation. It is believed that pain relief plays a major role in reducing the risks for amputation. Better mobilization will have a beneficial effect on distal blood flow. In addition good local skin care can stabilize and even improve the local condition of the threatened distal limb region (Rivers et al., 1986). A number of publications describe a good to excellent effect of SCS on pain (Cook et al., 1976; Groth, 1985; Broseta et al., 1986; Graber et al., 1987; Jivegard et al., 1987; Jacobs et al., 1988; Franzetti et al., 1989; Jacobs et al., 1990; Bunt et al., 1991; Galley et al., 1992; Jivegard et al., 1995). Some of these publications suggest that limb salvage may be an important effect of SCS. However, these studies were primarily directed to the effect of SCS on pain relief. In order to solve the question of limb salvage a randomized study was undertaken. Primary outcome measures were pain relief and quality of life.

\section{METHODS}

\section{Study design}

The study took place between November 1991 and January 1996 in 17 hospitals in The Netherlands. A total of 120 patients were enrolled during the intake period, which ended in December 1994. Data were sampled at intake and at $1,3,6,12$ and 18 months postrandomization. The follow-up period for all patients was at least 1.5 years. Patients with atherosclerotic vessel disease were included as soon as they were diagnosed as having critical ischaemia as defined by the European consensus and if no vascular recon- 
Table 1. Inclusion and exclusion criteria.

General condition:

- Surgically non-reconstructible atherosclerotic vessel disease of the lower limb.

Inclusion criteria:

1. Persisting pain at rest for at least 2 weeks,

2. And / or skin lesions ( ulcerations or gangrene) in the region of the feet or toes, which surface may not exceed $3 \mathrm{~cm}^{2}$.

3. Doppler ankle systolic pressure $\leq 50 \mathrm{~mm} \mathrm{Hg}$ or ankle/brachial pressure index $\leq 35 \%$. For patients with diabetes mellitus and incompressible ankle arteries, absence of arterial ankle pulsations with physical examinations.

4. Patient's written informed consent.

Exclusion criteria:

1. Vascular disorders other than atherosclerotic disease.

2. No rest pain (e.g., only intermittent claudication) and no gangrene or ulceration.

3. Ulcerations deeper than the fascia or gangrene with a diameter larger than $3 \mathrm{~cm}^{2}$.

4. Intractable existing infections of the ulcerations or gangrene area.

5. Neoplastic or concomittant disease restricting life expectancy to less than a year.

6. Presence of a cardiac pacemaker

7. Inadequate patient compliance due to psychological or social incompetence.

structive surgery was possible (European working group, 1992, Klomp et al., 1995). Inclusion criteria are summarized in Table 1.

Patients were eligible if all inclusion criteria, and none of the exclusion criteria, were met. Randomization was performed by a random numbers table and the list was held in an independent research institute, which was available around the clock. The clinicians could phone the randomization centre, which step-by-step checked eligibility, registered the patient and assigned treatment. Randomization was stratified for presence or absence of diabetes and institution. Patients were randomized between medical treatment and medical treatment plus spinal cord stimulation. Medical treatment included proper care for wound ulcers, pain medication (minor and major analgesics), antithrombothic drugs such as aspirin and coumarins, and vasoactive drugs such as pentoxyfilline, buflomedil, or ketanserin. There was no fixed treatment regimen. Chemical lumbar sympathectomy and prostanoids were not excluded but were used in only three patients. The spinal cord stimulation consisted of the implantation in one session of a complete system containing a lead, an extension cable and a pulse generator, [Itrel II, Quad lead, Medtronic, Minneapolis, USA]. Those 
who were allocated to SCS were seen at each follow-up period by the anaesthesiologist or the neurosurgeon responsible for the technical and surgical care of the implant. This implies that patients with SCS were seen more often by a physician than those with only medical treatment.

\section{ASSESSMENT MEASURES}

\section{Quality of life}

1. The Nottingham Health Profile (NHP) is an established measure of perceived health and detailed descriptions of its features and shortcomings are well documented (Hunt et al., 1981, 1982; Jenkinson et al., 1990; Wiklund, 1990a). It is divided into two parts. Part 1 has 38 yes/no questions divided into six different dimensions of health: pain (P), sleep (S), energy (E), mobility (M), social isolation (I) and emotional behaviour (B). Each dimension has a score with a maximum of 100 (worst score). Part II comprises seven general yes/no questions referring to the effects of health on occupation, ability to perform tasks around the home, personal relationships, sex life, social life, hobbies and holidays. Each question is attributed a value of 1 on affirmation and 0 in case it is not applicable. The NHP has simple instructions, is easy to answer and administer, even by mail. The questionnaire is short, acceptable to the patient and reliable to the clinician and has been used successfully in community surveys and in clinical settings. The Dutch version was validated by Erdman (Erdman et al., 1993). In the present study only the first part of the NHP was used. Normative values of the NHP (women aged 55-59 years) for the subscore of energy are 18.6, pain 14.5, emotional reactions 7.7 , sleep 11.7, social isolation 3.4 and physical mobility 3.7. Mean value of the six dimensions is 9.9 (Jenkinson \& Fitzpatrick, 1990). 2. The EuroQol is a short questionnaire of five items that contribute to the state of health: mobility, ability to perform self-care, ability to do usual activities, pain/discomfort and anxiety/ depression. Each item contains three questions. The maximal (worst) score if each factor is scored is 100 . The score system requests information about the patient's situation during the previous week. For analysis, a linear index was used (The EuroQol group, 1990; Humphreys et al., 1994).

3. SIP - mobility score: the SIP is a well-evaluated, 136-item measure, organized into 12 subscales. The physical dimension contains items measuring a broad range of $\mathrm{ADL}$, mobility and complex physical activities. Only the mobility subscore was used as a comparison with the mobility score of the 
NHP. The score ranged from 0 to $100=$ the worst possible score (de Witte et al., 1987).

\section{Pain evaluation}

The visual analogue scale (VAS) is a simple method of measuring the 'intensity' of pain. The scale is a line, on which the left represents 'no pain at all' (score 0 ) and the right 'unbearable pain' (score 10). The number between 0 and 10 expresses the intensity of pain. The brief pain inventory which scores pain intensity at different moments gives an impression of the maximal and minimal pain over time (Carlsson et al., 1983, 1984; Chapman et al., 1985; Jensen et al., 1986). Pain relief of $>50 \%$ was considered to be good, a $25-50 \%$ reduction was seen as moderate, and a reduction less than $25 \%$ was considered unsuccessful. In tabel 4 and figure 3 the scores are expressed as values between 0 and 100

The McGill Pain Questionnaire (MPQ) is a measure of pain 'magnitude', looking at not only pain intensity but also at the other dimensions of pain: emotion, cognitive-evaluative and sensorial dimension (Hunt et al., 1982; Melzack, 1975, 1993). The questionnaire is divided into two parts: the pain assessment questionnaire and the home recording card. Only the first part with the pain descriptors has been validated. A Dutch language version does exist (MPQ-DV) (Visser et al., 1994). The questionnaire looks at the subjective perception of pain qualities and can be used in a dynamic way for a length survey (Chapman et al., 1985). The pain descriptors are divided into categories, the descriptors in a category differing only in intensity. The sum of the words used by the patient for a given category produces the score for the subclass. The global Pain Rating Index (PRI) of the MPQ, is the sum of the scores of the sensory, affective and evaluative categories. Only the first part of the MPQ has been used in the present study. This weights sensory aspects of pain more heavily than affective and evaluative aspects. In limb ischaemia, the sensory aspect is important and more or less equivalent to the intensity of pain. Subscale patterns of the MPQ are highly interrelated. It is believed that differentiating groups of patients on the basis of subscales is inappropriate (Holroyd et al., 1992).

A Medication Quantification Scale (MQS) consisting of two components was used to evaluate the use of analgesics (Steedman et al., 1992). The first component is the detriment weight (DW), based on the potential harmful effects in case of long term use. The detriment weight originally included eight classes of medications prescribed frequently for the management of pain. Light analgesics such as aspirin and paracetamol have a DW $=1$; morphine and morphine analogues have a DW $=6$. The second element is 
the dosage level based on the daily dosage ranges recommended by the manufacturer. The score ranged from $0(<1$ dose per week) to 4 (supratherapeutic dose). In the case of morphine, $1-20 \mathrm{mg} / \mathrm{d}$ was considered as a dosage level of 1 , and $71-120 \mathrm{mg} / \mathrm{d}$ had a value of 3 . For narcotics, the dosage levels were based on the morphine equivalent in milligrams. The MQS for each medication is obtained by multiplying the detriment score of its class by the dosage level. If the patient was taking multiple medications, the MQS score for each medication was summed to obtain the total MQS score. As an example: a patient taking amitriptyline $75 \mathrm{mg} / \mathrm{d}(\mathrm{DW}=2$, dosage level $=2$. $\mathrm{MQS}=4$ ), and morphine $60 \mathrm{mg} / \mathrm{d}(\mathrm{DW}=6$, dosage level $=2, \mathrm{MQS}=12)$ has a total MQS of $4+12=16$.

\section{STATISTICS}

Based on the number of patients selected for the study, this study had a statistical power (1- $\beta$ ) of more than $80 \%$ to detect an increase in median limb survival from 3-6 months with a $\alpha$-level of $5 \%$. The power was primarily calculated only for differences in limb survival. Baseline differences were tested with the t-test for continuous variables and the chi-square tests for categorized variables. Differences between SCS and standard treatment in quality of life scores during follow-up were tested with covariance analysis, where the covariate was the baseline measurement of the quality of life instrument. For example when testing for differences in mobility score at 6 months, the mobility score at baseline was the covariate. Two-sided p-scores less than 0.05 were considered statistically significant. Differences in scores at the different time intervals of follow-up between treatment modalities were analysed.

\section{RESULTS}

One hundred and forty-one patients were eligible. Twenty-one were not randomized: four refused informed consent, one had no rest pain, three had other diseases than atherosclerosis, five had extensive necrosis, seven had a Doppler pressure above $50 \mathrm{mmHg}$ and one had critical ischaemia in both legs.

Patients' characteristics at intake were not statistically different for the two treatment modalities (Table 2). In case of SCS treatment the mean (SD) hospital stay before implantation of the stimulator was 4.9 days (2.3). 
Table 2. Intake values of both treatment groups with critical limb ischemia expressed in percentages. $n=$ number of patients assessed for each characteristic.

\begin{tabular}{|c|c|c|}
\hline \multirow[t]{2}{*}{ Characteristics } & \multirow{2}{*}{$\begin{array}{l}\text { Standard } \\
\% \quad(n=60)\end{array}$} & SCS \\
\hline & & $\% \quad(n=60)$ \\
\hline female & $38 \%(23)$ & $45 \%(27)$ \\
\hline age (mean $\pm S D)$ & $72 \pm 10.6$ & $73 \pm 9.8$ \\
\hline diabetes & $38 \%(23)$ & $37 \%(22)$ \\
\hline \multicolumn{3}{|l|}{ contralateral leg } \\
\hline - symptomatic & $48 \%(29)$ & $32 \%(19)$ \\
\hline - amputated & $12 \%(7)$ & $15 \%(9)$ \\
\hline \multicolumn{3}{|l|}{ smoking } \\
\hline - not for > lyear & $27 \%(16)$ & $37 \%(22)$ \\
\hline - still smoking & $44 \%(26)$ & $30 \%(18)$ \\
\hline CVA/TIA & $27 \%(16)$ & $22 \%(13)$ \\
\hline myocardial infarction & $37 \%(22)$ & $38 \%(23)$ \\
\hline angina pectoris & $25 \%(15)$ & $20 \%(12)$ \\
\hline ulcerations / gangrene & $68 \%(41)$ & $63 \%(38)$ \\
\hline \multicolumn{3}{|l|}{ gangrene } \\
\hline - dry & $38 \%(23)$ & $40 \%(24)$ \\
\hline - wet & $8 \%(5)$ & $13 \%(8)$ \\
\hline \multicolumn{3}{|l|}{ previous vascular surgery } \\
\hline - none & $18 \%(11)$ & $25 \%(15)$ \\
\hline-1 or 2 & $48 \%(29)$ & $42 \%(25)$ \\
\hline$\geq 3$ & $33 \%(20)$ & $32 \%(19)$ \\
\hline sympathectomy (randomized leg) & $32 \%(19)$ & $35 \%(21)$ \\
\hline ankle pressure (mean $\pm \mathrm{SD}$ ) & $41.6 \pm 21.8$ & $35.2 \pm 24.8$ \\
\hline ankle-brachial index (mean $\pm S D$ ) & $0.28 \pm 0.13$ & $0.23 \pm 0.16$ \\
\hline
\end{tabular}

All p-values $>0.1$.

Median follow-up was 605 days (244-1171). Limb survival at 6 months was $66 \%$ in the SCS group and $68 \%$ in the standard group. At 1 year limb survival was 60 vs $46 \%$ and at 2 years limb survival was 52 vs $46 \%$ ( $p=0.47$ ). The hazard ratio was 0.81 (95\%CI: 0.47-1.51). In the SCS treatment group 13 lead displacements occurred and 11 repositions and one reimplantation procedure were done. Infection was reported in three cases and three batteries failed within 18 months. Because of these difficulties, eight patients (13\%) had suboptimal stimulation. All patients were treated following the intention to treat principle. (Klomp et al., 1999). 


\section{Quality of life}

The mean value of the overall NHP score at intake was 47 ( $\mathrm{SE}=2.6, \mathrm{n}=58$ ) for the standard treatment and $48(\mathrm{SE}=2.6, \mathrm{n}=57)$ for the SCS group. Between 3 and 6 months follow-up there was a decline of mean values to 34 ( $\mathrm{SE}=3, \mathrm{n}=$ 41 ) for the standard group and 35 ( $S E=2.6, n=44$ ) for the SCS group, which remained unchanged until the end of the follow-up period at 18 months. The global NHP score obscures the effect in subgroups. Difference in mean values of mobility between SCS and conservative treatment is statistically significant from 6 months after randomization. Patients on SCS who were not amputated had better mobility and energy scores than the conservatively treated non-amputated patients $(\mathrm{p}<0.01)$.

In case of amputation, mobility was reduced and not influenced by rehabilitation programmes (Fig. I; Table 3).

Figure 1. Mean NHP mobility score in patients treated with SCS. The scores vary between zero $=$ normal and $100=$ the worst possible score. Only the SCS patients are represented. In the table below the scores of the patients with a standard treatment are given and can be compared with SCS

The EuroQol (EQ) simple linear index showed a similar improvement over time as the NHP. Initial values of the EQ were $51(n=58, S E=2.9)$ in the standard group and $54(n=56, S E=2.8)$ in the SCS group. The decrease at $t=12$ was 43 in the standard group and 41 in the SCS group. Patients who underwent an amputation early in the trial had worse initial EQ scores than those amputated later. Scores after amputation worsened to 66 at $\mathrm{t}=1(\mathrm{n}=8, \mathrm{SE}=$ 8.2) in the standard group and $61(\mathrm{n}=4, \mathrm{SE}=4.9)$ in the SCS group. Gradually, over a period of months, scores regained values comparable to those of non-amputated patients.

The mean value of the mobility index of the Sickness Impact Profile at intake was $36(\mathrm{SE}=1.9, \mathrm{n}=58)$ for the standard treatment and $34(\mathrm{SE}=1.7, \mathrm{n}=57)$ for the SCS group. During follow-up the score declined but the difference was not significant nor was there a difference between treatment modalities.

\section{Pain relief}

\section{VAS score}

At intake the VAS score for the SCS treatment was $5(n=58, S E=0.2)$, with a mean minimum pain score of $2.5(\mathrm{SE}=0.3)$ and mean maximum pain score of 8 (SE $=0.2$ ). The scores were similar for the standard group. During follow-up, a narrowing of the range between the lower and upper mean 


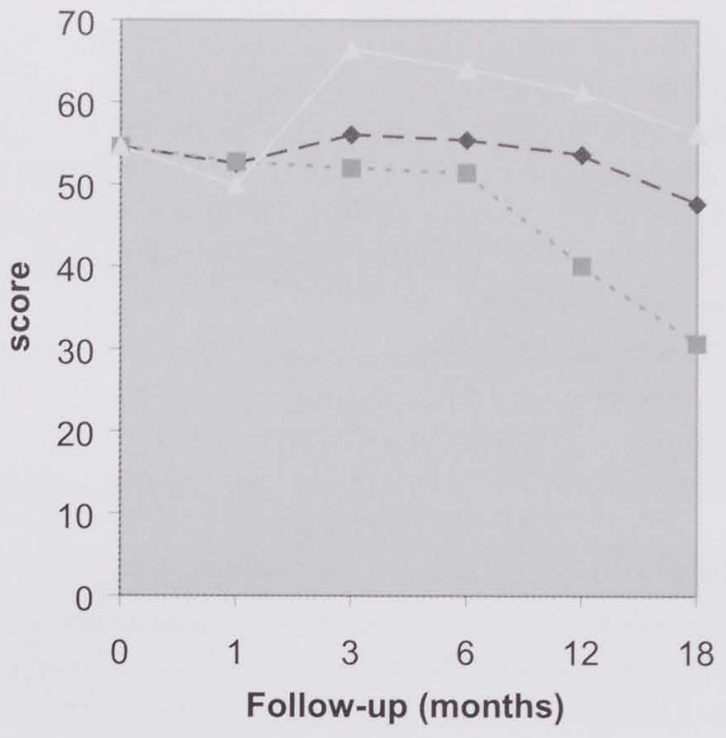

$-\rightarrow-$ ALL $\cdots+$ NOT AMP. AMPUT

Figure 1. Mean NHP mobility score in patients treated with SCS. The scores vary between zero and $100=$ the worst possible score. Only the SCS patients are represented. In the table below the scores of the patients with a standard treatment are given and can be compared with SCS.

Table 3. Mean mobility score for both treatments.

\begin{tabular}{lllllll}
\hline Follow-up & 0 & 1 & 3 & 6 & 12 & 18 \\
\hline Cons .all & 54 & 52.5 & 52 & 51 & 54 & 51 \\
- Non - amp & & 48 & 49.6 & 44.5 & 50.5 & 49 \\
- Amputated & & 75 & 58.5 & 60.5 & 57 & 51.5 \\
$n$ & 60 & 43 & 38 & 36 & 23 & 17 \\
SCS all & 54.5 & 52.5 & 56 & 50.5 & 53.7 & 47.7 \\
- Non - amp & & 52.8 & 52 & 51.5 & 40 & 30.7 \\
- Amputated & & 49.9 & 66.5 & 64 & 61.2 & 56.2 \\
$n$ & 60 & 50 & 39 & 37 & 29 & 17 \\
\hline
\end{tabular}

Follow-up in months. SCS = spinal cord stimulation treatment, Cons. = conservative medical treatment. SCS = spinal cord stimulation. $\mathrm{n}=$ numbers of patients alive and amputation free at each follow-up period. Mean NHP mobility score during follow-up for both treatments. 
scores was observed. At $\mathrm{t}=6$ months, the VAS score in the SCS group was 3 ( $\mathrm{n}$ $=44, \mathrm{SE}=0.4)$ with a minimum score of $2(\mathrm{SE}=0.3)$ and a maximum score of $5.3(\mathrm{SE}=0.5)$.

Mean pain scores declined from $5(n=58, S E=0.2)$ to $2.5(n=23, S E=0.5)$ at $t=$ 18 months for the standard group ( $p<0.0001)$. A similar reduction was recorded for the SCS-treated group. Looking at the best pain reduction in both groups combined at 1 month follow-up $(n=51), 19$ patients had a reduction of more than $50 \%, 17$ patients had a reduction less than $50 \%$, and pain was worse in 15 patients. After amputation the pain score declined to values between 3.9 and 1.8 in patients receiving standard treatment and to 2.6 and 1.4 for SCS treatment $(\mathrm{p}<0.001)$. (Table 4$)$. In patients with a good level of pain relief the pain duration during a 24 -h period changed from continuous to intermittent and was often only present during part of the day.

\section{McGill pain questionnaire}

The pain-rating index (PRI), part I of the McGill, was used and represents the sum from the sensorial, affective and evaluative indices. Intake values of the PRI did not differ between standard treatment and SCS: standard treatment $=21.5(n=58, \mathrm{SE}=1.5)$ and SCS treatment $=22.6(n=57, \mathrm{SE}=1.5)$. The differ -

Table 4. Visual Analogue Score of patients.

\begin{tabular}{|c|c|c|c|c|c|c|}
\hline $\begin{array}{l}\text { Follow-Up } \\
\text { (months) }\end{array}$ & 0 & 1 & 3 & 6 & 12 & 18 \\
\hline \multicolumn{7}{|l|}{ Cons } \\
\hline All (mean values) & 51.3 & 38.3 & 33.4 & 25.6 & 29.8 & 25.2 \\
\hline - Not amp & & 38.4 & 37.7 & 27.9 & 42.6 & 35.6 \\
\hline - Amput & & 38 & 20.2 & 21.3 & 21.7 & 18.5 \\
\hline$n$ & 58 & 47 & 47 & 42 & 38 & 24 \\
\hline \multicolumn{7}{|l|}{ SCS } \\
\hline All & 51.8 & 43.6 & 33.7 & 33.5 & 27.6 & 22.5 \\
\hline - Not amp & & 45.2 & 40.3 & 39.3 & 34 & 37.7 \\
\hline - Amput & & 25.9 & 15.6 & 21.3 & 23.5 & 14.5 \\
\hline$n$ & 57 & 47 & 46 & 44 & 42 & 27 \\
\hline
\end{tabular}

Scores are between $0=$ none and $100=$ maximal pain. Data are mean values. As for the other pain measurements the overall scores hide the differential effect between amputated and not amputated patients. All = values of amp + not amp patients. $n=$ patients censored at time to follow-up. Not amp = patients not amputated at time of follow-up and amput = patients amputated at time of follow-up 
Table 5. McGill Pain Questionnaire.

\begin{tabular}{llccccc}
\hline Follow-up & 0 & 1 & 3 & 6 & 12 & 18 \\
\hline Cons all & 21.5 & 15.8 & 10.9 & 9.2 & 8.5 & 8.1 \\
Non-amp & & 15 & 13 & 12.5 & 13 & 13 \\
Amp & & 18 & 4.2 & 4 & 5.8 & 5.8 \\
$n$ & 60 & 43 & 38 & 36 & 23 & 17 \\
SCS all & 22.6 & 17.9 & 11.9 & 13.2 & 11.1 & 8.7 \\
Non amp & & 18.9 & 14.2 & 17.1 & 15 & 18.5 \\
Amp & & 7 & 5.8 & 4.7 & 8.8 & 5 \\
$n$ & 60 & 50 & 39 & 37 & 29 & 17 \\
\hline
\end{tabular}

Mean values for pain-rating index (PRI) of the conservative treated patients (Cons) and the stimulated patients (SCS). Follow-up in months. $\mathrm{n}=$ patients amputation free and alive at time of follow-up

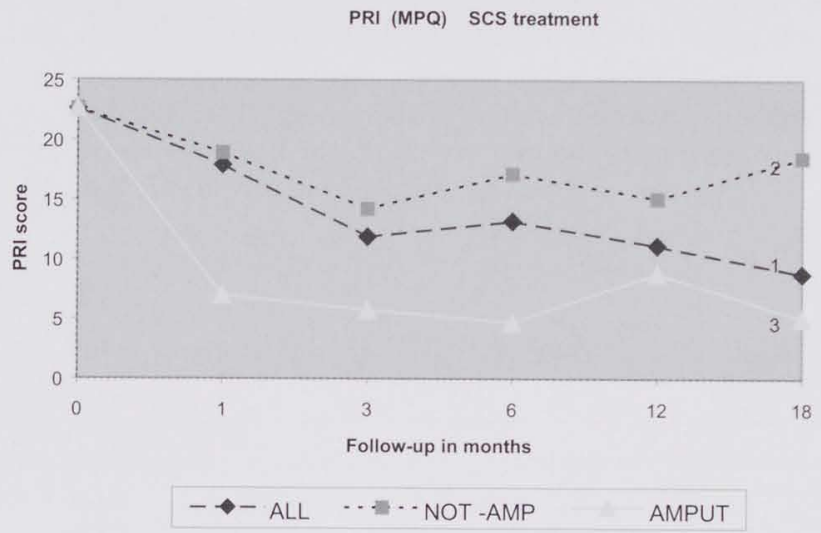

Figure 2. McGill Pain Questionnaire. Mean values of pain-rating index (PRI) of the SCS treated patients. Group 1 =all patients, 2 = patients not amputated, and $3=$ amputated patients. $X$-axis $=$ follow-up in months, Y-axis = PRI value. The higher the score the worse the pain intensity. The difference between amputated and non-amputated patients is statistically significant. 
ence between intake and one month fellow-up $\left(\mathrm{T}_{0}-\mathrm{T}_{1}\right)$ for the standard treatment was $32 \%(\mathrm{p}=0.005)$ and slightly less for the SCS. At 3 months the scores declined to values between 13 and 17 for both treatment modalities, remaining unchanged until the end of follow-up. In the case of amputation the differences between intake and follow-up were more pronounced in both groups and were slightly in favour of standard treatment. The values dropped $70-80 \%$ to nearly normal compared to the intake $(p=0.001)$ (Fig. 2; Table 5). The pain score of the NHP at intake was $72(\mathrm{n}=58, \mathrm{SE}=3.5)$ for the standard treatment and $70(n=57, S E=3.9)$ for the SCS treatment and declined to $36(\mathrm{n}=24, \mathrm{SE}=6)$ and $31(\mathrm{n}=27, \mathrm{SE}=6)$ respectively at 18 months. This reduction of $50 \%$ is significant, but included all the patients. Pain relief in non-amputated patients was substantially less in the standard group, while patients who underwent an amputation had significantly lower pain scores in both treatment groups $(\mathrm{p}<0.01)$.

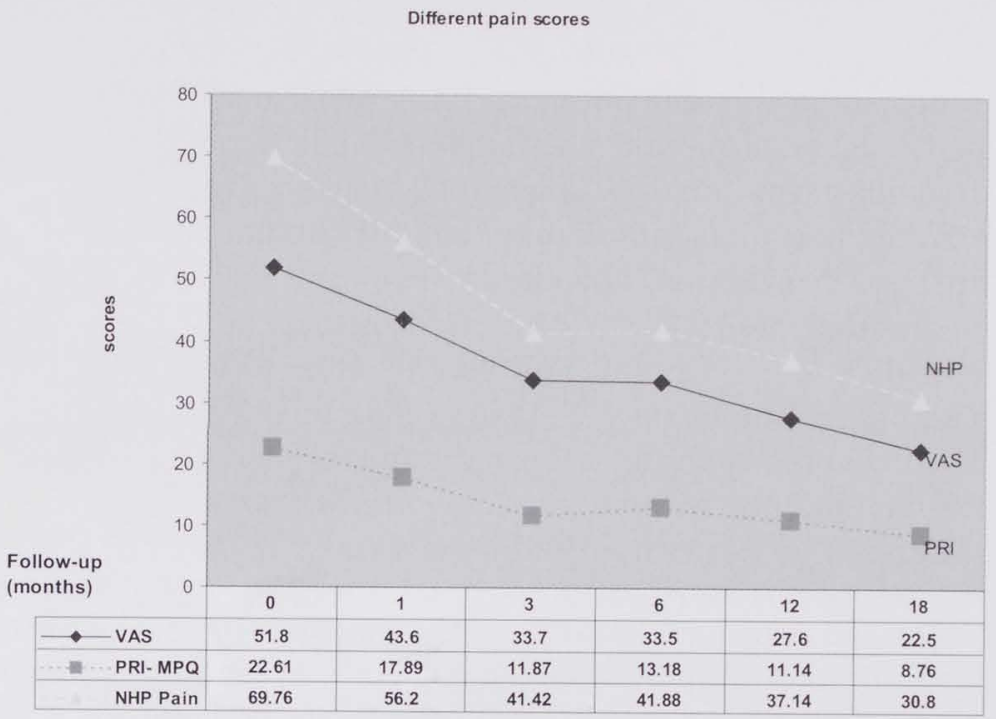

Figure 3. Different pain scores for patients under SCS treatment. Follow-up in months (0-18). $\mathrm{VAS}=$ visual analogue score measured as a value between $0=$ none and $100=$ maximal pain . PRI-MPQ= the pain rating index of the McGill Pain Questionnaire which is the sum of the sensory, emotional and affective parts of the list of synonyms. The NHP Pain is the combination of different questions in the questionnaire related to pain. The higher the values are in both measures (NHP and MPQ) the worse is the condition of the patient. The data of the patients under conservative treatment are comparable and summarized in table $3,4,5$. Important is the parallel evolution over time in the different scores. 
Table 6. Medication quantification scale at $\mathrm{t}=0$.

\begin{tabular}{lll}
\hline Drugs & Standard & SCS \\
\hline paracetamol & $41(68 \%)$ & $43(72 \%)$ \\
NSAIDS & $21(35 \%)$ & $22(37 \%)$ \\
morphine and analogues & $21(35 \%)$ & $18(30 \%)$ \\
MQS (mean \pm SD) & $7.3 \pm 5.2$ & $6.7 \pm 5.0$ \\
\hline
\end{tabular}

Indication of the drugs used in both treatment modalities at intake. The difference is not significant. Although in the article of Steedman [35] drugs were divided into six classes, for the purpose of comprehensibility they were reduced to three classes in the present study. Only a minority of patients used drugs as muscle relaxants, benzodiazepines and barbiturates.

Table 7. Mean \pm SE for the quantification of the use of analgesic drugs in both groups.

\begin{tabular}{llll}
\hline Follow-up & Standard & SCS & p-value \\
\hline $\mathrm{t}=0$ & $7.3 \pm 0.7$ & $6.7 \pm 0.6$ & NS \\
$\mathrm{t}=1$ & $8.9 \pm 0.9$ & $3.5 \pm 0.6$ & $<0.001$ \\
$\mathrm{t}=3$ & $6.8 \pm 0.8$ & $2.8 \pm 0.7$ & $<0.001$ \\
$\mathrm{t}=6$ & $5.6 \pm 0.9$ & $2 \pm 0.5$ & 0.002 \\
$\mathrm{t}=12$ & $3.6 \pm 0.8$ & $1.7 \pm 0.5$ & 0.055 \\
$\mathrm{t}=18$ & $1.9 \pm 0.7$ & $2.4 \pm 1.0$ & 0.70 \\
\hline
\end{tabular}

The evolution in time of the three pain measurements is given in Fig. 3. There is a remarkable parallel evolution during follow-up.

\section{MQS score}

Scoring the use of drugs was carried out using the Medication Quantification Scale (MQS). The analgesics were divided into three categories: (1) paracetamol and aspirin (ASA); (2) non-steroid anti-inflammatory drugs (NSAID); (3) morphine and morphine analogues. At intake, the mean MQS of the standard group was $7.35(\mathrm{SE}=0.68$ ) and for the SCS group was 6.68 (SE $=0.65$ ) (Table 6). During follow-up there was a significant difference between the two treatment modalities. Patients receiving SCS used less non-narcotic and narcotic drugs (Table 7). 


\section{DISCUSSION}

For the study of quality of life and pain a number of questionnaires and scales are available. All of them, uni or multi-dimensional, are subjected to critics related to their clinical relevance. As Carlsson stated: "the patient should complete each scale without having the possibility of comparing with previous estimates. However, the reliability of a pain relief score calculated as a difference between two estimates on the absolute scale may be low, because the double influence of the measurement error, which may be different in different patients. When assessing efficacy of treatment attention should therefore focus on several complementary indices of pain relief, as well as on the individual's tendency to bias his estimates" (Carlsson, 1984). Graham reported that the reliability of the McGill pain questionnaire was high (Graham et al., 1980). In this study the different pain scales (VAS, McGill PRI and the NHP pain score) were compared and revealed a strong correlation ( $\mathrm{p}<0.001)$. Critical limb ischaemia is an extremely high burden for the quality of life of these patients. Other chronic discases such as severe angina pectoris, hip disease and rheumatoid arthritis revealed comparable results having pain and restriction of mobility as a common constraint (Borgquist et al., 1992; Visser et al., 1994). A general analysis of the quality of life 'general well being' (GWB) suggested that patients with limb ischaemia had fear of pain and amputation and suffered from a restricted mobility (Chapman et al., 1985; Wade et al., 1990; Crosby et al., 1993; Lindholm et al., 1993).

\section{Quality of life}

Mean scores on quality of life (NHP) in patients with peripheral vascular disease 'amenable to surgery' and who were surgically treated were 30.3 for energy, 22.6 for pain, 13.9 for emotional reactions, 9 for social isolation, 24.7 for sleep and 22 for physical mobility, with an overall score of 20.4 (Hunt et al., 1981; Pell et al., 1993). This was well below, and thus better than the scores in patients with critical ischaemia 'not amenable to surgery' studied in this trial.

Augustinsson reported on quality of life in patients with SCS for ischaemic pain using the Sickness Impact Profile (SIP) and a Mood Adjective Checklist (MACL). Seventeen of the 54 patients had critical ischaemia (22\%). Functions of daily life were reported as unchanged. In a supplementary short (1 month) prospective study on 23 patients, of whom 13 had ischaemic pain, clear improvements were seen in sleep, rest and emotional behaviour $(\mathrm{p}<$ 0.01) (Augustinsson, 1985). Humphreys reported on the QoL of a large group 
of patients with peripheral vascular disease using the Rosser classification and the EuroQol. In a subgroup of 10 patients with critical ischaemia no change in QoL was found comparing the situation before and six months after amputation; this reflected the problem of rehabilitation (Humpheys et al., 1994; Pell et al., 1993).

\section{Pain relief}

In this study the pain relief was reported using the VAS, the PRI of the McGill pain questionnaire and the pain weighted scores of the NHP. All these measures revealed an important reduction in pain, which was seen from the first month follow-up on. There was, however, no difference between treatment strategies in the VAS, PRI and the pain-weighted score of the NHP. The PRI showed a higher decrease in value for the patients under conservative treatment and not amputated. The difference was, however, at any interval not statistically significant between treatment modalities. Augustinsson reported 'excellent' pain relief, which, according to his classification was more than $66 \%$ pain relief in $15 \%$ of his patients (Augustinsson et al., 1985). Broseta mentioned 'substantial' pain relief $(75-100 \%)$ in $78 \%(29 / 37)$ of the patients (Broseta et al., 1986). Mingoli reported pain relief in $75 \%$ of patients at 2 years with infrequent use of analgesics (Mingoli et al., 1993). Meglio noted more than $50 \%$ pain relief (mean $90.1 \%$ ) in $85 \%$ (34/40) of the patients treated (Meglio et al., 1989). Bunt reported a pain relief of $75 \%$ or more in 11 of 15 patients (73\%) (Bunt et al., 1991).

The existing literature, in which no randomized study was available at the start of this study, remains responsible for the impression that pain relief is almost complete in most patients with SCS. Careful analysis indicates that only a small percentage (15-20\%) has 'excellent' ( $>75 \%)$ pain relief.

Excellent pain relief after a trial period of stimulation was considered as a predictive factor for long-term success. No scientific data were available confirming this hypothesis. A trial stimulation period was therefore not incorporated in the study design. Subsequent simulation of a trial stimulation with our data proved to be negative. Data on pain relief were compared between time of implantation and 1 month follow-up. Although limb survival was lower in patients without good pain relief, there was no difference in survival between a good reaction on stimulation or a good reaction on pain medication.

Another element in the evaluation of pain relief is the reduction in medication. A useful method is the medication quantification technique, which gives the physician a better insight on the kind and quantity of drugs taken by the patient (Steedman et al., 1992). We consider this method adequate, 
but could not find data to compare with our results in the literature. Several authors described the influence of hypertension on limb survival. Patients having hypertension seemed to have a worse outcome (Jivegard et al., 1995; Claeys et al. 1996). This analysis was also performed in the Dutch randomized trial. Although there was a tendency towards an imbalance in the numbers of patients between treatment $(p=0.07)$, no statistical significant difference was found. The hazard ratio for the risk of amputation in the presence of hypertension was $0.72(p=0.25)$.

\section{CONCLUSION}

Both treatments resulted in a significantly positive effect on pain and quality of life. The overall outcome measures did not differ between the two treatment modalities. The mobility and energy scores of the NHP were significantly better in SCS. Patients under SCS treatment used significantly fewer analgesics. Amputation was very successful regarding pain relief, but decreased the mobility of the patient and rendered rehabilitation more difficult. A trial period of stimulation is not needed if limb survival is the endpoint of the study. In the case of critical limb ischaemia a follow-up period of 18 months seems adequate because most amputations and complications occurred within this period.

\section{REFERENCES}

1. Augustinsson LE, Carlsson CA, Holm J, Jivegard L. Epidural electrical stimulation in severe limb ischemia. Evidences of pain relief, increased blood flow and a possible limb-saving effect. Ann Surg 1985; 202: 104-111.

2. Augustinsson LE, Epidural spinal electrical stimulation (ESES) in chronic pain. Thesis. Goteborg 1985.

3. Borgquist L, Nilsson LT, Lindelow G, Wiklund I, Thorngren KG. Perceived health in hip fracture patients: a prospective follow-up of 100 patients. Age and Aging 1992; 21:109-116.

4. Broseta J, Barbera J, de Vera JA, Barcia-Salorio JL, March G, Gonzalez-Darder J, Rovaina F, Joanes V. Spinal cord stimulation in peripheral arterial disease. A cooperative study. J Neurosurg 1986; 64: 71-80.

5. Bunt TJ, Holloway GA, Lawrence P, Cherney D, Malone JM. Experience with epidural spinal stimulation in the treatment of end-stage peripheral vascular disease. Seminars in Vascular Surgery 1991; 4: 216-220.

6. Carlsson AM. Assessment of chronic pain. I. Aspects of the reliability and validity of the visual analogue scale. Pain 1983;16:87-101.

7. Carlsson AM. Assessment of chronic pain. II. Problems in the selection of relevant questionnaire items for classification of pain and evaluation and prediction of therapeutic effects. Pain 1984; 19: 173-184. 
8. Chapman CR, Casey KL, Dubner R, Foley KM, Gracely RH. Reading AE. Pain measurement: an Overview. Pain 1985; 22:1-31.

9. Claeys L, Horsch S. Transcutaneous oxygen pressure as predictive parameter for ulcer healing in endstage vascular patients treated with spinal cord stimulation. Int Angiol 1996; 15:344-349.

10. Cook AW, Oygar A, Baggenstos P, Pacheco S, Kleriga E. Vascular disease of extremities: Electrical stimulation of spinal cord and posterior roots. N. Y. State J. Med 1976; 76:366-368.

11. Crosby FE, Ventura MR, Frainier MA, Wu YW. Well-being and concerns of patients with peripheral arterial occlusive disease. J Vasc Nurs 1993; 11: 5-11.

12. Dormandy JA, Thomas PRS. What is the natural history of a critical ischaemic patient with and without his leg? In: Greenhalgh RM, Jamieson CW, Nicolaides AN eds. Limb salvage and amputation for vascular disease. Philadephia: Saunders, 1988: 11-26.

13. European working group on critical leg ischemia: Second European consensus document on chronic critical leg ischemia. Eur J Vasc Surg 1992; 5 (Suppl. A), 1-32.

14. The Euroqol group: Euroqol: a new facility for the measurement of health related quality of life. Health Policy 1990; 11:1201-1206.

15. Erdman RAM, Passchier J, Kooijman M, Stronks DL. The Dutch version of the Nottingham Health Profile: investigations of psychometric aspects. Psychological Reports 1993; 72:1027-1035.

16. Franzetti I, De Nale A, Bossi A, Greco M, Morricone L, Ruggerini M, Meazza D, Sciolla A, Caviezel F, Oriani G. Epidural spinal electrostimulatory system [ESES] in the management of diabetic foot and peripheral arteropathies. Pace 1989;12: 705-708.

17. Galley D, Rettori R, Boccalon $\mathrm{H}$. et al La stimulation électrique médullaire dans les artériopathies des membres inférieurs: une étude multicentrique chez 244 patients. J Mal Vasc 1992;17: 208-213.

18. Graber JN, Lifson A. The use of spinal cord stimulation for severe limb threatening ischemia: a preliminary report. Ann Vasc Surg 1987; 1: 578-581.

19. Gracely RH. Evaluation of multi-dimensional pain scales. Pain 1992; 48: 297-300.

20. Graham C, Bond SS, Gerkousch MM, Cook MR. Use of the McGill pain questionnaire in the assessment of cancer pain: replicability and consistency. Pain 1980; 8: 377-387.

21. Groth KE. Spinal cord stimulation for the treatment of peripheral vascular disease-European Multi-center Study. In Fields (ed) Advances in Pain Research and Therapy. New York: Raven Press, 1985; 9: 861-870.

22. Haan de R, Aaronson N, Limburg M, Langton Hewer R, van Crevel H. Measuring quality of life. Stroke 1993; 24: 320-327.

23. Humphreys W, Evans F, Williams T. Quality of life: Is it a practical tool in patients with vascular disease. J Cardiovasc. Pharmacol 1994; 23: S34-S36.

24. Hunt SM, McKenna SP, McEwen J, Williams J, Papp E. The Nottingham Health Profile: subjective health status and medical consultations. Soc Sci Med 1981; 15A: 221-229.

25. Hunt SM, McEwen J, McKenna SP, Backett EM, Pope C. Subjective health of patients with peripheral vascular disease. Practitioner 1982; 226: 133-136.

26. Holroyd KA, Holm JE, Keefe FJ, Turner JA, Bradley LA, Murphy WD, Johnson P, Anderson K, Hinkle AL, O'Malley WB. A multi-center evaluation of the McGill Pain Questionnaire: results from more than 1700 chronic pain patients. Pain 1992; 48: 301-311. 
27. Jacobs MJ, Jörning PJ, Joshi SR, Kitslaar PJ, Slaaf DW, Reneman RS. Epidural spinal cord electrical stimulation improves microvascular blood flow in severe limb ischemia. Ann Surg 1988; 207: 179-183.

28. Jacobs MJ, Jörning PJG, Beckers RCY, Ubbink DT, van Kleef M, Slaaf DW, Reneman RS. Foot salvage and improvement of microvascular blood flow as a result of epidural spinal cord electrical stimulation. J Vasc Surg 1990;12: 354-360.

29. Jenkinson C, Fitzpatrick R. Measurement of health status in patients with chronic illness: comparison of the Nottingham Health Profile and the General Health Questionnaire. Family Practice 1990; 7: 121-124.

30. Jensen MP, Karoly $P$, Braver $S$. The measurement of clinical pain intensity: a comparison of six methods. Pain 1986; 2: 117-126.

31. Jivegard L, Augustinsson LE, Carlsson CA, Holm J. Long term results by epidural spinal electrical stimulation [ESES] in patients with inoperable severe lower limb ischemia. Eur J Vasc Surg 1987; 1: 345-349.

32. Jivegard L, Augustinsson LE, Holm J, Risberg B, Ortenwall P Effects of spinal cord stimulation (SCS) in patients with inoperable severe lower limb ischemia: a prospective randomized controlled study. Eur J Vasc Surg 1995; 9: 421-425.

33. Kaada B. Promoted healing of chronic ulceration by transcutaneous nerve stimulation. VASA 1983; 12: 262-269.

34. Klomp HM, Spincemaille GH, Steyerberg EW, Berger MY, Habbema JDF, van Urk H. Design issues of a randomized controlled clinical trial on spinal cord stimulation in critical limb ischemia. Eur J Endovasc Surg 1995; 10:(4) 478.

35. Klomp H, Spincemaille G, Steyerberg E, Habbema J, van Urk H. Spinal cord stimulation in critical limb ischaemia: a randomised trial. Lancet 1999; 353: 1040-1044.

36. Lindholm C, Bjellerup M, Christensen OB, Zederfeldt B. Quality of life in chronic leg ulcer patients. An assessment according to the Nottingham Health Profile. Acta Derm Venereol 1993; 73: 440-443.

37. Meglio M, Cioni B, Rossi GF. Spinal cord stimulation in chronic pain: a 9-year experience. J Neurosurg 1989; 70: 519-524.

38. Melzack R. The McGill pain questionnaire: major properties and scoring methods. Pain $1975 ; 1$ : 277-299.

39. Melzack R. The short-form McGill pain questionnaire. Pain 1987; 30:191-197.

40. Mingoli A, Sciacca V, Tamorri M, Fiume D, Sapienza P Clinical results of epidural spinal cord stimulation in patients affected with limb-threatening chronic arterial obstructive disease. Angiology 1993; 44: 21-25.

41. Ohta T, Hosaka M, Ishibashi H, Mihara E, Hida K, Takeuchi N, Hachiya J, Kato M, Kazui H, Nagata Y Limb salvage and survival rates among elderly patients with advanced limb ischemia. Surg Today 1998; 28: 156-161.

42. Pell JP, Donnan PT, Fowkes FGR, Ruckley CV. Quality of life following lower limb amputation for peripheral arterial disease. Eur J Vas Surg 1993; 7: 448-451.

43. Steedman SM, Middaugh SJ, Kee WG, Carson DS, Harden RN, Miller C. Chronic-pain medications: equivalence levels and method of quantifying usage. The Clinical Journal of Pain 1992; 8: 201-214.

44. Rivers SP, Veith FJ, Ascer E, Gupta SK. Successful conservative therapy of severe limb: the value of nonsympathectomy. Surgery 1986; 99: 759-762.

45. Turk DC, Rudy TE, Salovey P. The McGill Questionnaire reconsidered: Confirming the factor structure and examining appropriate uses. Pain 1985; 21: 385-397. 
46. Vanderiet $\mathrm{K}$, Adriaensen $\mathrm{H}$, Carton $\mathrm{H}$. The McGill pain questionnaire constructed for the Dutch language (MPQDV). Preliminary data concerning reliability and validity. Pain 30: 395-408.

47. Visser MC, Fletcher AE, Parr F, Simpson A, Bulpitt CJ. A comparison of three quality of life instruments in subjects with angina pectoris: the Sickness Impact Profile, the Nottingham Health Profile and the quality Well Being Scale. J Clin Epidemiol 1994; 47: 157-163.

48. Wade JB, Price DD, Hamer RM, Schwartz SM, Hart RP An emotional component analysis of chronic pain. Pain 1990; 40:303-310.

49. Whitney CW, Von Korff M. Regression to the mean in treated versus untreated chronic pain. Pain 1992; 50:281/285.

50. Wiklund I. The Nottingham Health Profile - A measure of health-related Quality of Life. Scand J Prim Health Care 1990; (Suppl. 1): 15-18.

51. Wiklund I. Measuring quality of life in medicine. Scand J Prim Health Care Suppl 1990; 1: 11-14.

52. de Witte L, Jacobs H, van der Horst F, Luttik A, Joosten J, Philipsen H. De waarde van de Sickness Impact Profile als maat voor het functioneren van de patiënten. Gezondheid en samenleving 1987; 8: 20-127. 


\section{Technical Data and Complications of Spinal Cord Stimulation: Data from a Randomized Trial on Critical Limb Ischemia}

G.H. Spincemaille a , H.M. Klomp b, E.W. Steyerberg c , H. van Urk b, J.D.F. Habbema ${ }^{c}$ for the ESES study group

a Department of Neurosurgery, University Hospital Maastricht,

$\mathrm{b}$ Department of Vascular Surgery, Academic Hospital Dijkzigt Rotterdam,

${ }^{\mathrm{c}}$ Department of Public Health, Erasmus University, Rotterdam, The Netherlands 


\section{SUMMARY}

This study was done to evaluate the effect of spinal cord stimulation (SCS) on critical limb ischemia and to report technical problems and complications. One hundred and twenty patients with critical limb ischemia were eligible for randomization between medical treatment and medical treatment plus SCS. Sixty received a spinal cord stimulator (Itrel II; Medtronic; Minneapolis, Minn., USA). Primary outcome measures were limb salvage and pain relief. The mean pain reduction in both treatment groups was $50 \%$ (from 5 to 2.5 on the visual analog scale). The 2 -year limb survival was $52 \%$ (SCS) versus $46 \%$ (standard treatment; $\mathrm{p}=0.47$ ). The number of patients undergoing major amputations in the SCS group with intermediate $\mathrm{TcpO}_{2}$ values was half of that in the standard group ( 14 vs. $28 ; 24$ vs. $48 \% ; p=0.17$ ). Implantation was successful in 51 patients. Technical problems such as loss of stimulation due to lead displacement occurred in 13 patients $(22 \%)$, local infection at the site of implantation occurred in 3 patients (5\%), resulting in a total complication rate of $27 \%$. Premature depletion of the battery occurred within 2 years in 3 patients $(5 \%)$. There were no lead fractures, epidural infections, hematoma or cerebrospinal fluid leakage. Training of physicians and better reliability of the hardware should reduce the frequency of technical problems. Lead displacement remains the major technical problem. The search for prognostic factors of limb salvage is important. One microcirculatory measurement $\left(\mathrm{TcpO}_{2}\right)$ seems to have a prognostic value, which remains to be described more precisely.

\section{Key Words}

Spinal cord stimulation - Limb ischemia - Peripheral vascular disease 


\section{INTRODUCTION}

Over the last 10 years, many attempts have been undertaken to improve limb survival in patients with critical limb ischemia. The most important treatment options were the use of prostaglandins and spinal cord stimulation (SCS).

Good to excellent effects of SCS on pain in patients with critical ischemia have been described [1-8]. Some suggested that SCS also might have an important effect on limb salvage $[1,9,10]$. Final conclusions on the efficacy of SCS in critical limb ischemia were difficult to reach in the absence of randomized trials. The only randomized study was published by Jivegard [11] some years after the start of the Dutch randomized study and was not conclusive regarding limb salvage. When SCS is compared with other treatment options, it is important to realize that SCS is a technique still in evolution. The aim of new hardware development is to improve stimulation coverage of the pain region and reduction of technical problems and failures. Any discussion on the effectiveness of SCS is therefore related to the actual state of the hardware. A better understanding of the mechanisms of SCS may influence the selection of patients eligible for this treatment.

\section{MATERIALS AND METHODS}

One hundred and twenty patients were selected on the basis of clinical symptoms and macrocirculatory data, as described in the European consensus document on critical limb ischemia[12]. They were randomized between medical treatment and medical treatment plus SCS. Randomization was performed by a random numbers table, and the list, which was available around the clock, was held in an independent research institute. Inclusion criteria were critical limb ischemia and non-reconstructible peripheral arterial occlusive disease (table l). Data were collected at intake and $1,3,6,12,18$ and 24 months. Outcome measures were limb salvage, pain relief and quality of life. Patient and limb survival was estimated with the Kaplan-Meier method at 1 and 2 years follow-up. Pain was evaluated using the visual analogue scale (VAS), the Pain Rating Index (PRI) of the McGill Pain Questionnaire (MPQ), which is the sum of the scores of the sensory, affective and evaluative categories of the questionnaire, and the pain score of the Nottingham Health Profile (NHP). The normative values of the NHP (women aged 55-59 years) for the subscore of energy are 18.6, pain 14.5, emotional reactions 7.7, sleep 11.7, social isolation 3.4 and physical mobility 3.7. The mean value of the six dimensions is 9.9 [13]. 
The SCS hardware used consisted of a lead, an extension cable and a pulse generator (Quad lead; Itrel II, Medtronic, Minneapolis, Minn., USA). The stimulation parameters were controlled by telemetry using an external programmer [14]. Implantation was performed as a one-stage procedure under local anesthesia in the operating room.

Implantation problems, stimulation parameters, complications and adverse events were monitored during follow-up. TcpO $\mathrm{O}_{2}$, laser Doppler and capillary microscopy were used to evaluate microcirculation. Ubbink et al. [16] categorized patients according to the status of their baseline skin microcirculation into good $\left(\mathrm{TcpO}_{2}\right.$ above $\left.30 \mathrm{~mm} \mathrm{Hg}\right)$, intermediate $\left(\mathrm{TcpO}_{2}\right.$ between 10 and $30 \mathrm{~mm} \mathrm{Hg}$ ) and poor $\left(\mathrm{TcpO}_{2}\right.$ below $\left.10 \mathrm{~mm} \mathrm{Hg}\right)$.

Baseline data were general characteristics of the population, circulatory measurements and pain. Technical data related to SCS were time between randomization and implantation, localization of the tip of the lead, stimulation parameters and adverse events. Parameter adjustments secondary to lead repositioning or replacement were registered as a minor complication. Data were analyzed with the $t$ test for continuous variables and the $\chi 2$ - test for categorized variables. Two-sided $p$ values less than 0.05 were considered statistically significant. Based on the number of patients selected for the study, this study had a statistical power $(1-\beta)$ of more than $80 \%$ to detect an increase in median limb survival from 3 to 6 months with an $\alpha$-level of $5 \%$.

\section{RESULTS}

One hundred and forty-one patients were evaluated. Twenty-one were not randomized: 4 refused informed consent, 1 had no rest pain, 3 had other diseases than atherosclerosis, 5 had extensive necrosis, 7 had a Doppler pressure above $50 \mathrm{~mm} \mathrm{Hg}$, and 1 had critical ischemia in both legs.

Baseline data are shown in table 1. Sixty of the 120 eligible patients were randomized for SCS treatment.

The mean (SD) in-hospital stay after implantation of the stimulator was 4.9 days (2.3). Median follow-up was 605 days (244-1,171). Limb survival at 6 months was $66 \%$ in the SCS group and $68 \%$ in the standard group. At 1 year, limb survival was 60 versus $46 \%$, and at 2 years it was 52 versus $46 \%$ ( $p=$ 0.47).

At intake, the VAS score of all patients was between 4.7 and 5, the NHP pain score between 69 and 75, and the PRI of the MPQ between 21 and 24 . 
Table 1. Characteristics from patients randomized for SCS.

\begin{tabular}{lll}
\hline & $\mathrm{n}$ & $\mathrm{SCS}(\mathrm{n}=60)$ \\
\hline Female & 27 & $45 \%$ \\
Male & 33 & $55 \%$ \\
Age & $73.1(\mathrm{SD}=9.8)$ \\
Diabetes & 22 & $37 \%$ \\
Other leg & & \\
$\quad$ Symptomatic & 19 & $32 \%$ \\
$\quad$ Amputated & 9 & $15 \%$ \\
Smoking & & \\
$\quad$ Stopped for $>$ 1 y & 22 & $37 \%$ \\
$\quad$ Still smoking & 18 & $30 \%$ \\
CVA/TIA & 13 & $22 \%$ \\
Myocardial infarction & 23 & $38 \%$ \\
Angina pectoris & 12 & $20 \%$ \\
Ulcerations / gangrene & 38 & $63 \%$ \\
Gangrene & & \\
$\quad$ Dry & 24 & $40 \%$ \\
$\quad$ Wet & 8 & $13 \%$ \\
Previous vascular surgery & & \\
$\quad$ None & 15 & $25 \%$ \\
$\quad$ 1 or 2 & 25 & $42 \%$ \\
$\quad$ Sympathectomy* & 19 & $32 \%$ \\
Ankle pressure* & 21 & $35 \%$ \\
Ankle-brachial index & & $35.2(\mathrm{SD}=24.8)$ \\
\hline
\end{tabular}

Sympathectomy: mentioned are the patients with a sympathectomy in the leg randomized in the study. ${ }^{*}$ Ankle presure and ankle-brachial index $=\mathrm{mm} \mathrm{Hg}$

All scores declined over time (fig. 1) by $30-50 \%$ with no significant difference between groups. Looking at the best pain reduction in both groups combined at 1 month follow-up $(n=51), 19$ patients had a reduction of more than $50 \%, 17$ patients had a reduction less than $50 \%$, and pain was worse in 15 patients.

After amputation, pain intensity dropped by $70-80 \%$, reducing the pain score to 1.8 in the standard group and to 1.4 in the SCS group ( $<0.001)$.

Patients with a poor skin perfusion had a high amputation rate of $80 \%$ for SCS and $71 \%$ for standard treatment. Patients with good microcirculation had a good outcome irrespective of the treatment given. Amputation frequency in patients treated with SCS and an intermediate $T c \mathrm{O}_{2}$ value was 
Different pain scores

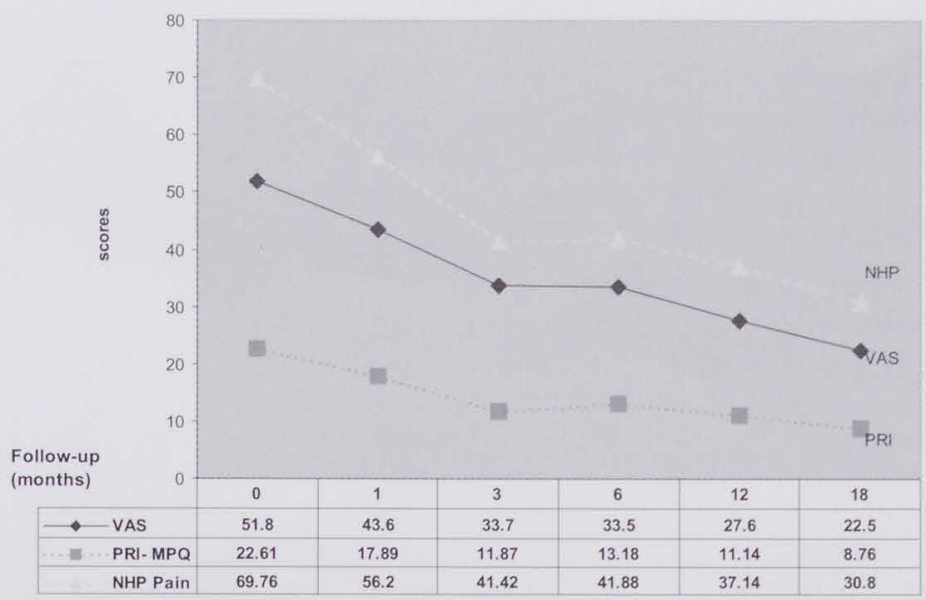

Figure 1. Different pain scores for patients under SCS treatment. Follow-up in months (0-18). VAS $=$ visual analogue score measured as a value between $0=$ none and $100=$ maximal pain . $\mathrm{PRI}-\mathrm{MPQ}=$ the pain rating index of the McGill Pain Questionnaire which is the sum of the sensory, emotional and affective parts of the list of synonyms. The NHP Pain is the combination of different questions in the questionnaire related to pain. The higher the values are in both measures (NHP and MPQ) the worse is the condition of the patient. The data of the patients under conservative treatment are comparable. Important is the parallel evolution over time in the different scores.

half of that in the standard group (24 vs. $48 \%$ ), indicating the possible prognostic value of categorization of $\mathrm{tcpO}_{2}$ [15].

Initial implantation problems resulted in a loss of 9 patients. One patient refused implantation after randomization. Proper lead positioning resulting in paresthesias covering the pain region was not secured in 4 patients $(7 \%)$, mainly due to technical problems while navigating with the lead in the epidural space. In 6 patients (10\%), positioning was not optimal because paresthesias overlapped the pain region only partially. A renewed intervention corrected this problem successfully in 2, but failed in 4 .

Baseline technical data are summarized in table 2. The tip of the lead was situated between the vertebral level $\mathrm{Th}_{11}-\mathrm{L}_{1}$ in 41 patients. Stimulation parameters were within the normal ranges of amplitude (lower than $3.7 \mathrm{~V}$ ), pulse width $(210 \mu \mathrm{s})$ and pulse rate (between 60 and $85 \mathrm{pps}$ ). A unipolar electrode combination was used in $49 \%$ of the patients. 
Table 2. Location of the tip of the electrode and baseline stimulation parameters.

$\begin{array}{lr}\text { Location of tip of the electrode } & \\ \mathrm{Th}_{11}-\mathrm{L}_{1} & 81 \% \\ \text { Above } \mathrm{Th}_{11} & 12 \% \\ \text { Below } \mathrm{L}_{1} & 4 \% \\ & \\ \text { Stimulation Parameters } & 2.9 \quad(\mathrm{SD}=1.4) \\ \text { Pulse amplitude }(\mathrm{V}) & 211 \quad(\mathrm{SD}=12.5) \\ \text { Pulse width ( } \mu \mathrm{sec}) & 72 \quad(\mathrm{SD}=20) \\ \text { Frequency (pps) } & \\ & \\ \text { Electrodes used } & 37 \% \\ \text { Bipolar } \quad 20 \% \\ \quad \text { Rostral anode } \quad 80 \% \\ \quad \text { Rostral cathode } & 49 \% \\ \text { Unipolar } & 14 \% \\ \text { Both (changing over time) } & \end{array}$

In 20 patients with a follow-up of 18 months, the mean amplitude rose from 3.3 to $3.8 \mathrm{~V}(\mathrm{SD} \pm 1.8)$. The increase was mainly due to changes in electrode combinations and not to an increased demand to maintain the intensity of paresthesias.

Multiple changes of electrodes used to stimulate were performed to correct loss of adequate stimulation in 21 patients which could be attributed to either a slight change in position of the lead, a technical failure of one of the electrodes or a migration of the lead. When there was a minimal change in position, changing the electrode combination would usually restore loss of adequate stimulation. The electrode configuration was changed in 8 patients as the only action to restore successful stimulation. This was considered to be a minor adverse event.

Major adverse events such as technical and medical complications included migration of the lead, infection and early depletion of the battery and are listed in table 3. Migration of the lead was considered as a major adverse event, necessitating hospitalization and additional surgical intervention to restore adequate stimulation. Surgical repositioning was done with the lead left in place in 12 patients, and 1 lead had to be removed and replaced by a new one (table 4). No lead fractures were observed. Because of these difficulties, 8 patients (13\%) had suboptimal stimulation. 
Table 3. Complications

\begin{tabular}{|c|c|c|c|c|c|c|c|}
\hline & \multicolumn{4}{|c|}{ Follow up (months) } & & & \multirow[t]{2}{*}{ Total } \\
\hline & 0 & 1 & 3 & 6 & 12 & 18 & \\
\hline Implant failure & 6 & & & & & & 6 \\
\hline Displacement & & 7 & 5 & & 1 & & 13 \\
\hline Infection & & 2 & & 1 & & & 3 \\
\hline Lead fracture & & 0 & & & & & 0 \\
\hline Battery eol & & & & & & 3 & 3 \\
\hline Total & 6 & 9 & 5 & 1 & 1 & 3 & 25 \\
\hline
\end{tabular}

Implant failures: mostly due to problems as impossibility to position the lead in the epidural canal. Displacement: positional change of the lead in lateral or rostro-caudal direction after correct initial positioning of the lead. Battery EOL: depletion of the battery.

Table 4. Measures taken to correct the complications Interventions scheduled to restore normal stimulation.

\begin{tabular}{|c|c|c|c|c|c|c|}
\hline & \multicolumn{5}{|c|}{ Follow-up (months) } & \multirow[t]{2}{*}{ Total } \\
\hline & 1 & 3 & 6 & 12 & 18 & \\
\hline \multicolumn{7}{|l|}{ Lead } \\
\hline Replacement & & 9 & 4 & & 1 & 14 \\
\hline Re-implantation & 2 & 1 & & & & 3 \\
\hline \multicolumn{7}{|l|}{ Pulse generator } \\
\hline Temporary removal & & 1 & & & & 1 \\
\hline Definitive removal & 0 & 1 & 4 & 3 & 1 & 9 \\
\hline Total & 2 & 12 & 8 & 3 & 2 & 27 \\
\hline
\end{tabular}

Replacement: percutaneous trial to reposition the lead. In case of failed percutaneous reposition a complete new percutaneous re-implantation was performed. Temporary removal of the lead or pulse generator was due to infection and definitive removal was caused by the depletion of the battery in 3 patients.

Problems with wound healing or erosion of the skin underneath the pulse generator were not seen. Three patients had an infection of the subcutaneous pocket of the pulse generator. One patient had the device explanted and died shortly afterwards of cardiac failure. The second patient was successfully treated with antibiotics after evacuation of the abscess in the pocket of the pulse generator, which was reimplanted later. The third patient, in whom a pulse generator was left in place after a below the knee 
amputation, had an infection at the site of the stimulator; removal of the stimulator solved the problem. Two patients reported discomfort at the site of the pulse generator, which was left in place long after amputation was performed. The devices were explanted. In 3 cases still under follow-up, an earlier than expected battery depletion occurred within 2 years (613 and 548 days) after randomization. In 1 case a new pulse generator was implanted.

\section{DISCUSSION}

The conclusion of the randomized multicenter trial indicated that SCS was not more effective in preventing amputations and reducing pain than an optimal medical treatment [15]. This statement is certainly quite provoking, as several clinicians involved in SCS reported better results of SCS for this indication. Nonrandomized studies and some experimental data suggest that SCS influences the peripheral microcirculation. Adding microcirculatory measurements and particular $\mathrm{TcpO}_{2}$ to the inclusion criteria may be the key to better patient selection. This is partially proven by the results of Ubbink et al. [16] in categorizing patients according to their intake value of $\mathrm{TcpO}_{2}$.

A further improvement in the results of SCS can be expected if the technical adverse events are reduced. The positioning of the lead in the epidural space is not always easy if one wants to cover the pain region with paresthesias. Leads with different electrode geometry were developed to overcome these problems [17-19]. One alternative is the use of more than one lead with multiple electrode contacts.

The frequency of lead repositioning reported to restore optimal stimulation using multichannel devices was between 15 and 25\%, which was comparable with our results [14]. Lead fracture was not seen in our study (Quad lead, Medtronic), but is reported in the literature as up to $23 \%$ for percutaneously inserted leads. These reports generally refer to older types of leads.

Early battery depletion occurred in 2 patients, who had initially a high intensity of stimulation ( 4.5 and $5 \mathrm{~V}$ ). Three other cases had high initial settings, which might have resulted in an early depletion. Early amputation resulted in discontinuation of the stimulation therapy. For patients with critical ischemia a mean battery life of 3-5 years is generally sufficient because of the high number of dropouts due to amputation and mortality within a period of 2 years.

Other complications mentioned in the literature were infection, epidural hematoma and leakage of cerebrospinal fluid. Infection was reported with a 
frequency of 2-12\% [14]. Treatment usually consists of removing the system, followed by antibiotics for 1 or 2 weeks. Our infection rate was 5\%. In 2 cases, the pocket became infected months after an amputation when the stimulator was no longer used. It seems therefore wise to explant the device once it is no longer used, certainly in patients such as these with skin lesions and diabetes who are more susceptible to infections. Neither epidural hematoma nor leakage of CSF was encountered in this study.

A possible factor responsible for a lower than expected successful implantation was the high incidence of degenerative disease of the spine in a group of patients at this age.

\section{CONCLUSION}

A better selection of patients using microcirculatory measurements $\left(\mathrm{TcpO}_{2}\right)$ as indicated by Ubbink et al. [16] and a reduction of adverse events will improve the results of SCS. One of the possible refinements of the inclusion criteria is to include only patients having intermediate baseline $\mathrm{TcpO}_{2}$ values. Technical improvement will accompany better and more reliable leads, as these remain the critical part for successful long-term use of the SCS system. Lead fracture became rare after the introduction of the larger and stiffer leads, but displacement remains a frequent problem (24\%). Regular adaptation of stimulation parameters and, if needed, percutaneous or surgical repositioning of the lead makes this therapy difficult and demanding to prolong a good result over time. A regular outpatient clinic control is necessary. Infections are rare, but, if present, compromise the outcome of the therapy. Battery life of the pulse generator is sufficient for this population. It can be enhanced by proper parameter settings to reduce energy consumption. For other indications better and newer battery technology extending the battery life is needed.

\section{REFERENCES}

1. Augustinsson LE, Carlsson CA, Holm J, Jivegard L: Epidural electrical stimulation in severe limb ischemia. Evidences of pain relief, increased blood flow and a possible limb-saving effect. Ann Surg 1985;202:104-111.

2. Broseta J, Barbera J, de Vera JA, Barcia-Salorio JL, March G, Gonzalez-Darder J, Rovaina F, Joanes V: Spinal cord stimulation in peripheral arterial disease. A cooperative study. J Neurosurg 1986;64:71-80. 
3. Bunt TJ, Holloway GA, Lawrence P, Cherney D, Malone JM: Experience with epidural spinal stimulation in the treatment of end-stage peripheral vascular disease. Semin Vasc Surg 1991;4: 216-220.

4. Cook AW, Oygar A, Baggenstos P, Pacheco S, Kleriga E: Vascular disease of extremities: Electrical stimulation of spinal cord and posterior roots. NY State J Med 1976;76:366-368.

5. Franzetti I, De Nale A, Bossi A, Greco M, Morricone L, Ruggerini M, Meazza D, Sciolla A, Caviezel F, Oriani G: Epidural spinal electrostimulatory system (ESES) in the management of diabetic foot and peripheral arteriopathies. Pace 1989;12:705-708.

6. Galley D, Rettori R, Boccalon H, Medvedowsky A, Lefebre JM, Sellier F, Chauvreau C, Serise JM, Pieronne A: La stimulation électrique médullaire dans les artériopathies des membres inférieurs. J Mal Vasc 1997;17:208-213.

7. Graber JN, Lifson A: The use of spinal cord stimulation for severe limb threatening ischemia: A preliminary report. Ann Vasc Surg 1987;1:578-581.

8. Groth KE: Spinal cord stimulation for the treatment of peripheral vascular disease European Multi-center Study; in Fields W (ed): Advances in Pain Research and Therapy. New York, Raven Press, 1985, vol 9, pp 861-870.

9. Jacobs MJ, Jörning PJ, Joshi SR, Kitslaar PJ, Slaaf DW, Reneman RS: Epidural spinal cord electrical stimulation improves microvascular blood flow in severe limb ischemia. Ann Surg 1988;207: 179-183.

10. Jacobs MJ, Jörning PJG, Beckers RCY, Ubbink DT, van Kleef M, Slaaf DW, Reneman RS: Foot salvage and improvement of microvascular blood flow as a result of epidural spinal cord electrical stimulation. J Vasc Surg 1990;12:354-360.

11. Jivegard L, Augustinsson LE, Holm J, Risberg B, Ortenwall P: Effects of spinal cord stimulation (SCS) in patients with inoperable severe lower limb ischemia: A prospective randomized controlled study. Eur J Vasc Surg 1995; 9:421-425.

12. European working group on critical leg ischemia: Second European consensus document on chronic leg ischemia. Eur J Vasc Surg 1992;(suppl A):1-32.

13. Jenkinson C, Fitzpatrick R: Measurement of health status in patients with chronic illness: Comparison of the Nottingham Health Profile and the General Health Questionnaire. Family Pract 1990;7: 121-124.

14. Mullet KR, Rise MT, Shatin D: Design and function of spinal cord stimulators - Theoretical and developmental considerations. Pain Digest 1992;1:281-287.

15. Klomp HM, Spincemaille GH, Steyerberg EW, Habbema JDF, van Urk H: Spinal cord stimulation in critical limb ischaemia: A randomised trial. Lancet 1999;353:1040-1044.

16. Ubbink DT, Spincemaille GH, Prins MH, Reneman RS, Jacobs JH: Microcirculatory investigations to determine the effect of spinal cord stimulation for critical leg ischemia: The Dutch Multicenter Randomized Controlled Trial. J Vasc Surg 1999;30:236-244.

17. Holsheimer J, Wesselink W: Clinical evaluation of paresthesia steering with a new system for spinal cord stimulation. Neurosurgery 1998;42:541-549.

18. Holsheimer J, Struijk JJ: How do geometric factors influence epidural cord stimulation? A quantitative analysis by computer modeling. Stereotact Funct Neurosurg 1991;56:234-239.

19. Holsheimer J, Wesselink W: Effect of anode-cathode configuration on paresthesia coverage in spinal cord stimulation. Neurosurgery 1997;41:654-660. 



\section{Microcirculatory investigations to determine the effect of spinal cord stimulation for critical leg ischemia: The Dutch Multicenter Randomized Controlled Trial}

Dirk Th. Ubbink, AM, PhD, Geert H.J.J. Spincemaille, MD, Martin H. Prins, MD, PhD, Robert S. Reneman, $\mathrm{AM}, \mathrm{PhD}$, and Michael J.H.M. Jacobs, MD, PhD.

(for the Dutch Spinal Cord Stimulation Study Group), Amsterdam, Heerlen, and Maastricht, The Netherlands 


\section{SUMMARY}

Purpose: Patients with non-reconstructable critical limb ischemia generally undergo medical treatment only to prevent or postpone amputation. There is some evidence that spinal cord stimulation (SCS) stimulates ischemic wound healing. Thus, this could benefit limb survival through improved skin perfusion. We investigated the effect of SCS versus conservative treatment on skin microcirculation in relation to treatment outcome in patients with non-reconstructable critical limb ischemia.

Methods: Standard medical treatment plus SCS was compared with only standard medical treatment in a multicenter randomized controlled trial comprised of 120 patients with surgically non-reconstructable chronic rest pain or ulceration. We investigated skin microcirculation by means of capillary microscopy, laser Doppler perfusion, and transcutaneous oxygen measurements in the foot. The microcirculatory status just before treatment was classified in three categories (poor, intermediate, and good) and was related to limb survival after a minimum follow-up period of 18 months.

Results Clinical parameters, peripheral blood pressures, and limb survival rates showed no significant differences between the SCS and standard groups during the follow-up period. In both treatment groups, amputation frequency after 18 months was high in patients with an initially poor microcirculatory skin perfusion (SCS $80 \%$ vs standard treatment $71 \%$; NS) and low in those with a good skin perfusion ( $29 \%$ vs $11 \%$, respectively; NS). In patients with an intermediate skin microcirculation amputation, frequency was twice as low in patients additionally treated with SCS as in the standard treatment group ( $48 \%$ vs $24 \% ; \mathrm{P}=.08$ ). In these patients, microcirculatory reactive hyperemia during the follow-up period reduced in the standard group but not in the SCS group $(\mathrm{P}<0.01)$.

Conclusion: Selection on the basis of the initial microcirculatory skin perfusion identifies patients in whom SCS can improve local skin perfusion and limb survival. 


\section{INTRODUCTION}

Patients with chronic critical limb ischemia, defined as persistent ischemic rest pain or tissue loss that necessitate analgesics and a severely reduced peripheral blood pressure, ${ }^{1}$ have a high risk of amputation within 1 year $(22 \%)^{2}$ The treatment of choice is vascular reconstruction, percutaneous angioplasty, or both. However, a considerable number of patients (40\%) remains in whom vascular reconstruction is not performed. ${ }^{1}$ These patients generally undergo treatment by means of medical treatment (analgesics, anticoagulants, and vasoactive drugs) and local wound care or by means of primary amputation. Epidural spinal cord stimulation (SCS) has been proposed in the literature as an alternative treatment. ${ }^{3}$ This technique consists of a subcutaneously implanted neurostimulator that stimulates the lower thoracic spinal cord via an electrode placed in the epidural space, evoking paresthesias in the area of pain. This technique has been accepted in the treatment of some chronic pain syndromes and may improve limb survival and healing of ischemic ulcers. ${ }^{4,5}$ The basis of limb salvage and ulcer healing may be correlated to the observation in a pilot study that skin capillary perfusion improves in patients with critical limb ischemia after SCS treatment. ${ }^{6}$ Although this technique is applied increasingly in the treatment of peripheral vascular disease, ${ }^{6-10}$ nearly all studies so far lack adequate control groups, which illustrates the need for randomized controlled trials. ${ }^{11,12}$ Today, only one randomized controlled study has been published, showing a statistically non-significant difference in 18-month limb survival of $62 \%$ versus $45 \%$ in favor of SCS. ${ }^{13}$ No controlled studies have been performed so far that investigate the effect of SCS on skin microcirculation.

To assess the potential effect of SCS in patients with critical non-reconstructable leg ischemia, a multicenter randomized controlled study supported by the Dutch Health Care Council was performed in the Netherlands. This study compared standard treatment plus SCS with standard treatment only. The outcome measures were limb salvage, quality of life, and cost effectiveness. The results of this study were published separately. ${ }^{14}$ Part of the protocol was the investigation of the effect of both treatment methods on skin microcirculation. This was based on the allegedly positive effect of SCS on ischemic ulcer healing, ${ }^{4,5}$ indicating that improved skin nutritive blood flow may be the mechanism underlying the potential beneficial effects of SCS. The aim of this study was to evaluate the effect of standard and SCS treatment on skin microcirculation and the effects of the initial microcirculatory status on treatment outcome. 


\section{METHODS}

\section{Patient population}

The randomized controlled clinical study was approved by the medical ethical committees of all 17 contributing hospitals in the Netherlands. The patients were randomized via an independent randomization center. Stratification was performed for diabetes, ankle blood pressure, and the participating center. The patients were included if.

1. They suffered clinically from critical limb ischemia (ie, Fontaine ${ }^{15}$ stages III [rest pain] or IV [ulceration or gangrene]).

2. Peripheral blood pressures met the criteria in the European consensus document on chronic critical leg ischemia. ${ }^{1}$

3. Vascular reconstruction was not considered because of non-reconstructability.

Non-reconstructability was defined as the absence of a suitable autologous vein for distal bypass grafting surgery or the absence of all three crural arteries on a selective angiogram, which was a prerequisite for judgment of the calf and foot arteries. It should delineate contrast down to the distal foot to assess a possible recipient artery. The adequacy of the angiogram was validated by an independent vascular surgeon. Venous mapping was performed by means of routine duplex scanning. Superficial femoral veins were not used.

The inclusion and exclusion criteria are summarized in Table 1. Further details are described elsewhere. ${ }^{14}$

\section{Treatment}

Treatment consisted of either optimal medical treatment, including analgesics, anticoagulants, vasoactive agents, local wound care, and antibiotics if indicated (standard treatment), or SCS plus standard treatment. Standard treatment was identical in both groups. The neurostimulator and lead pulse generator with quadripolar electrode (Itrel II, Medtronic, Minn) were implanted in one session. The surgical procedure of the SCS implantation has been described in detail elsewhere. ${ }^{6}$

\section{Follow-up examination}

Follow-up examination, including clinical examination, Doppler scan peripheral blood pressure, and microcirculatory measurements, was performed $1,3,6,12$, and 18 months after randomization and at the end of 
Table 1. In- and exclusion criteria

\section{Inclusion criteria}

Chronic critical ischemia of one of the lower limbs in patients in whom a meaningful vascular reconstructive procedure is not considered:

- Persistent rest pain for at least two weeks, being treated with analgesics and/or ulceration or gangrene of foot or toes.

- Doppler ankle systolic pressure $\leq 50 \mathrm{~mm} \mathrm{Hg}$ ) or ankle/brachial pressure index $\leq 35 \%$ ).

For patients with diabetes mellitus and incompressible ankle arteries: absence of arterial ankle pulsations by physical examination.

- Patient's written informed consent.

\section{Exclusion criteria}

- Vascular disorders other than atherosclerotic disease.

- No rest pain (e.g. only intermittent claudication) and no gangrene or ulceration.

- Ulceration deeper than the fascia or with a largest diameter of $>3 \mathrm{~cm}$.

- Intractable infection of ulceration or gangrene.

- Bilateral critical ischemia.

- Neoplastic or other concomitant disease restricting life expectancy to <l year.

- Presence of a cardiac pacemaker.

- Psycho-social incompetence of the patient to satisfy the follow-up schedule.

the trial. This period was considered adequate, given the high incidence of amputation and death. I The patients who underwent SCS were checked regularly to ensure that the paresthesias were of sufficient amplitude and were experienced in the painful ischemic area. Complications leading to inadequate stimulation or removal of the system implied that the patient underwent only standard treatment but remained in the SCS group according to the intention-to-treat principle. The endpoint of the study was a major amputation of the limb (ie, of the foot or higher).

\section{Microcirculatory investigations}

The non-invasive skin microcirculatory investigations (capillary microscopy, transcutaneous oxygen pressure, and laser Doppler perfusion measurements) were performed by a single, experienced investigator with mobile equipment in a minivan, which allowed the use of the same equipment in each center.

Capillary microscopy. Capillary microscopy enables the visualization of the nailfold capillaries of the big toe in the sitting position and provides information about capillary morphology (density, in number per square millimeter of nail fold skin) and erythrocyte velocity at rest (restv, in micrometers 
per second) and during reactive hyperemia (peakv, in micrometers per second) after a standard period of arterial occlusion (1 minute) by inflating a cuff around the ankle. The time to reach peakv (in seconds) was assessed as well. This technique yields information exclusively about skin nutritive flow. Images were recorded on videotape for off-fine analysis.

Transcutaneous oxygen pressure. Transcutaneous oxygen pressure measurements enable the assessment of skin oxygen supply by the superficial vessels. Measurements were performed on the dorsum of the foot, with an electrode temperature of $44^{\circ} \mathrm{C}$, at rest $\left(\right.$ restpO $\mathrm{O}_{2}$, in millimeters of mercury) and after a 3-minute arterial occlusion (peakpO $\mathrm{O}_{2}$, in millimeters of mercury). This enabled measurement of the rate at which restpO $\mathrm{O}_{2}$ is restored (reoxygenation rate, in millimeters of mercury per second) and of the time to reach $50 \%$ (in seconds) of restpO $\mathrm{O}_{2}$ or $100 \%$ (in seconds) of the peakpO $\mathrm{O}_{2}$.

Laser Doppler perfusion. Laser Doppler perfusion (LDP) measurements on the pulp of the great toe provide information about total skin perfusion (ie, flow in capillaries and deeper vessels), including the arteriolovenular anastomoses that are mainly involved in thermoregulation. The reactive hyperemie response after a 3-minute arterial occlusion was measured as well (peak LDP minus rest LDP, in arbitrary units) to assess the reserve capacity of skin blood supply because the variability of LDP under resting conditions is known to be great. Also, time to $50 \%$ of rest LDP or $100 \%$ of peak LDP (in seconds) and the reperfusion rate (to recover rest LDP, in arbitrary units per second) were assessed. Transcutaneous oxygen pressure and LDP were performed while the patient was in the supine position, which improves discriminative power. ${ }^{16}$ In case the patient had undergone a minor amputation (toe, forefoot), measurements were performed just proximal to the amputation level. For further details concerning the techniques used, a previous publication can be referenced. ${ }^{16}$

Microcirculatory data analysis was performed at least 6 months after each visit to avoid knowledge of the patient's identity and clinical status and recognition of the recordings. The microcirculatory status of the patient's, ischemic foot was classified into three categories according to the microcirculatory findings at the first visit just before the start of any treatment. These categories (ie, patients with a poor, an intermediate, and a good microcirculatory perfusion) were defined on the basis of microcirculatory criteria to detect critical ischemia, as assessed in previous studies. ${ }^{16,17}$

The criteria for this categorization are shown in Table 2 . The treating physician was kept unaware of the microcirculatory results. 
Table 2. Microcirculatory categories of skin perfusion

Poor

When complying to the criteria of all three techniques:

Capillary microscopy:

Low capillary density (Density $<20 / \mathrm{mm}^{2}$ ) or:

Low peak erythrocyte velocity (Peakv $<50 \mu \mathrm{m} / \mathrm{s}^{*}$ ) or:

No reactive hyperemia (Peakv - Restv $\leq 0 \mu \mathrm{m} / \mathrm{s}^{* *}$ )

$\mathrm{TcpO}_{2}$ :

Poor skin oxygenation (RestpO $\mathrm{O}_{2}$ and $\mathrm{PeakpO}_{2}<10 \mathrm{~mm} \mathrm{Hg}$ )

Laser Doppler Perfusion:

No reactive hyperemic response (Peak - Rest LDP $\leq 3$ AU*)

\section{Intermediate}

When the criteria of the other two categories were not met, i.e.:

Rest or PeakpO $\mathrm{O}_{2}$ between 10 and $30 \mathrm{~mm} \mathrm{Hg}$ or:

The results of the different techniques fit into different categories

\section{Good}

When complying to the criteria of all three techniques:

Capillary microscopy:

Normal capillary density (Density $\geq 20 / \mathrm{mm}^{2 * *}$ ) and

Present reactive hyperemia (Peakv - Restv $>0 \mu \mathrm{m} / \mathrm{s}^{* *}$ ) and

Normal peak erythrocyte velocity (Peakv $\geq 50 \mu \mathrm{m} / \mathrm{s}^{*}$ )

$\mathrm{TcpO}_{2}$ :

Good skin oxygenation (RestpO $\mathrm{O}_{2}$ and PeakpO $2 \geq 30 \mathrm{~mm} \mathrm{Hg}^{*}$ )

Laser Doppler Perfusion:

Present reactive hyperemic response (Peak - RestLDP >3 AU)

* See reference 16

** See reference 17

\section{Statistical analysis}

The study had an $80 \%$ power to detect a hazard ratio of 1.8 on the basis of a sample size of 60 in each treatment group at an $\alpha$ - level of .05, given an estimated overall amputation frequency of $60 \%$ and a mean limb survival in the SCS-treated group of 6 months and in the standard treatment group of 3 months. Limb survival analysis was performed with the Kaplan Meier method for all strata and for each microcirculatory category separately. Statistical significance of the differences between the strata was assessed with the Wilcoxon rank sum test adapted for censored data because the hazards in both treatment groups may have been non-proportional. The effect of treatment on microcirculatory parameters over time was evaluated with general estimating equation methods for repeated measurements. ${ }^{18}$ 
Analysis was performed with both the intention-to-treat and the per-protocol principle. Missing values as the result of death or amputation were treated with the "last-observation carried-forward" approach. Interaction terms between the microcirculatory categories and treatment were introduced to evaluate differential therapy effects between the microcirculatory categories. The $\chi^{2}$ test for trends was used to assess the treatment effect on the microcirculatory status after 1 month. For this purpose, the patients who underwent an amputation in the first month were not discarded but were assumed to have a poor microcirculation just before amputation. This was taken for the evaluation at 1 month.

\section{RESULTS}

\section{Patient population}

From November 1991 to May 1994, 120 patients with non-reconstructable chronic critical limb ischemia consented to participate in the study. Of these patients, only 111 were available for microcirculatory analysis because seven patients were randomized and underwent treatment before the first microcirculatory investigation could take place and two were excluded because of protocol violation (too large an ulcer, therapy refusal after randomization).

Patient intake data are presented in Table 3. There were no significant differences in these data between both treatment groups. Also, cerebrovascular ischemic events (standard 53\% vs SCS $48 \%$ ), smoking ( $44 \%$ vs $30 \%$ ), and number of previous vascular interventions $(82 \%$ vs $73 \%$ undergoing one or more than one intervention) were comparable.

\section{Treatment and follow-up examination}

Fifty-five patients were allocated to the standard treatment, and 56 were allocated to the SCS treatment group. Complications of SCS treatment were dislocation of the lead $(n=13)$, implantation difficulties $(n=6)$, infection ( $n$ $=3$ ), and an empty battery $(n=3)$. In nine patients, the electrode was removed during the follow-up period. In six patients (10\%), the electrode was removed because SCS did not function at all or because the leads could not be implanted. In the remaining three patients, the electrode was removed because of a major amputation. The number of patients in the SCS group with analgesics (paracetamol, nonsteroidal anti-inflammatory drugs, or morphine derivatives) was significantly lower than in the standard group 
Table 3. Patient intake data

\begin{tabular}{lll}
\hline & Standard treatment & SCS treatment \\
\hline Number of patients & 55 & 56 \\
Sex (male/female) & $33 / 22$ & $32 / 24$ \\
Diabetes & 20 & 23 \\
Fontaine stage (III/IV) & $20 / 35$ & $22 / 34$ \\
Age (years)* & $72(38-93)$ & $74 \quad(41-89)$ \\
Ankle pressure (mm Hg)* & $45(0-96)$ & $35(0-70)$ \\
Ankle/brachial index (\%)* & $30(20-35)$ & $25(0-63)$ \\
\hline
\end{tabular}

*: shown as median values and ranges

after 1,3, and 6 months, as quantified by means of the Medication Quantification Scale. ${ }^{19}$ Cumulative patient survival in both groups was comparable: $83 \%$ after 18 months in both groups, and $62 \%$ (standard) versus $64 \%$ (SCS) after 2 years. The percentage of patients censored because of death was similar in both groups: $18 \%$ versus $25 \%$, respectively. Cumulative limb survival was $68 \%$ versus $66 \%$ after 6 months, $46 \%$ (standard) versus $60 \%$ after 1 year, and $46 \%$ versus $52 \%$ after 2 years for the standard and SCS treatment, respectively (Fig 1).

Because of the lower amputation frequency, the post hoc power of the study was reduced. Consequently, the Wilcoxon test showed no significant differences between the two groups $(\mathrm{P}=.47)$.

\section{Microcirculatory investigations}

Skin microcirculation could be investigated in all patients at each follow-up examination until they died, they underwent major amputation, or the study was ended. Capillary microscopy was not possible in 18 patients (16\%) because of amputation or ulceration of the big toe. In these patients, LDP and $\mathrm{pO}_{2}$ measurements were performed only.

The median values at baseline and during the follow-up period of the parameters used to classify the patients in both treatment groups are shown in Table 4, in which the last observations of patients who underwent amputation were carried forward. With general equation estimation, evaluation of the effect of time on skin microcirculation showed a significant improvement of peakv-restv $(\mathrm{P}<.01)$, restpO $\mathrm{O}_{2}(\mathrm{P}<.05)$, and time to 50\% $\mathrm{pO}_{2}(\mathrm{P}<.05)$ 


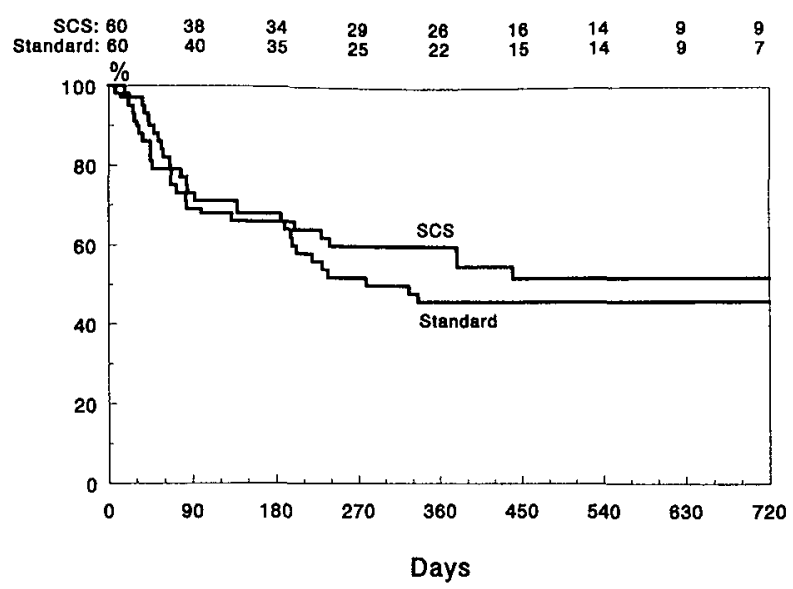

Figure 1. Overall cumulative limb survival (Kaplan-Meier) of patients receiving standard treatment and those receiving additional spinal cord stimulation (SCS). The numbers indicate the patients at risk at the different follow-up moments.

Table 4. Microcirculatory results for each treatment group at $t=0$ through 18 months (Median values)

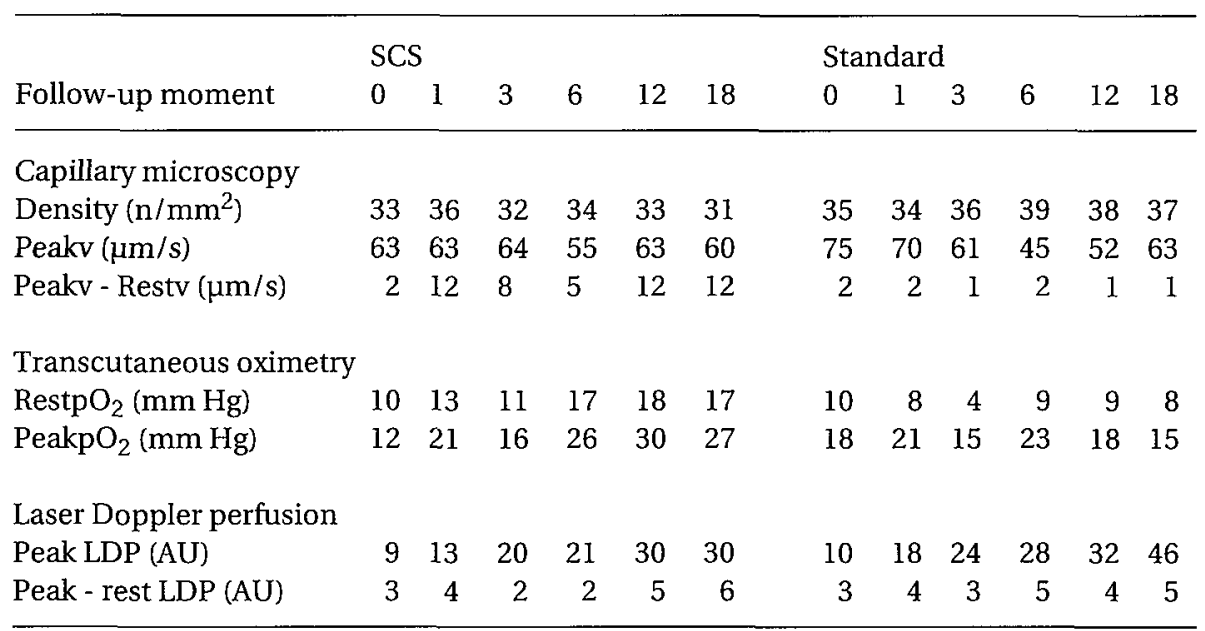


Table 5. Amputation frequency in both treatment groups for each microcirculatory category

\begin{tabular}{|c|c|c|c|c|c|c|c|c|}
\hline \multirow{2}{*}{$\begin{array}{l}\text { Microcirculatory } \\
\text { assessment at } \mathrm{T}=0\end{array}$} & \multirow[b]{2}{*}{$\mathrm{N}$} & \multicolumn{2}{|c|}{6 months } & \multicolumn{2}{|c|}{12 months } & \multicolumn{2}{|c|}{18 months } & \multirow[b]{2}{*}{$\mathrm{P}^{*}$} \\
\hline & & $\mathrm{N}$ & $\%$ & $N$ & $\%$ & $N$ & $\%$ & \\
\hline \multicolumn{9}{|l|}{ Intention to treat } \\
\hline \multicolumn{9}{|l|}{ Poor } \\
\hline SCS & 15 & 11 & 73 & 12 & 80 & 12 & 80 & 0.69 \\
\hline Standard & 17 & 9 & 53 & 12 & 71 & 12 & 71 & \\
\hline \multicolumn{9}{|l|}{ Intermediate } \\
\hline SCS & 34 & 6 & 18 & 7 & 21 & 8 & 24 & 0.17 \\
\hline Standard & 29 & 6 & 21 & 14 & 48 & 14 & 48 & \\
\hline \multicolumn{9}{|l|}{ Good } \\
\hline SCS & 7 & 1 & 14 & 1 & 14 & 2 & 29 & 0.65 \\
\hline Standard & 9 & 1 & 11 & 1 & 11 & 1 & 11 & \\
\hline \multicolumn{9}{|l|}{ Per protocol } \\
\hline \multicolumn{9}{|l|}{ Poor } \\
\hline SCS & 15 & 11 & 73 & 12 & 80 & 12 & 80 & 0.79 \\
\hline Standard & 17 & 9 & 53 & 12 & 71 & 12 & 71 & \\
\hline \multicolumn{9}{|l|}{ Intermediate } \\
\hline SCS & 31 & 5 & 16 & 6 & 19 & 7 & 23 & 0.08 \\
\hline Standard & 29 & 6 & 21 & 14 & 48 & 14 & 48 & \\
\hline \multicolumn{9}{|l|}{ Good } \\
\hline SCS & 4 & 0 & 0 & 0 & 0 & 0 & 0 & 0.56 \\
\hline Standard & 9 & 1 & 11 & 1 & 11 & 1 & 11 & \\
\hline
\end{tabular}

SCS: Spinal cord stimulation; *: Wilcoxon rank sum test

during follow-up examination, irrespective of treatment. No significant effect of treatment was found over all microcirculatory categories. When interaction terms were introduced for initial microcirculatory classification, a statistically significant treatment effect $(\mathrm{P}<.01)$ was apparent in the intermediate category for the parameters concerning the reactive hyperemie response (peakv-restv and peak-rest LDP), which deteriorated in the standard treatment group but not in the SCS group.

Intention to treat. Subdivision of the patients according to their microcirculatory categorization before treatment showed that the amputation 


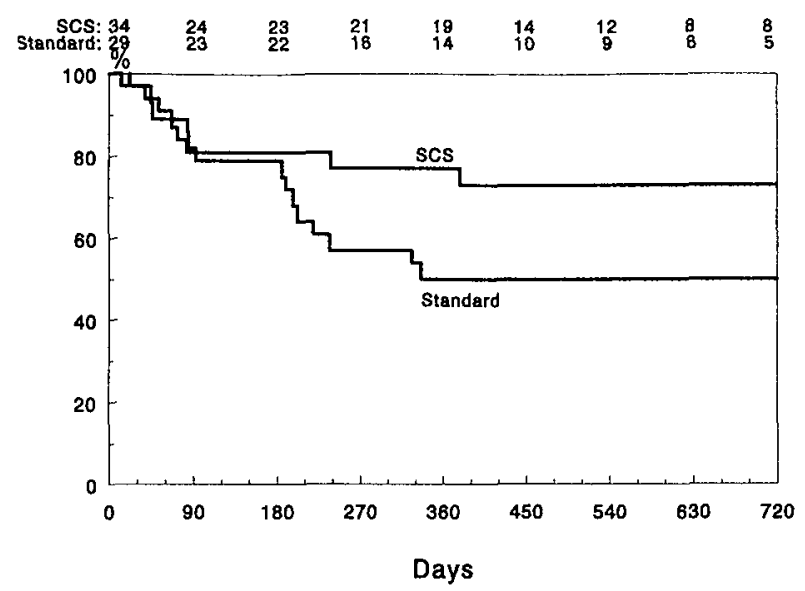

Figure 2. Cumulative limb survival (Kaplan-Meier) of patients in the intermediate microcirculatory category, receiving standard treatment or additional spinal cord stimulation (SCS). The numbers indicate the patients at risk at the different follow-up moments.

rate after 18 months was high $(75 \%)$ in patients with a poor initial microcirculatory status (Table 5).

In this category, amputation rate and limb survival rate did not differ between the SCS and the standard treatment groups $(\mathrm{P}=.82)$. In the good category, the amputation rate was low (19\%) and, thus, limb survival rate was high, but not significantly different between the treatment groups $(\mathrm{P}=$ .44). In contrast, in the intermediate category, which comprised most of the patients $(n=63)$, major amputation frequency after 12 and 18 months in the SCS group (24\%) was twice as low as in the standard treatment group (48\%).

The cumulative limb survival curve for the intermediate category is shown in Fig 2. In the intermediate category, limb survival rate tended to be better in the SCS than in the standard group $(\mathrm{P}=.17)$. A significantly different effect of the treatment in these categories could not be found $(P=.20)$. The short-term effect of treatment on skin microcirculation after 1 month showed no significant effect in either treatment group.

Per protocol. The effects of a properly functioning SCS (paresthesias in the painful area) on skin microcirculation and limb survival was assessed by means of a per-protocol analysis. For this purpose, the periods from 0 to 1 month after randomization, from 1 to 3 months, and from 3 months to end of the follow-up period were considered as separate observations in which 
SCS could be effective, so that patients with effective paresthesias that occurred not until after 1 or 3 months (eg, after repositioning of the lead) could be included as well. Thus, 105 patients were available for analysis (Table 5). Again, amputation rare was high $(75 \%)$ in the poor microcirculation group as opposed to a low rare (8\%) in the good microcirculation group, irrespective of the therapy applied. In patients with an intermediate skin microcirculation, amputation frequency, after 12 and 18 months in the standard treatment group, was twice as high as compared with the SCS group. Consequently, limb survival rate was higher in the SCS group than in the standard treatment group, but this difference did not reach the level of statistical significance $(\mathrm{P}=.08)$.

\section{DISCUSSION}

The overall effect of SCS on limb survival or skin microcirculation was not significantly better than in that of the standard conservative therapy. However, when considering the status of skin microcirculation in the ischemic area before treatment, patients with an intermediate microcirculatory perfusion tended to benefit from SCS, which deserves further investigation. Apparently, the ischemic legs of patients with poor microcirculation are in a state that cannot be reversed by any therapy; these patients may be better off with primary amputation. Patients with a good microcirculation have an advantageous natural course, irrespective of the therapy. In these patients, SCS has no specific advantage over other alternatives. Blood pressure or clinical parameters were not able to discern patients who would benefit from a limb-saving treatment. In contrast, microcirculatory investigations could distinguish patients with a high risk for amputation. These techniques may therefore be a useful additional technique to assess the severity and prognosis of (critical) limb ischemia. Transcutaneous oxygen measurements are easy to perform and could discern between the three microcirculatory groups, with cutoff values of 10 and $30 \mathrm{~mm} \mathrm{Hg}$. Thus, this technique appeared to be the best stand-alone technique to assess the severity of critical limb ischemia, and other techniques may be more complicated and are not readily available in most vascular laboratories. On the other hand, capillary microscopy is the technique of choice to appreciate nutritive skin perfusion and is therefore particularly capable of judging its viability. ${ }^{20,21}$ The high overall amputation frequency in the first months illustrates the severity of the disease, which may have been enhanced by the stringent blood pressure inclusion criteria. As to the possible working mechanism of SCS, the beneficial effect on the reactive hyperemia response and the trend of an increase in skin oxygen 
pressure, combined with a more discrete effect on total skin perfusion as measured by means of laser Doppler and the absence of an effect on ankle blood pressure, suggests a redistribution of flow towards particularly the nutritive part of skin microcirculation rather than an increase in total blood flow to the limb. This redistribution may be the result of the suppression of pain stimuli, which thereby lowers the sympathetic tone of the arterioles and precapillary vessels of the skin, and, thus, a better use of skin reserve capacity. The relief of pain was more obvious in the SCS group than in the standard treatment group. So, patients with a marginal, intermediate microcirculatory perfusion may have benefited more from SCS in that their microcirculation remained sufficient to avoid further tissue loss and finally an amputation. A short-term effect of SCS could not be detected, probably because of the high amputation rate in the first months after the start of the treatment. This early period included patients who eventually underwent an amputation and who had a poor microcirculation, which is reflected by the finding that microcirculatory results after 1 month did not differ much from those at the start.

In conclusion, SCS showed a possible beneficial effect only in a subgroup of patients with chronic critical limb ischemia, which deserves further study. Skin microcirculatory investigation is a useful aid in the prediction of an imminent amputation. The subgroup that might profit from SCS had an intermediate skin microcirculatory perfusion and an amputation frequency half as high as in the standard group after 12 months. This suggests that, for the future application and chances of success of this treatment method, microcirculatory investigations are worthwhile to screen the suitability of the patients and the effectiveness of the treatment. A prospective randomized study is needed to prove this possible profitable effect in a group of patients with chronic critical limb ischemia, selected on the basis of their skin microcirculation in centers that are familiar with SCS and microcirculatory investigation.

\section{REFERENCES}

1. Anonymous. Second European consensus document on chronic critical leg ischemia. Circulation 1991;84(Suppl):1-3.

2. Anonymous. Critical limb ischaemia: management and outcome. Report of a national survey. The Vascular Surgical Society of Great Britain and Ireland. Eur J Vasc Endovasc Surg 1995;10:108-13.

3. Meglio M, Cioni B, Rossi GF. Spinal cord stimulation in management of chronic pain. A 9-year experience. J Neurosurg 1989;70:519-24. 
4. Cook AW, Oygar A, Baggenstos P, Pacheco S, Kleriga E. Vascular disease of extremities. Electrical stimulation of spinal cord and posterior roots. $N$ Y State J Med 1976;76:366-8.

5. Augustinsson L, Carlsson CA, Holm J, Jivegárd L. Epidural electrical stimulation in severe limb ischemia, evidences of pain relief, increased blood flow and a possible limb-saving effect. Ann Surg 1985;202:104-11.

6. Jacobs MJHM, Jorning PJG, Beckers RCY, Ubbink DT, van Kleef M, Slaaf DW, et al. Foot salvage and improvement of microvascular blood flow as a result of epidural spinal cord stimulation. J Vasc Surg 1990;12:354-60.

7. Broseta J, Barbera J, De Vera JA, et al. Spinal cord stimulation in peripheral arterial disease. J Neurosurg 1986;64:71-80.

8. Jivegard L, Augustinsson L, Carlsson C, Holm J. Long-term

results by epidural spinal electrical stimulation (ESES) in patients with inoperable severe lower limb ischaemia. Eur J Vasc Surg 1987;1:345-9.

9. Steude U, Abenroth D, Sunder-Plasmann L. Epidural spinal electrical stimulation in the treatment of severe arterial occlusive disease. Acta Neurochir Suppl 1991;52:118-20.

10. Horsch S, Claeys L. Epidural spinal cord stimulation in the treatment of severe peripheral arterial occlusive disease. Ann Vasc Surg 1994;8:468-74.

11. Nachbur B, Gersbach P, Hasdemir M. Spinal cord stimulation for unreconstructable chronic limb ischaemia. Eur J Vasc Surg 1994;8:383-8.

12. LoGerfo FW. Epidural spinal cord electrical stimulation: an unproven methodology for management of lower extremity ischemia. J Vasc Surg 1991;13:518-9.

13. Jivegard LE, Augustinsson LE, Holm J, Risberg B, Ortenwall P. Effects of spinal cord stimulation (SCS) in patients with inoperable severe lower limb ischaemia: a prospective randomised controlled study. Eur J Vasc Endovasc Surg 1995;9:421-5.

14. Klomp MM, Spincemaille GHJJ, Steyerberg EW, Habbema JDF, van Urk H. Spinal cord stimulation in critical limb ischaemia: a randomised trial. Lancet 1999;353:1040-4.

15. Fontaine R, Riveaux R, Kim M, Kieny R. Résultats des opérations hyperémiantes (sympathectomies lombaires et artériectomies) dans les oblitérations artérielles chroniques spontanées des membres. Revues de Chirurgie 1953;72:204-30.

16. Ubbink DTh, Jacobs MJHM, Tangelder GJ, Slaaf DW, Reneman RS. The usefulness of capillary microscopy, transcutaneous oximetry and laser Doppler fluxmetry in the assessment of the severity of lower limb ischaemia. Int J Microcirc Clin Exp 1994;14:34-44.

17. Ubbink DTh, Jacobs MJHM, Slaaf DW, Tangelder GJ, Reneman RS. Capillary recruitment as the cause of pain relief on dependency in patients with severe lower limb ischemia. Circulation 1992;85:223-9.

18. Liang KY, Zeger SL. Longitudinal data analysis using generalized linear models. Biometrika 1986;73:13-22.

19. Masters Steedman S, Middaugh SJ, Kee WG, Carson DS, Harden RN, Miller MC. Chronic-pain medications: equivalence levels and method of quantifying usage. Clin J Pain 1992;8:204-14.

20. Fagrell B. Vital microscopy. A clinical method for evaluating the risk of skin necrosis in patients with occlusive arterial disease. Bibliotheca Anatomica 1973;11:328-33.

21. Ubbink DT, Jacobs MJHM, Slaaf DW. Can transcutaneous oximetry detect nutritive perfusion disturbances in patients with lower limb ischemia? Microvasc Res $1994 ; 4: 315-24$. 


\section{Prediction of imminent amputation in patients with non-reconstructible leg ischemia by means of microcirculatory investigations}

Dirk Th. Ubbink, MD, PhD, Geert H.J.J. Spincemaille, MD,

Robert S. Reneman, MD, PhD, and Michael J.H.M. Jacobs, $\mathrm{MD}, \mathrm{PhD}$.

Amsterdam, Heerlen, and Maastricht, The Netherlands

Adapted from J Vasc Surg 1999;30:114-121 


\section{SUMMARY}

Purpose: We investigated the usefulness of skin microcirculatory investigations to predict imminent major amputation in patients with non-reconstructible critical limb ischemia.

Methods: One hundred eleven patients with non-reconstructible chronic rest pain or small ulcers and an ankle blood pressure of $50 \mathrm{~mm} \mathrm{Hg}$ or less or an ankle-to-brachial pressure index of 0.35 or less were included. Nailfold capillary microscopy (CM; big toe, sitting), transcutaneous oxygen pressure $\left(\mathrm{TcpO}_{2}\right.$; forefoot, supine; $44^{\circ} \mathrm{C}$ ), and laser Doppler perfusion measurements (LD; pulp of big toe, supine) were performed at rest and during reactive hyperemia. Patients were classified according to their skin microcirculatory status just before the start of the treatment in three groups: those with a "good," "intermediate," or "poor" microcirculation, according to a combination of predefined cutoff values (Poor: capillary density less than $20 / \mathrm{mm}^{2}$, absent reactive hyperemia in $\mathrm{CM}$ and $\mathrm{LD}, \mathrm{TcpO}_{2}$ less than $10 \mathrm{~mm} \mathrm{Hg}$; good: capillary density of $20 / \mathrm{mm}^{2}$ or more, present reactive hyperemia in CM and $\mathrm{LD}, \mathrm{TcpO}_{2}$ of $30 \mathrm{~mm} \mathrm{Hg}$ or more). Subsequently, patients received maximum conservative therapy from the surgeon, who was unaware of the microcirculatory results. After a follow-up period of as long as 36 months, limb survival and disposing factors were analyzed and compared with the initial microcirculatory status.

Results: Cox regression analysis showed a significant prognostic value of the microcirculatory classification (hazard ratio $=0.28, \mathrm{P}<.0001$ ), but not of the Fontaine stage, ankle blood pressure, or the presence of diabetes mellitus for the occurrence of an amputation. Positive and negative predictive values were $73 \%$ and $67 \%$, respectively. The cumulative limb survival at 6 and 12 months was $42 \%$ and $17 \%$ in the poor microcirculatory group, $80 \%$ and $63 \%$ in the intermediate microcirculatory group, and $88 \%$ and $88 \%$ in the good microcirculatory group $(\mathrm{P}<.0001$, log-rank).

Conclusion: Microcirculatory screening and classification is useful in detecting non-reconstructible critical ischemia that requires amputation, which is not detectable by means of the clinical stage or blood pressure parameters. Most of the poor patient group will require amputation. In the intermediate and good groups, nonsurgical treatment appears sufficient for limb salvage. 


\section{INTRODUCTION}

According to the second European consensus document on critical limb ischemia, patients who have chronic critical leg ischemia have a high risk of amputation (approximately $25 \%$ ) within 1 year, despite optimal therapy. ${ }^{1}$ In the United States, the incidence of amputations for ischemic disease was estimated to be 250 per million per year 2,3 and 3900 per million per year in patients with diabetes mellitus, ${ }^{3}$ whereas about 150,000 patients per year have critical limb ischemia. ${ }^{4}$ The treatment of choice is a vascular reconstruction and/or percutaneous angioplasty as a limb salvage procedure. However, there are a considerable number of patients $(40 \%)$ in whom no reopening procedures can be performed. About half of these patients are treated with a primary amputation, the other half with nonsurgical treatment. $^{1}$

The decision to amputate is mainly based on the patient's clinical condition (intolerable pain, intractable infection, major tissue loss, concomitant diseases). Objective criteria, such as routine Doppler systolic pressure measurements at the ankle, were found to be not useful in making the proper decision about amputation..$^{5-8}$ The assessment of skin microcirculatory parameters may be of more value, ${ }^{9-11}$ because these parameters are more suited to obtain information about skin viability and wound healing capacity. ${ }^{12,13}$ Skin perfusion parameters, for example, were found to be helpful in assessing the amputation level. ${ }^{14,15}$ Most of the studies performed so far, however, were retrospective and included patients at different stages of ischemia or patients with ischemia of different etiology, thus inducing a confusing heterogeneity, and they lacked predefined cutoff values.

In 1992, a multicenter prospective randomized controlled study was started in the Netherlands to assess the potential benefit of spinal cord stimulation in patients with non-reconstructible critical leg ischemia. ${ }^{16}$ In this study, skin microcirculation was assessed, and patients were classified according to their microcirculatory status on the basis of predefined microcirculatory criteria for critical ischemia just before the start of the treatment. In this population, we evaluated the usefulness of microcirculatory parameters in predicting imminent amputation by correlating these parameters with the patient's clinical outcome. 


\section{PATIENTS AND METHODS}

Patients. One hundred eleven patients with chronic critical leg ischemia were investigated prospectively. The study was performed in 17 Dutch hospitals and was approved by their medical ethical committees. Patients were included on the basis of clinical assessment, aided by knowledge of the Doppler systolic ankle blood pressures, ie, when they had critical limb ischemia (rest pain or ulceration/gangrene; Fontaine stages III or IV, Society for Vascular Surgery/ International Society for Cardiovascular Surgery categories 4 or $5^{17}$ ) and had an ankle blood pressure of $50 \mathrm{~mm} \mathrm{Hg}$ or less or an ankle/brachial pressure index (ABI) of 0.35 or less 1,18 and in whom a meaningful vascular reconstruction was not possible. These blood pressure cutoff values were applied to both patient categories to stay in concert with the European consensus of the definition of chronic critical ischemia. Toe blood pressures were not performed as a routine in all contributing centers. Moreover, not all laboratories were equipped with toe pressure and/or transcutaneous oxygen pressure $\left(\mathrm{TcpO}_{2}\right)$ measuring techniques, and thus, in this multicenter study, only the ankle pressure was used as a uniform selection criterion. Non-reconstructibility was defined as the absence of all three crural arteries by means of a selective angiogram (visualizing the crural and the pedal arteries) or the absence of a suitable autologous vein for distal bypass grafting surgery. The inclusion and exclusion criteria are summarized in Table I.

Treatment. Treatment of the patients consisted of optimal conservative medical treatment, including analgesics, anticoagulants, vasoactive agents, local wound care, and antibiotics when indicated. Other treatments, such as prostaglandins or (chemical) sympathectomy, were also allowed. Half the patients received additional spinal cord stimulation, which did not alter the need for amputation. These data will be published elsewhere. Treatment started when inclusion criteria were met and baseline skin microcirculation was assessed.

Follow-up. At the start of the treatment, the treating surgeon made an estimation of the expected limb survival to assess the value of the patient's clinical status in the prediction of an imminent amputation. Follow-up examinations (including clinical examination, Doppler systolic pressure, and microcirculatory measurements) were performed at $1,3,6,12$, and 18 months after inclusion and at the end of the trial. The endpoint of the study was a major amputation of the affected limb (i.e., Symes amputation, the 
Table I. Inclusion and exclusion criteria

\section{Inclusion criteria}

Chronic critical ischemia of one of the lower limbs in patients in whom a meaningful vascular reconstructive procedure is considered not to be possible:

- Persistent rest pain for at least 2 weeks, being treated with analgesics and/or ulceration or gangrene of foot or toes.

Doppler ankle systolic pressure of $50 \mathrm{~mm} \mathrm{Hg}$ or ankle/brachial pressure index of 0.35 or less. For patients with diabetes mellitus and incompressible ankle arteries: absence of arterial ankle pulsations.

Patient informed consent.

\section{Exclusion criteria}

- Vascular disorders other than atherosclerotic disease.

- No rest pain (e.g. only intermittent claudication) and no gangrene or ulceration.

- Ulceration deeper than the fascia or with a largest diameter of more than $3 \mathrm{~cm}$.

- Intractable infection of ulceration or gangrene necessitating primary amputation.

- Bilateral critical ischemia.

- Neoplastic or other concomitant disease restricting life expectancy to less than 1 year.

- Psychosocial incompetence of the patient to satisfy the follow-up schedule.

whole foot or more). Patients who died before the end of the follow-up period were censored in life table projections.

Microcirculatory investigations. The noninvasive skin microcirculatory investigations (capillary microscopy $[\mathrm{CM}]$, transcutaneous oxygen pressure $\left[\mathrm{TcpO}_{2}\right]$, and laser Doppler perfusion measurements [LDP]) were performed by a single, experienced investigator. The mobile equipment was transported and taken into the ward or outpatient clinic of the hospitals involved. The examination of one patient by means of the three techniques took 50 minutes, after a standard acclimatization period of 15 minutes. First, CM was performed in the sitting position, followed by the other two examinations in the supine position. These techniques, including their reproducibility, have been described in detail before. ${ }^{8,19}$

$\mathrm{CM}$ enables visualization of the nailfold capillaries of the big toe in the sitting position and provides information about capillary morphology (Density, in $\mathrm{n} / \mathrm{mm}^{2}$ of nail fold skin) and erythrocyte velocity at rest (Restv, in $\mu \mathrm{m} / \mathrm{s}$ ) and during reactive hyperemia (Peakv, in $\mu \mathrm{m} / \mathrm{s}$ ) after a 1-minute arterial occlusion by inflating a cuff around the ankle. This technique yields information exclusively about skin nutritive perfusion. Images were recorded on videotape for off-line analysis. 
$\mathrm{TcpO}_{2}$ measurements enable the assessment of skin oxygen supply from the superficial vessels. Measurements were performed on the dorsum of the foot, at an electrode temperature of $44^{\circ} \mathrm{C}$, at rest $\left(\mathrm{RestpO} \mathrm{O}_{2}\right.$ in $\left.\mathrm{mm} \mathrm{Hg}\right)$, and after a 3-minute arterial occlusion $\left(\mathrm{PeakpO}_{2}\right.$, in $\mathrm{mm} \mathrm{Hg}$ ).

LDP measurements on the pulp of the great toe give information about total skin perfusion, including capillaries, deeper vessels, and arteriolovenular anastomoses, which are mainly involved in thermoregulation. The reactive hyperemia response after a 3-minute arterial occlusion was measured (Peak minus Rest LDP, in arbitrary units [AU]) to assess the reserve capacity of skin blood supply, because the variability of LDP in resting conditions is known to be substantial. $\mathrm{TcpO}_{2}$ and LDP were performed while the patient was in the supine position, which improves discriminative power. ${ }^{8}$ The $\mathrm{TcpO}_{2}$ and LDP data obtained were stored on recording paper for off-line analysis. In case the patient had undergone a minor amputation (big toe, transmetatarsal), measurements were performed just proximal to the amputation level.

Off-line analysis of the microcirculatory data obtained (video images and paper recordings) can be done immediately, but was performed in this study at least 6 months after each investigation, without knowledge of the patient's identity and condition to avoid bias caused by recognition of the recordings. The microcirculatory status of the patient's ischemic foot was classified according to the microcirculatory findings at the first visit (just before the start of the treatment) in three categories: those with a "poor," an "intermediate," and a "good" microcirculatory perfusion. These categories were defined on the basis of microcirculatory criteria to detect critical ischemia, as derived from previous studies. ${ }^{8,19}$ The criteria for this categorization are shown in Table II. The patient's surgeon was kept unaware of the microcirculatory results.

\section{RESULTS}

Patients. From November 1991 to May 1994, 111 patients with non-reconstructible chronic critical limb ischemia consented to participate in the study. Of the patients included, $42(38 \%)$ had rest pain, and $69(62 \%)$ had tissue loss. Forty-one patients $(37 \%)$ had diabetes mellitus. Patient intake data are presented in Table III.

The limb survival as estimated by the treating surgeon on the basis of the patient's clinical status was poorly correlated with the eventual true limb survival (Fig 1). 
Table II. Microcirculatory categories of skin perfusion

\section{Poor}

When complying to the criteria of all three techniques:

Capillary microscopy:

- Low capillary density (Density $<20 / \mathrm{mm}^{2 * *}$ ) or:

- No reactive hyperemia (Peakv - Restv $\leq 0 \mu \mathrm{m} / \mathrm{s}^{* *}$ ) or:

- Low peak erythrocyte velocity (Peakv $<50 \mu \mathrm{m} / \mathrm{s}^{*}$ )

$\mathrm{TcpO}_{2}$ :

- Poor skin oxygenation (RestpO $\mathrm{O}_{2}$ and $\mathrm{PeakpO}_{2}<10 \mathrm{~mm} \mathrm{Hg}$ )

Laser Doppler Perfusion:

- No reactive hyperemic response (Peak - Rest LDP $\leq 3 \mathrm{AU}^{*}$ )

\section{Intermediate}

When the criteria of both other categories were not met, i.e.:

- Rest or $\mathrm{PeakpO}_{2}$ between 10 and $30 \mathrm{~mm} \mathrm{Hg}$ or:

- The results of the different techniques fit into different categories

\section{Good}

When complying to the criteria of all three techniques:

Capillary microscopy:

- Normal capillary density (Density $\geq 20 / \mathrm{mm}^{2 * *}$ ) and:

- Present reactive hyperemia (Peakv - Restv $>0 \mu \mathrm{m} / \mathrm{s}^{* *}$ ) and:

- Normal peak erythrocyte velocity (Peakv $>50 \mu \mathrm{m} / \mathrm{s}$ )

$\mathrm{TcpO}_{2}$ :

- Good skin oxygenation (RestpO $\mathrm{O}_{2}$ and $\mathrm{PeakpO}_{2}>30 \mathrm{~mm} \mathrm{Hg}^{*}$ )

Laser Doppler Perfusion:

- Present reactive hyperemic response (Peak - RestLDP >3 AU*)

* See reference 8

** See reference 19

Table III. Patient intake data

$\begin{array}{ll}\text { Age* }^{*} & 73 \quad(38-93) \\ \text { Sex (male/female) } & 65 / 46 \\ \text { Fontaine stage (3/4) } & 42 / 69 \\ \text { Diabetes } & 41 \\ \text { Ankle pressure (mm Hg)* } & 44(0-76) \\ \text { Ankle/brachial index* } & 0.26(0-0.56) \\ \text { Incompressible ankle arteries } & 27 \text { (of which 19 diabetics) }\end{array}$

* shown as median values and ranges. 


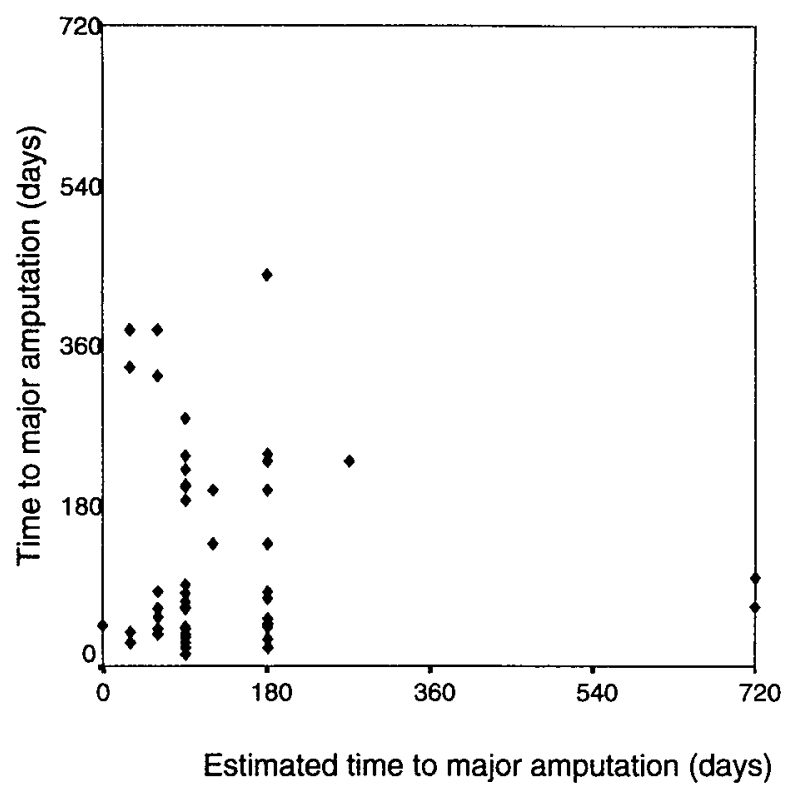

Figure 1. Scatter plot of the time to major amputation against the time estimated at $\mathrm{t}=0$ by the treating surgeon in patients receiving an amputation during the follow-up period.

The surgeon's prediction usually underestimated true limb survival. Only in four patients did the surgeon estimate the patient would not undergo amputation during the follow-up period, whereas 57 patients did not undergo an amputation within 18 months. During the follow-up period, 49 patients (44\%) underwent a major amputation.

Macrocirculation. No significant contribution of the Fontaine stage, Doppler systolic pressure at the ankle, ankle/brachial index, presence of diabetes mellitus, or treatment with spinal cord stimulation as to the occurrence of an amputation during the follow-up period was shown by means of Cox regression analysis. Mean ABI and ankle pressures did not differ significantly between patients who underwent an amputation during the follow-up period $(0.22$ and $34 \mathrm{~mm} \mathrm{Hg} ; \mathrm{P}=.14)$ and those who did not $(0.27$ and $43 \mathrm{~mm} \mathrm{Hg}$ P = .18).

Microcirculation. The microcirculatory data of two patients were excluded from evaluation, because the patients underwent a vascular reconstruction during the follow-up period. Microcirculatory investigation could be 
Table IV. Microcirculatory results (expressed as medians and obtained at $\mathrm{T}=0$ and at the last follow-up visit prior to amputation) in patients who did and did not undergo an amputation during follow-up.

\begin{tabular}{|c|c|c|c|c|c|}
\hline \multirow{2}{*}{$\begin{array}{l}\text { Parameters } \\
\text { Capillary microscopy }\end{array}$} & \multicolumn{2}{|c|}{$\begin{array}{l}\text { Amputated } \\
\text { (before) } \mathrm{P} \text { value }^{*}\end{array}$} & \multicolumn{2}{|c|}{$\begin{array}{l}\text { Not amputated } \\
\text { (at } \mathrm{T}=0 \text { ) } \mathrm{P}_{\text {value }}\end{array}$} & \multirow[t]{2}{*}{$\begin{array}{l}\text { Amputated } \\
\text { (at } \mathrm{T}=0 \text { ) }\end{array}$} \\
\hline & & & & & \\
\hline Density $\left(\mathrm{n} / \mathrm{mm}^{2}\right)$ & 26 & $<0.005$ & 37 & $<0.05$ & 27 \\
\hline $\operatorname{Restv}(\mu \mathrm{m} / \mathrm{s})$ & 37 & $<0.005$ & 66 & $<0.005$ & 38 \\
\hline Peakv $(\mu \mathrm{m} / \mathrm{s})$ & 40 & $<0.001$ & 90 & $<0.001$ & 51 \\
\hline Peakv - Restv $(\mu \mathrm{m} / \mathrm{s})$ & 0 & $<0.05$ & 9 & $<0.05$ & 1 \\
\hline \multicolumn{6}{|c|}{ Transcutaneous oximetry } \\
\hline $\mathrm{RestpO}_{2}(\mathrm{~mm} \mathrm{Hg})$ & 2 & $<0.001$ & 19 & $<0.005$ & 2 \\
\hline $\mathrm{PeakpO}_{2}(\mathrm{~mm} \mathrm{Hg})$ & 2 & $<0.001$ & 25 & $<0.005$ & 2 \\
\hline \multicolumn{6}{|l|}{ Laser Doppler perfusion } \\
\hline Rest LDP (a.u.) & 2 & $<0.001$ & 12 & $<0.001$ & 2 \\
\hline Peak LDP (a.u.) & 4 & $<0.001$ & 19 & $<0.001$ & 3 \\
\hline Peak - Rest LDP (a.u.) & 1 & $<0.001$ & 6 & $<0.001$ & 0.5 \\
\hline
\end{tabular}

* Mann-Whitney test.

performed in all patients at each follow-up examination until they died, underwent major amputation, or the end of the study was reached. CM could not be performed in $16(15 \%)$ patients because of amputation or ulceration of the big toe. In these patients, only LDP and $\mathrm{TcpO}_{2}$ measurements were performed to categorize the patients. In patients undergoing an amputation during the follow-up period, all skin microcirculation parameters at $\mathrm{T}=0$ and at the last follow-up examination before amputation were significantly worse, compared with patients who did not undergo amputation at $\mathrm{T}=0$ (Table IV).

At the last follow-up examination before amputation, the microcirculatory parameters in patients who underwent amputation were not different from those at $\mathrm{T}=0$ (data not shown).

Application of the microcirculatory categorization yielded 30 patients with poor skin microcirculation, 63 with intermediate skin microcirculation, and 16 with good skin microcirculation. The prevalence of diabetes mellitus in the three microcirculatory groups was not significantly different (Kruskall-Wallis test): poor $=10(33 \%)$, intermediate $=25(40 \%)$, and good $=8$ (50\%). Also, no differences among the groups were found in mean Doppler systolic ankle pressure $(40,40$, and $33 \mathrm{~mm} \mathrm{Hg}$, respectively), ABI $(0.26,0.25$, 
Table V. Amputation frequency after 6, 12 and 18 months for each microcirculatory category

\begin{tabular}{|c|c|c|c|c|c|c|c|}
\hline \multirow{2}{*}{$\begin{array}{l}\text { Microcirculatory } \\
\text { assessment at } \mathrm{T}=0\end{array}$} & \multirow[t]{2}{*}{$\mathrm{N}$} & \multicolumn{2}{|c|}{6 months } & \multicolumn{2}{|c|}{12 months } & \multicolumn{2}{|c|}{18 months } \\
\hline & & $\mathrm{N}$ & $\%$ & $\mathrm{~N}$ & $\%$ & $\mathrm{~N}$ & $\%$ \\
\hline Poor & 30 & 20 & 67 & 24 & 80 & 24 & 80 \\
\hline Intermediate & 63 & 12 & 19 & 12 & 33 & 22 & 35 \\
\hline Good & 16 & 2 & 13 & 2 & 13 & 3 & 19 \\
\hline
\end{tabular}

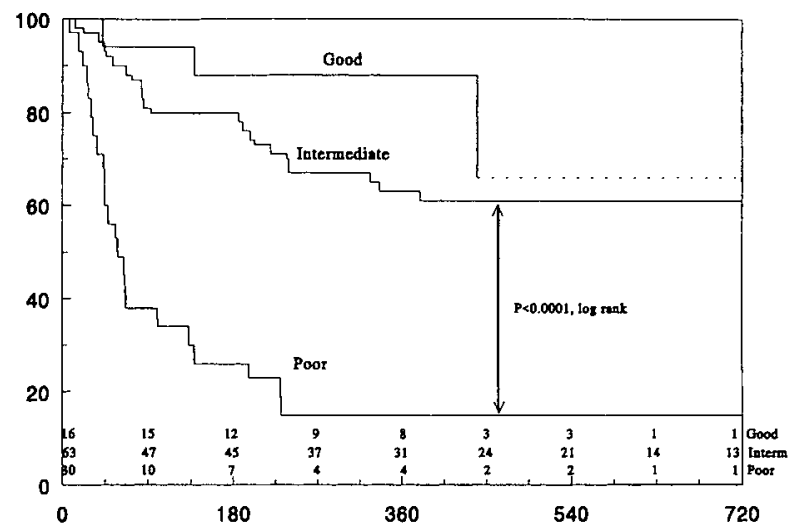

Figure 2. Cumulative limb survival in the three microcirculatory categories. A dotted line indicates a standard error $>10 \%$. The numbers per category indicate the number of patients at risk.

and 0.20 , respectively), sex, age, or Fontaine stage. Table $\mathrm{V}$ shows the incidence of amputations after 6,12 , and 18 months of follow-up, which was significantly higher in the poor microcirculatory group than in both other microcirculatory groups $(\mathrm{P}<.001$, Mann-Whitney). Limb survival, according to the Kaplan-Meier method for each microcirculatory group, is shown in Fig 2. The cumulative limb survival at 6 and 12 months was $26 \%$ and $15 \%$ in the poor group, $80 \%$ and $63 \%$ in the intermediate group, and $88 \%$ and $88 \%$ in the good group, respectively. Mean survival time before amputation was 213 days for the poor group, 700 days for the intermediate group, and 820 days for the good group. Limb survival in the poor group was significantly lower than in the two other groups combined ( $P<.001$; log-rank). The 
Table VI. Predictive values, sensitivity and specificity of microcirculatory parameters to predict amputation using the predefined cut-off values.

\begin{tabular}{llllll}
\hline & PPV & NPV & Sensitivity & Specificity & Accuracy \\
\hline Capillary microscopy* & $56 \%$ & $81 \%$ & $86 \%$ & $48 \%$ & $65 \%$ \\
Transcutaneous oximetry & $57 \%$ & $65 \%$ & $53 \%$ & $68 \%$ & $60 \%$ \\
Laser Doppler perfusion $^{2}$ & $60 \%$ & $76 \%$ & $74 \%$ & $62 \%$ & $67 \%$ \\
$\mathrm{TcpO}_{2}+\mathrm{LDP}$ & $61 \%$ & $65 \%$ & $48 \%$ & $75 \%$ & $63 \%$ \\
$\mathrm{CM}+\mathrm{TcpO}_{2}$ & $66 \%$ & $58 \%$ & $48 \%$ & $80 \%$ & $66 \%$ \\
$\mathrm{CM}+\mathrm{LDP}_{\mathrm{CM}}+\mathrm{TcpO}_{2}+\mathrm{LDP}$ & $70 \%$ & $75 \%$ & $73 \%$ & $75 \%$ & $74 \%$ \\
& $73 \%$ & $67 \%$ & $46 \%$ & $87 \%$ & $69 \%$ \\
\hline
\end{tabular}

*The values given are only valid for patients in whom capillary microscopy could be performed at $\mathrm{T}=0$. PPV positive predictive value; NPV negative predictive value.

microcirculatory classification had a significant prognostic value for amputation (Cox regression: hazard ratio $=0.28 ; \mathrm{P}<.0001$ ).

The predictive values, sensitivity, specificity, and accuracy of the various (combinations of) parameters are presented in Table VI, illustrating that the combination of all microcirculatory parameters at baseline as applied in this study offers the highest predictive value (73\%) for the occurrence of an amputation (likelihood ratio for amputation $=3.5$ ), as well as the highest specificity (87\%), compared with the values when only one of the three techniques was used.

\section{DISCUSSION}

This is the first prospective study showing that the assessment of foot skin microcirculation in patients with non-reconstructible critical ischemia of the leg is an important and valuable tool in predicting which patients will and which patients will not require an amputation in the near future, despite optimal medical treatment and choosing the most suitable therapy with the cutoff values applied. In patients with a poor skin microcirculation, as illustrated by a low skin capillary density (less than $20 / \mathrm{mm}^{2}$ ), a poor skin oxygenation (less than $10 \mathrm{~mm} \mathrm{Hg}$ ), and exhausted hyperemic reserve capacity, skin and, thus, leg viability is so threatened that a primary amputation appears unavoidable. In patients with an intermediate or good microcirculation, amputation is inappropriate and any non-reconstructive treatment can and should be applied to offer a fair chance of limb salvage. 
Clinical and Doppler systolic pressure parameters were found to be unable to predict an imminent amputation, because all patients met these criteria, whereas only $44 \%$ of the patients underwent amputation. This is in accordance with previous observations, ${ }^{20}$ showing that the European consensus criteria, especially Doppler systolic pressure at the ankle, are poor discriminators of critical limb ischemia requiring intervention. The more recent North American reporting standards, ${ }^{17}$ which define different cutoff values for rest pain and ulceration, may be more discriminating, because the healing of an ischemic ulcer requires a higher perfusion pressure than the mere elimination of rest pain. Hence, amputation risk is different between patients with and without an ischemic ulcer, despite similar ankle pressures. The addition of toe blood pressure and $\mathrm{TcpO}_{2}$ measurements were found to improve this discrimination, indicating that microcirculatory parameters may be more suited to grade the severity of the disease. ${ }^{20}$ The usefulness of $\mathrm{TcpO}_{2}$ measurements in the treatment of patients with non-reconstructible ischemia was also shown in a recent study by Gersbach et a1. ${ }^{21}$

The decision in the individual patient whether it is wise to try or continue conservative treatment or to perform a (primary) amputation is not in the least determined by the patient's general condition, pain tolerance, progression of tissue loss, infection, etc. In this decision, however, microcirculatory investigation and classification is of value, because all these patients with non-reconstructible leg ischemia faced an ultimate amputation on the basis of clinical and pressure parameters. In the present study, the microcirculatory classification in three groups was applied prospectively, based on previous data. ${ }^{19}$ In retrospect, the intermediate and the good group could have been combined. Nevertheless, patients with a poor microcirculation had a significantly higher amputation rate, compared with those in the intermediate or good category. Thus, when a patient is classified as having a poor skin microcirculation, he will likely undergo an amputation within 18 months. On the other hand, an intermediate or good skin microcirculation, which was the case in most patients, indicates a low risk of a future amputation, and amputation should therefore be avoided by intense conservative therapy.

In this study, a combination of three microcirculatory techniques, each providing information about different skin perfusion entities, were applied to establish which technique or parameter would be most predictive for the occurrence of an amputation. The combination of all three techniques showed the highest specificity ( $87 \%$ ), but a rather low sensitivity (46\%). CM could predict amputation in $86 \%$ of the cases, because it specifically measures (disturbances in) nutritive perfusion governing limb viability. The $\mathrm{TcpO}_{2}$ measures differentiated all three groups, was the easiest measure- 
ment to perform, and can be applied without the need of provocation maneuvers. Hence, one of those two methods may be eligible as a stand-alone technique.

On the other hand, eight patients who were "false-positive" on the basis of the microcirculatory classification would have undergone a premature amputation. This may be because capillary microscopic and laser Doppler parameters were measured only in the big toe, whereas critical ischemia may be patchy. Moreover, because the microcirculatory criteria used in this study were derived from studies assessing the presence of critical ischemia, which is not synonymous with the risk of amputation, adaptation of the cutoff values may be useful. For instance, applying a $\mathrm{TcpO}_{2}$ cutoff value of $15 \mathrm{~mm} \mathrm{Hg}$ instead of $10 \mathrm{~mm} \mathrm{Hg}$, as derived from a receiver operating characteristic analysis, increases the predictive value of this parameter and its combinations: the $\mathrm{TcpO}_{2}$ measurement's sensitivity, specificity, and accuracy would be $69 \%, 63 \%$, and $66 \%$, respectively, and positive predictive value and negative predictive value $60 \%$ and $72 \%$, respectively. The diagnostic value of the combination of parameters would become $56 \%, 85 \%, 72 \%, 75 \%$, and $71 \%$, respectively.

In conclusion, this study shows that microcirculatory investigations are of additional usefulness in patients with non-reconstructible critical limb ischemia to assess the risk of future amputation and the required therapy, which is impossible with only clinical and Doppler pressure parameters.

\section{REFERENCES}

1. Second European consensus document on chronic critical leg ischemia. Circulation 1991;84(Suppl).

2. Kacy SS, Wolma FJ, Flye MW. Factors affecting the results of below knee amputation in patients with and without diabetes. Surg Gynecol Obstet 1982;155:513-8.

3. Most RS, Sinnock P. The epidemiology of lower extremity amputations in diabetic individuals. Diabetes Care 1983; 6:87-91.

4. Gupta SK, Veith FJ. Is arterial reconstruction cost-effective compared with amputation? In: Greenalgh RM, Jamieson CW, Nicolaides AN, editors. Limb salvage and amputation for vascular disease. Philadelphia: WB Saunders;1988. p. 447-52.

5. Matzke S, Ollgren J, Lepäntalö M. Predictive value of distal pressure measurements in critical leg ischaemia. Ann Chir Gynaecol 1996;85:316-21.

6. Troeng T, Janzon L, Bergqvist D. Adverse outcome in surgery for chronic leg ischaemia-Risk factors and risk prediction when using different statistical methods. Eur J Vasc Surg 1992;6:628-35.

7. Devin R, Ciosi G, Cormier JM. Procedures in critical ischemia of the legs in non emergency situations. Journal des Maladies Vasculaires 1990;15:114-38.

8. Ubbink DTh, Jacobs MJHM, Tangelder GJ, Slaaf DW, Reneman RS. The usefulness of cappillary microscopy, transcutaneous oximetry and laser Doppler fluxmetry in the 
assessment of the severity of lower limb ischaemia. Int J Microcirc Clin Exp 1994;14:34-44.

9. Bongard O, Krahenbühl B. Predicting amputation in severe ischaemia: The value of transcutaneous $\mathrm{pO}_{2}$ measurement. Bone Joint Surg 1988;70 B:465-7.

10. Ray SA, Buckenham TM, Belli AM, Taylor RS, Dormandy JA. The predictive value of laser Doppler fluxmetry and transcutaneous oximetry for clinical outcome in patients under-, going revascularisation for severe leg ischaemia. Eur J Vasc Endovasc Surg 1997;13:54-9.

11. Padberg FT Jr, Back TL, Hart LC, Franco CD. Comparison of heated-probe laser Doppler and transcutaneous oxygen measurements for predicting outcome of ischemic wounds. J Cardiovasc Surg 1992;33:715-22.

12. Padberg FT, Back TL, Thompson PN, Hobson RW 2nd. Transcutaneous oxygen $\left(\mathrm{TcpO}_{2}\right)$ estimates probability of healing in the ischemic extremity. J Surg Res 1996;60:365-9.

13. Dwars BJ, van den Broek TA, Rauwerda JA, Bakker FC. Criteria for reliable selection of the lowest level of amputation in pheriperal vascular disease. J. Vasc Surg 1992;15:536-42.

14. Wurscherr R, Bournacaux H. Determination of amputation level in ischemic limbs. Reappraisal of the measurement of $\mathrm{TcpO}_{2}$. Diabetes Care 1997;20:1315-8

15. Tyrrell MR, Wolfe JH. Critical leg ischaemia; An appraisal of clinical definitions. Joint Vascular Research Group. Brit J Surg 1993;80:177-80.

16. Klomp HM, Spincemaille GHJJ, Steyerberg EW, Berger MY, Habbema JDF, Van Urk H. Design issues of a randomised controlled clinical trial on spinal cord stimulation in critical limb ischemia. Eur J. Vasc Endovascular Surg 1995;10:478:85.

17. Rutherford RB, Baker JD, Ernst C, Johnston KW, Porter JM, Ahn S, et al. Recommended standards for reports dealing with lower extremity ischemia: Revised version. J Vasc Surg 1997; 26:517-39

18. Thompson MM, Sayers RD, Varty K, Reid A, London NJ, Bell PR. Chronic critical leg ischaemia must be redefined. Eur J Vasc Surg 1993, 7:420-6

19. Ubbink DTh, Jacobs MJHM, Slaaf DW, Tangelder GJ, Reneman RS. Capillary recruitment as the cause of pain relief on dependency in patients with severe lower limb ischemia. Circulation 1992;85:223-9.

20. Ubbink DTh, Tulevski H, den Hartog D, Koelemay MJW, Legemate DA, Jacobs MJHM. The value of noninvasive techniques for the assessment of critical limb ischaemia. Eur J Vasc Endovasc Surg 1997;13:296-300.

21. Gersbach P, Hasdemir MG, Stevens RD, Nachbur B, Mahler F. Discriminative microcirculatory screening in patients with refractory limb ischaemia for dorsal column stimulation. Eur J Vasc Endovasc Surg 1997;13:464-71. 


\section{The Results of Spinal Cord Stimulation in Critical Limb Ischaemia: A Review}

G. H. J. J. Spincemaille*1, H. C. W. de Vet ${ }^{2}$, D. Th. Ubbink ${ }^{3}$ and M. J. H. M. Jacobs 3

${ }^{1}$ Department of Neurosurgery, Academic Hospital Maastricht,

${ }^{2}$ Department of Epidemiology, University Maastricht, and

${ }^{3}$ Department of Vascular Surgery, Academic Medical Centre, Amsterdam 


\section{ABSTRACT}

Objectives: to determine which patients with unreconstructible critical limb ischaemia (CLI) might benefit from spinal cord stimulation (SCS).

Methods: literature review.

Results: limb salvage in patients with an intermediate transcutaneous oxygen pressure $\left(\mathrm{TcpO}_{2}\right)$ was not significantly higher with SCS $(76 \%)$ than with conservative therapy ( $\mathrm{p}=0.08$ ). However, a limb salvage of $88 \%$ was achieved with SCS if the difference between the supine and sitting TcpO2 baseline values $(\Delta \mathrm{TcpO})_{2}$ ) was $\geq 15 \mathrm{mmHg}$. A rise in $\mathrm{TcpO}_{2}$ after trial stimulation of at least $15 \%$ resulted in a limb salvage of $77 \%$ at 18 months ( $<<0.01$ ). Conclusion: randomised studies show no benefit of SCS over conservative therapy in patients with non-reconstructible CLI. However, data from experimental and non-randomised studies suggest this may be due to sub-optimal patient selection for SCS. Further trials are needed to identify subgroups that may benefit from SCS.

Key Words: Critical limb ischaemia; Spinal cord stimulation; Microcirculation; $\mathrm{TcpO}_{2}$. 


\section{INTRODUCTION}

Patients with non-reconstructible CLI have a poor prognosis. ${ }^{1}$ Cook was the first to suggest that SC might avert the need for amputation in a proportion of such patients. ${ }^{2}$ Dooley also believed that SCS would increase blood flow to the limb and reduce pain. ${ }^{3}$ Non-randomised studies suggested that SCS might increase limb salvage by $40-50 \% .{ }^{4-8}$ However, this has not been borne out by randomised controlled trials (RCTs), which, in general, showed treatment such as prostaglandins and SCS to be only $10-20 \%$ better than standard conservative therapy. ${ }^{9-12}$

Experimental data suggest that SCS may have beneficial effect upon the microcirculation of certain patients ${ }^{13}$ and that $\mathrm{TcpO}_{2}$ might be able to distinguish responders from non-responders. 5,6,9,13,14

The aim of the review was to identify which patient with non-reconstructible CLI might benefit from SCS.

\section{METHODS}

Medline (1980-98), the Cochrane database, congress proceedings (INS, Groningen, Orlando, Luzern) and books. Inclusion criteria was (1) unreconstructible CLI, (2) minimum 20 patients, (3) minimum 6 months follow-up, (4) assessment of the micro- and macrocirculation in relation to limb salvage (Table 1).

\section{RESULTS}

Many reports did not fulfil the inclusion criteria. ${ }^{15-23}$ Studies, which did meet the criteria, are shown in Table 1 and, unsurprisingly, comprised high-risk patients with some pain and/or tissue loss (Table 2). The mean limb salvage after SCS in the studies was $62 \%$ (range $60 \%$ to $68 \%$ ), with a follow-up of 2 years (Figure 1). Mortality was very high: about 33\% after a follow-up of 2 years and $50 \%$ after 5 years (Table 3 ).

\section{Microcirculatory data}

The results are summarised in Tables 4 and 5. Galley et al. ${ }^{5}$ found a significant increase in $\mathrm{TcpO}_{2}(13.5$ to $24 \mathrm{mmHg}, \mathrm{p}<0.001)$ following $9 \pm 4$ days of $\mathrm{SCS}$. The $\mathrm{TcpO}_{2}$ (sitting) changed from $24.4 \pm 22$ (before stimulation) to $50.4 \pm$ 18 (after stimulation). The gradient between sitting and supine $\mathrm{TcpO}_{2}$ 
Table 1. List of selected articles

\begin{tabular}{lrrrrrrr}
\hline Author & year & N & $\begin{array}{l}\text { N (PAOD) } \\
\text { SCS } \\
\text { treatment }\end{array}$ & $\begin{array}{l}\text { N (PAOD) } \\
\text { Controls }\end{array}$ & $\begin{array}{l}\text { Follow-up } \\
\text { Months } \\
\text { (mean) }\end{array}$ & $\begin{array}{l}\text { Selection Level of } \\
\text { criteria }\end{array}$ & evidence \\
& & & & & & & \\
\hline Augustinsson & 1985 & 44 & 27 & 10 & 16 & 1,2 & 2 \\
Galley & 1992 & 244 & 208 & 0 & 24 & $1,2,3$ & 1 \\
Horsch & 1994 & 177 & 177 & 0 & 35.6 & & 1 \\
Jivegard & 1995 & 51 & 25 & 26 & 18 & 1,2 & 3 \\
Claeys & 1996 & 86 & 45 & 41 & 12 & $1,2,3$ & 3 \\
Gersbach & 1997 & 20 & 20 & 0 & 14 & $1,2,3$ & 1 \\
Kumar & 1997 & 46 & 46 & 0 & 21 & $1,2,3$ & 1 \\
Klomp, Ubbink & 1999 & 120 & 60 & 60 & 20 & $1,2,4$ & 3 \\
Total & & 788 & 608 & 137 & & & \\
\hline
\end{tabular}

$\mathrm{N}=$ all patients including other diseases than PAOD. $\mathrm{N}(\mathrm{PAOD})=$ only patients with peripheral arterial occlusive disease. Selection criteria: $1=$ macrocirculatory data; $2=$ microcirculatory data; $3=$ trial stimulation and $\mathrm{TcpO}^{2}$ evaluation; $4=$ capillary microscopy. Level of evidence: $1=$ case reports; 2 = cohort studies with historical controls; $3=$ randomised studies.

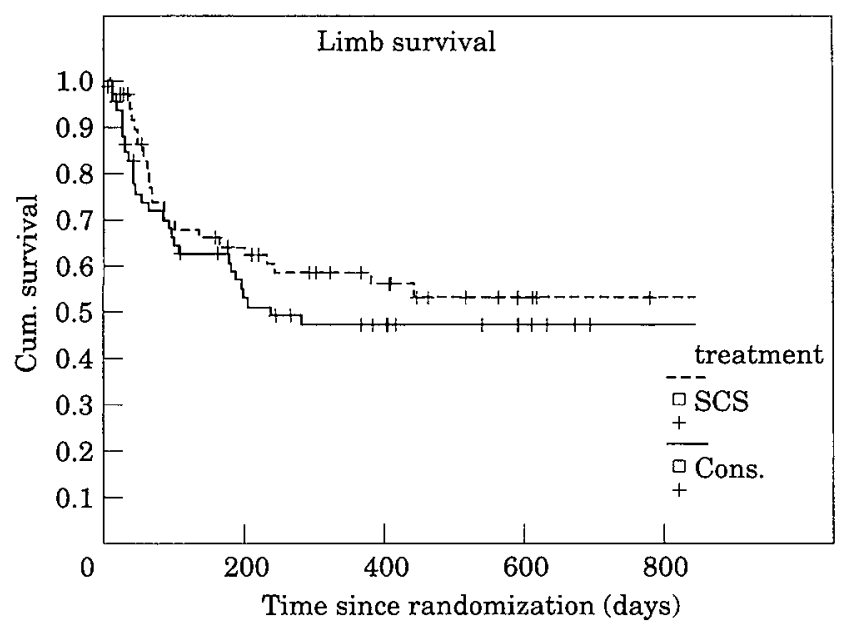

Patients at risk

\begin{tabular}{|lllllllll|}
\hline 60 & 39 & 37 & 30 & 25 & 25 & 22 & 20 & SCS \\
60 & 40 & 32 & 25 & 23 & 22 & 20 & 17 & Standard \\
\hline
\end{tabular}

Figure 1. Limb survival in patients with critical limb ischaemia. Data of the Dutch randomised trial. 
Table 2. Characteristics of patients on SCS with critical ischaemia from Klomp ${ }^{11}$

\begin{tabular}{ll}
\hline Characteristic & $\%$ \\
\hline Female & $45 \%$ \\
Age (mean) & 73 \\
Diabetes & $37 \%$ \\
Contralateral leg & \\
$\quad$ - symptomatic & $32 \%$ \\
$\quad$ amputated & $15 \%$ \\
Smoking & \\
$\quad$ not for > 1 year & $37 \%$ \\
$\quad$ - still smoking & $30 \%$ \\
CVA/TIA & $22 \%$ \\
Myocardial infarction & $38 \%$ \\
Angina pectoris & $20 \%$ \\
Ulcerations / gangrene & $63 \%$ \\
Gangrene & \\
$\quad$ dry & $40 \%$ \\
$\quad$ - wet & $13 \%$ \\
Previous vascular surgery & \\
$\quad$ - none & $25 \%$ \\
$\quad$ - l or 2 & $42 \%$ \\
$\quad$ Sympathectomy (randomised leg) & $32 \%$ \\
Ankle pressure (mean \pm SD in mm Hg) & $35 \%$ \\
Ankle-brachial index (mean $\pm \mathrm{SD}$ ) & $35.2 \pm 24.8$ \\
TcpO ${ }_{2}$ at rest (mm Hg) & $0.23 \pm 0.16$ \\
TcpO 2 peak (mm Hg) & 10 \\
\hline & 12 \\
\hline
\end{tabular}

$\left(\Delta \mathrm{TcpO}_{2}\right)$ increased from $22.4 \pm 22$ (prestimulation) to $41.4 \pm 18$ (poststimulation).

Horsch et al. ${ }^{7}$ reported on 177 patients belonging to the Fontaine stages III ( $\mathrm{n}=114)$ and $\mathrm{NV}(\mathrm{n}=63)$. A SCS system was implanted in 139 patients who had excellent pain relief after stimulation. Mean supine $\mathrm{TcpO}_{2}$ was 24 $\mathrm{mmHg}$ in stage III and $16 \mathrm{mmHg}$ in stage IV patients. During treatment $\mathrm{TcpO}_{2}$ increased to 48 and $37 \mathrm{mmHg}$, respectively.

Gersbach et al. ${ }^{7}$ started with a trial period of SCS for 1 week irrespective of the initial microcirculatory data. Baseline supine $\mathrm{TcpO}_{2}$ was $19.5 \pm 15$ $\mathrm{mmHg}$ and baseline-sitting $\mathrm{TcpO}_{2}$ was $42 \pm 15 \mathrm{mmHg}\left(\Delta \mathrm{TcpO} \mathrm{O}_{2}=23 \mathrm{mmHg}\right)$. Retrospective analysis of the different tests revealed that the supine-sitting $\mathrm{TcpO}_{2}$ gradient was the strongest predictor of limb salvage. If the gradient was greater than $15 \mathrm{mmHg}$, limb salvage rate (LSR) was as high as $88 \%$. All 
Table 3. Literature data about limb salvage.

\begin{tabular}{|c|c|c|c|c|}
\hline author & $\begin{array}{l}\text { SCS } \\
\mathrm{n}\end{array}$ & Limb survival & $\begin{array}{l}\text { Follow-up } \\
\text { (years) }\end{array}$ & $\begin{array}{l}\text { Conservative } \\
\text { n Limb survival }\end{array}$ \\
\hline \multicolumn{5}{|l|}{ Case reports } \\
\hline Augustinsson & 26 & $62 \%$ & $1^{*}$ & \\
\hline Galley & 199 & $64 \%$ & 2 & \\
\hline Horsch & 177 & $66 \%$ & 4 & \\
\hline Gersbach & 20 & $63 \%$ & 2 & \\
\hline Kumar & 46 & $65 \%$ & 2 & \\
\hline \multicolumn{5}{|c|}{$\begin{array}{l}\text { Randomised } \\
\text { controlled trials }\end{array}$} \\
\hline Jivegard & 25 & $62 \%$ & 1.5 & $26 \quad 45 \%$ \\
\hline Claeys & 45 & $68 \%$ & 1 & $41 \quad 65 \%$ \\
\hline Klomp & 60 & $60 \%$ & 2 & $60 \quad 46 \%$ \\
\hline
\end{tabular}

Follow-up in the case studies and randomised controlled trials (RCT). Mortality in the RCT was between $22 \%$ and $33 \%$ at 1 -year follow-up. In the case report studies the limb survival is mentioned with the years of follow up in the right half of the column $\left(^{*}\right)$. Conservative $=$ conservative treatment.

patients with a sitting $\mathrm{TcpO}_{2} \leq 20 \mathrm{mmHg}$ underwent amputation of the ischaemic limb.

Kumar et al. ${ }^{24}$ treated patients only if they had undergone a 6-month period of conservative therapy for pain relief. Patients with excellent pain relief $(>75 \%)$ and a substantial increase in $\mathrm{TcpO}_{2}$ after trial stimulation showed a significant positive correlation with long-term success. Patients with a $\mathrm{TcpO}_{2}$ of less than $10 \mathrm{mmHg}$ following stimulation tended to undergo an amputation within the first 3 months. Improvement in pain control combined with an increase in $\mathrm{TcpO}_{2}$ greater than $10 \mathrm{mmHg}$ was significant early predictors of long-term success. The best results were seen in patients with severe claudication and rest pain without trophic changes in the foot. Claeys et al. ${ }^{9}$ compared SCS with optimal medical treatment (OMT). Patients started with 1 week of prostaglandin treatment $\left(\mathrm{PGE}_{1}\right)$ after which they were randomised between $S C S+P G E_{1}$ and $\mathrm{PGE}_{1}$ alone. Initial mean value of $\mathrm{TcpO}_{2}$ was $10 \mathrm{mmHg}$ (SCS) vs $11 \mathrm{mmHg}$. At 12 months $\mathrm{TcpO}_{2}$ was $21 \mathrm{mmHg}$ vs 11.4 , respectively $(\mathrm{p}<0.0001)$. The outcome of patients with an initial $\mathrm{TcpO}_{2}<10$ $\mathrm{mmHg}$ was significantly less than those with a $\mathrm{TcpO}_{2}>10 \mathrm{mmHg}$. Ubbink et al. categorised patients according the status of their baseline skin microcirculation in good $\left(\mathrm{TcpO}_{2}\right.$ above $\left.30 \mathrm{mmHg}\right)$, intermediate $\left(\mathrm{TcpO}_{2}\right.$ between 10 and $30 \mathrm{mmHg}$ ) and poor $\left(\mathrm{TcpO}_{2}\right.$ below $\left.10 \mathrm{mmHg}\right)$. Patients with 
Table 4. Microcirculatory data

\begin{tabular}{|c|c|c|c|}
\hline & Baseline & Follow-up & \\
\hline \multicolumn{4}{|l|}{ A. Case reports } \\
\hline & $\mathrm{TcpO}_{2}$ at rest (supine) & Change in $\mathrm{TcpO}_{2}$ & \\
\hline Galley ${ }^{1}$ & 13 & $+77 \% * *$ & \\
\hline Horsch $^{2}$ & 16 & $+130 \% *$ & \\
\hline Gersbach $^{3}$ & 19 & $+120 \% * *$ & \\
\hline Kumar $^{4}$ & 23 & $+130 \% *$ & \\
\hline \multicolumn{4}{|l|}{ B. RCT's } \\
\hline \multicolumn{4}{|l|}{ Claeys $^{5}$} \\
\hline SCS & 10 & $+100-137 \%$ & \\
\hline Conserv. & 11 & none & \\
\hline \multicolumn{4}{|l|}{ Ubbink $^{6}$} \\
\hline SCS & 10 & $+70 \%$ & \\
\hline Conserv. & 9 & none & \\
\hline \multicolumn{4}{|l|}{ C. $\Delta \mathrm{TcpO}_{2}$} \\
\hline & Baseline & Prestim & Poststim. \\
\hline & $\mathrm{TcpO}_{2}$ (supine) $\mathrm{TcpO}_{2}$ (sitting) & $\Delta \mathrm{TcpO}_{2}$ & $\Delta \mathrm{TcpO}_{2}$ \\
\hline Galley ${ }^{1}$ & $13 \quad 24$ & $22^{* *}$ & 41 \\
\hline Gersbach $^{3}$ & 19 & 23 & \\
\hline
\end{tabular}

$\mathrm{TcpO}_{2}$ values presented in mm Hg. ${ }^{*}=\mathrm{p}<0.05 .{ }^{* *}=\mathrm{p}<0.001$. All data were mean values of $\mathrm{mm} \mathrm{Hg}$. Comparison of baseline and follow up values of TcpO2 in non-randomised (A) and randomised studies (B); 1 . (Study of Galley ${ }^{5}$. Only 77 out of 244 patients had $\mathrm{TcpO}_{2}$ measurements. The resting $\mathrm{TcpO}_{2}$ is much lower than in other reports; 2. (Study of Horsch ${ }^{7}$. The better the end result (pain relief, ulcer healing), the higher the increase in $\mathrm{TcpO}_{2}$. The standard group receiving optimal medical treatment did not show any increase in $\mathrm{TcpO}_{2}$. 3. (Study of Gersbach ${ }^{6}$. Prestimulation $\triangle \mathrm{TcpO} \mathrm{O}_{2}$ was $23 \mathrm{~mm} \mathrm{Hg}$. $88 \%$ of the responders had a $\Delta \mathrm{TcpO}_{2}$ of more than $15 \mathrm{~mm} \mathrm{Hg}$. 4. (Study of Kumar ${ }^{24}$. 5. (Results of Claeys ${ }^{9}$. Randomised study. Conservative treatment included prostaglandins. 6 . (Results from the Dutch randomised trial ${ }^{11}$. Increase in median $\mathrm{TcpO}_{2}$ for the SCS group. No change observed in the standard group. 
Table 5. Comparison of limb survival with and without specific $\mathrm{TcpO}_{2}$ measurements. A

\begin{tabular}{|c|c|c|c|c|}
\hline \multirow[t]{3}{*}{ Author } & \multirow{3}{*}{$\begin{array}{l}\text { Categorisation } \\
1\end{array}$} & \multirow{3}{*}{$\begin{array}{l}\mathrm{TcpO}_{2} \\
2\end{array}$} & \multicolumn{2}{|c|}{ Effect of stimulation in trial period } \\
\hline & & & $\begin{array}{l}\text { Change in } \\
\mathrm{TcpO}_{2}\end{array}$ & Pain relief \\
\hline & & & 3 & 4 \\
\hline \multicolumn{5}{|l|}{ Galley } \\
\hline Gersbach & & $>15 \mathrm{mmHg}$ & $\begin{array}{l}\text { Increase of } 15 \% \\
\text { of base value }\end{array}$ & $\begin{array}{l}\text { Complete } \\
\text { pain relief }\end{array}$ \\
\hline Kumar & $\begin{array}{l}\text { Comparable to } \\
\text { Ubbink }\end{array}$ & & Substantial & $>75 \%$ \\
\hline Claeys & $>10 \mathrm{mmHg}$ & & & \\
\hline Ubbink & $\begin{array}{l}\text { Intermediate } \\
\text { (>10 mm } \\
<30 \mathrm{mmHg})\end{array}$ & & & \\
\hline
\end{tabular}

A Description of the different methods used. Galley uses method 2-4 but goves no clear definition for success. The other authors give criteria as described in the table.

B

\begin{tabular}{|c|c|c|c|}
\hline Author & Limb survival (\%) & Limb survival & $\begin{array}{l}\text { Method used } \\
\text { expected using } \\
1,2,3 \text { or } 4\end{array}$ \\
\hline Galley & 62 & $?$ & $2-3-4$ \\
\hline Gersbach & 63 & 83 & $3-4$ \\
\hline Gersbach & 63 & 88 & 2 \\
\hline Kumar & 65 & 77 & $1,3-4$ \\
\hline Claeys & 68 & $?$ & 1 \\
\hline Ubbink & 60 & 72 & 1 \\
\hline
\end{tabular}

B. Suggested gain in limb survival and the different methods used. The authors indicated with (?) in the column-expected limb survival- give suggestions and describe the different measures but do not indicate the actual effect on limb survival.

Different methods are numbered 1-categorisation, 2- $\Delta \mathrm{tcpO}_{2}$, 3-effect of stimulation -change in $\mathrm{TcpO}_{2}$, 4- effect of stimulation- pain relief. Limb survival in column 2 is the survival according treatment following the European consensus. The expected limb survival is given in column 3 and is the result of a more accurate selection procedure using one of the methods mentioned. 


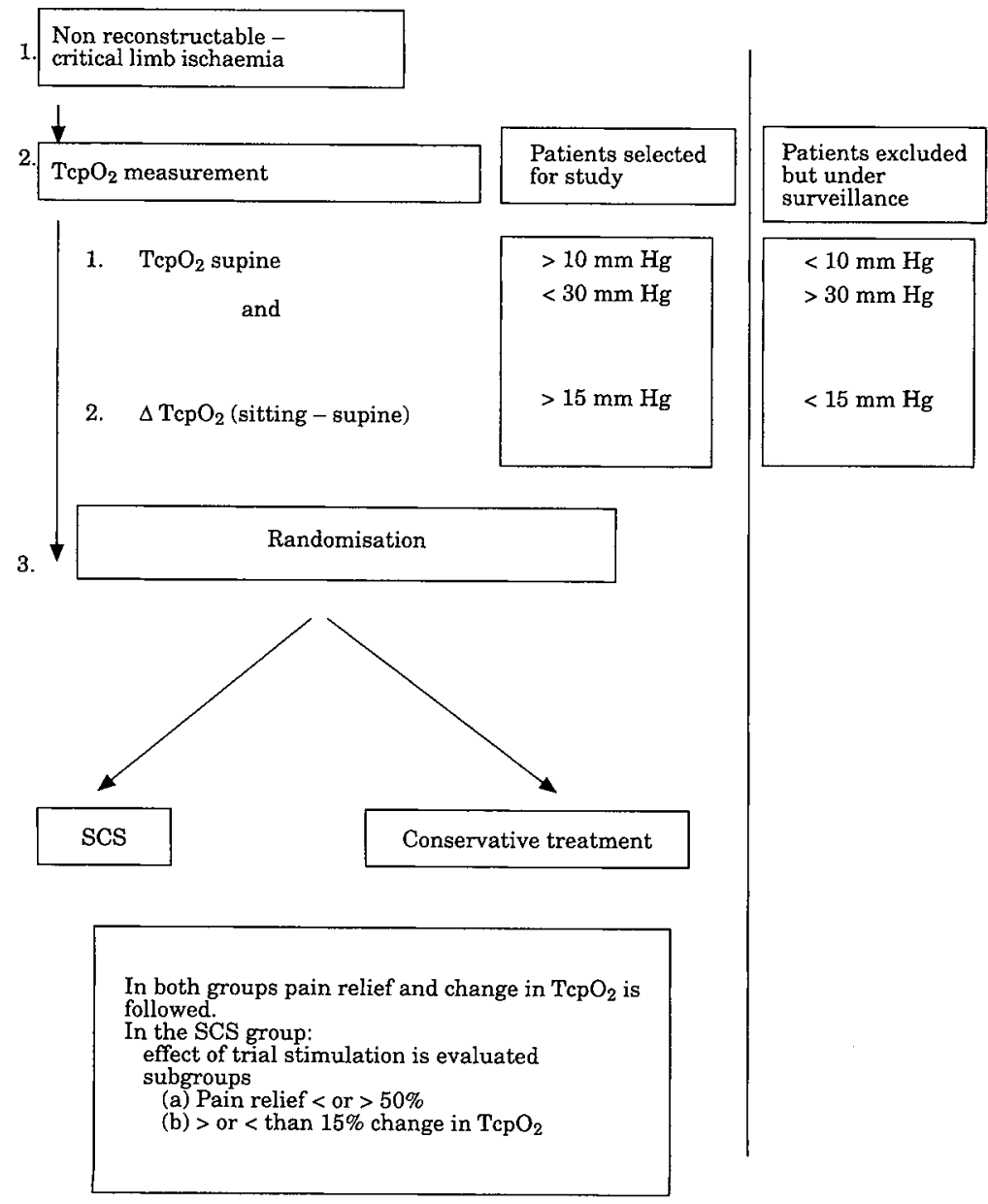

Figure 2. Algorithm for patient selection.

a poor skin perfusion had a high amputation rate of $80 \%$ for SCS and $71 \%$ for standard treatment. Patients with a good microcirculation had a good outcome irrespective of the treatment given. Amputation in patients treated conservatively with an intermediate $\mathrm{TcpO}_{2}$ value was half of that in the standard group ( 24 vs $48 \%$ ). ${ }^{25}$ This categorisation had a predictive value regarding limb salvage. ${ }^{14}$ 


\section{Pain reduction}

Pain reduction after trial stimulation was repeatedly suggested to correlate with limb salvage. 7,24 In the Dutch randomised study a trial stimulation was not performed. A retrospective analysis looked at the limb salvage at 6 months and 1-year follow-up of patients, which had a good or excellent pain relief scored at 1 month follow-up. The results between both treatment groups were comparable, proving that pain relief on itself was important, but not the way it was obtained. Patients with a bad response on pain had significantly lower limb salvage in both treatment groups, indicating that pain relief was related to limb salvage. One of the effects of pain relief is certainly the enhanced mobility of the patients, which may be responsible for a secondary amelioration in blood flow. ${ }^{11}$

\section{Algorithm design}

Based on this review, it is suggested that SCS is not indicated if patients have a baseline $\mathrm{TcpO}_{2}$ (supine and sitting) below 10 or above $30 \mathrm{mmHg}^{9,25}$ or a $\Delta \mathrm{TcpO}_{2}$ below $15 \mathrm{mmHg}{ }^{5,6}$ The eligible patients go on with a period of trial stimulation. At the end of that period pain relief and changes in $\mathrm{TcpO}_{2}$ are recorded. If pain relief is below $50 \%$, adjustment of medication is allowed to enhance pain relief. Should pain relief be above $50 \%$ and the change in $\mathrm{TcpO}_{2}$ is more than $15 \mathrm{mmHg} 5,24$ full implantation is considered. If no positive response is obtained, SCS is not indicated and symptomatic treatment is given, consisting of analgesics, vasoactive drugs and adequate care of foot ulcers.

This paradigm requires validation within a RCT (figure 2).

\section{DISCUSSION}

At present, the best available evidence indicates selection of patients for SCS cannot be based on the European consensus document or on the Fontaine grading. As skin microcirculation seems to be the major target of SCS, it seemed logical to look more carefully at $\mathrm{TcpO}_{2}$, laser Doppler and capillary microscopy. The initial $\mathrm{TcpO}_{2}$ value as measured at rest in the supine position appears to be a simple stand-alone parameter that is closely related to limb survival. Other $\mathrm{TcpO}_{2}$ parameters involved in the selection of patients, such as the difference between sitting and supine $\mathrm{TcpO}_{2}$, increase of $\mathrm{TcpO}_{2}$ after trial stimulation and pain reduction after stimulation need more evaluation. 
We suggest that CLI patients unsuitable for vascular reconstruction who have a good or poor $\mathrm{TcpO}_{2}$ should remain under surveillance. Patients with a $\mathrm{TcpO}_{2}$ between 10 and $30 \mathrm{mmHg}$ and a $\Delta \mathrm{TcpO} \mathrm{O}_{2}>15 \mathrm{mmHg}$ are considered for SCS. At this point randomisation is performed. If a patient is selected for SCS, further analysis is performed on pain relief and change in $\mathrm{TcpO}_{2}$ during the trial stimulation period. For both treatments the primary outcome is limb survival. Secondary outcomes are the analysis of pain relief and the changes in $\mathrm{TcpO}_{2}$ during follow-up.

The use of capillary microscopy and laser Doppler may further increase discriminative power, but seems to be reserved to those departments which have vascular surgery as a major topic and are devoted to those measurements which asks a lot of expertise and a special equipment. Some other questions still remain to be clarified as the prognostic value of some patient related risk factors, like hypertension and diabetes. ${ }^{6,9,21}$ In the Dutch study no prognostic value of the ankle pressure or diabetes was found. In contrast, microcirculatory parameters appear to have additional value in detecting critical leg ischemia and predicting an imminent amputation, even in the presence of diabetes, ${ }^{14,26}$ as well as in predicting wound healing in diabetic feet. $^{27}$

A prospective study, which to some extent uses the above-mentioned algorithm approach, is underway (SCS-EPOS - Medtronic). It is, however, a non-randomised study. This approach was considered inevitable, since refining the selection criteria results in a splitting up of patient groups in categories too small to be used for statistical analysis. For a country as The Netherlands with a population of 15 million people, the target group of patients with CLI and belonging to a specific group according to the $\mathrm{TcpO}_{2}$ (intermediate group as described by Ubbink) is probably not larger than 20 to 30 patients a year. It can be estimated from the power calculation of the study that in order to detect a difference of $30 \%$ in limb survival between treatments ( $50 \%$ vs $80 \%$ with SCS) with an $\alpha$ level of $5 \%$ less than 90 patients are needed for each treatment to prove a statistical difference.

In conclusion, there are different ways to better select patients that may potentially respond to a treatment like SCS. Using one of them could result in an increase of $10-20 \%$ in limb salvage compared to the results found in randomised trials. A study to prove this hypothesis is feasible as the number of patients needed is between 60 and 90 for each treatment option. At the same time enough information is obtained regarding the value of the different $\mathrm{TcpO}_{2}$ measurements. If the results are as predicted medical community and the healthcare payers will be convinced of the cost effectiveness of the therapy. Once this point is reached no further randomisation 
is needed and any patients eligible according the criteria described should be treated with spinal cord stimulation.

\section{REFERENCES}

1. Second European consensus document on chronic critical leg ischemia. European working group on critical leg ischemia. Eur J Vasc Surg 1992; (Suppl A), 1-32.

2. Cook AW, Oygar A, Baggenstos P, Pacheco S, Kleriga E. Vascular disease of extremities: electrical stimulation of spinal cord and posterior roots. NY State J Med. 1976; 76:366-378.

3. Dooley DM. Demyelinating, degenerative and vascular disease. Neurosurg 1977; 1:220-224.

4. Augustinsson LE, Carlsson.A, Holm J, Jivegard L. Epidural electrical stimulation in severe limb ischemia. Evidences of pain relief, increased blood flow and a possible limb-saving effect. Ann Surg 1985; 202:104-111.

5. Galley D, Rettori R, Boccalon H, Medvedowsky A, Lefebvre JM, Sellier F, Chauvreau C, Serise JM, Pieronne A. La stimulation électrique médullaire dans les artériopathies des membres inférieurs: une étude multicentrique chez 244 patients. J Mal Vasc 1992; $17: 208-213$

6. Gersbach P, Hasdemir MG, Stevens RD, Nachbur B, Mahler F. Discriminative microcirculatory screening of patients with refractory limb ischaemia for dorsal column stimulation. Eur J Vasc Endovasc Surg 1997; 13:464-471.

7. Horsch S, Claeys L. Epidural spinal cord stimulation in the treatment of severe peripheral arterial occlusive disease. Ann Vasc Surg 1994; 8:468-474.

8. Jacobs MJ, Jörning PJG, Beckers RCY, Ubbink DT, van Kleef M, Slaaf DW, Reneman RS. Foot salvage and improvement of microvascular blood flow as a result of epidural spinal cord electrical stimulation. J Vasc Surg 1990; 12: 354-360.

9. Claeys L, Horsch S. Transcutaneous oxygen pressure as predictive parameter for ulcer healing in endstage vascular patients treated with spinal cord stimulation. Int Angiology 1996; 15:344-349.

10. Jivegard LE, Augustinsson LE, Holm J, Risberg B, Ortenwall P. Effects of spinal cord stimulation (SCS) in patients with inoperable severe lower limb ischaemia: a prospective randomised controlled study. Eur J Vasc Endovasc Surg 1995; 9:421-425.

11. Klomp HM, Spincemaille GH, Steyerberg EW, Habbema JD, van Urk H. Efficacy of spinal cord stimulation in critical limb ischemia. Lancet 1999; 353:1040-44.

12. Loosemore TM, Chalmers TC, Dormandy JA. A meta-analysis of randomized placebo control trials in Fontaine stages III and IV peripheral occlusive arterial disease. Int Angiol 1994; 13: 133-142.

13. Linderoth B, Fedorcsak I, Meyerson BA. Peripheral vasodilatation after spinal cord stimulation: animal studies of putative effector mechanisms. Neurosurg 1991; 28:187-195.

14. Ubbink DT, Spincemaille GH, Reneman RS, Jacobs MJ. Prediction of imminent amputation in patients with non-reconstructible leg ischemia by means of microcirculatory investigations. JVasc Surg 1999; 30:114-121.

15. Bracale GC, Selvetella L, Mirabile F. Our experience with spinal cord stimulation (SCS) in peripheral vascular disease. Pace 1989; 12:695-697. 
16. Broseta J, Barbera J, de Vera JA, Barcia-Salorio JL, March G, Gonzalez-Darder J, Rovaina F, Joanes V. Spinal cord stimulation in peripheral arterial disease. A cooperative study. J Neurosurg 1986; 64:71-80.

17. Broggi G, Servello D,Franzini A, Giorgi C, Luccarelli M, Ruberti U, Cugnasca M, Odero A, Tealdi D, Denale A. Spinal cord stimulation for the treatment of peripheral vascular disease. Appl Neurophysiol 1987; 50:439-441.

18. Fiume D, Palombi M, Sciassa V, Tamorri M. Spinal cord stimulation (SCS) in peripheral vascular disease. Pace 1989; 12:698-704.

19. Franzetti I, De Nale A, Bossi A, Greco M, Morricone L, Ruggerini M, Meazza D, Sciolla A, Caviezel F, Oriani G. Epidural spinal electrostimulatory system [ESES] in the management of diabetic foot and peripheral arteriopathies. Pace 1989; 12: 705-708.

20. Groth KE. Spinal cord stimulation for the treatment of peripheral vascular disease European Multi-center Study. In: Fields (ed): Advances in Pain Research and Therapy. New York, Raven Press, 1985; 9: 861-870.

21. Kasprzak O, Raithel. Can spinal cord stimulation reduce the amputation rate in patients with critical limb ischemia, in Horsch S, Claeys L. (eds.): spinal cord stimulation. An innovative method in the treatment of PVD. Darmstadt, Steinkopff, 1994: 165-169.

22. Meglio M, Cioni B, Rossi GF. Spinal cord stimulation in management of chronic pain. A 9-year experience. J Neurosurg 1989; 70:519-524.

23. Rickman S, Wuebbels BH, Holloway GA. Spinal cord stimulation for relief of ischemic pain in end-stage arterial occlusive disease. J Vasc Nurs 1994; 12:14-20.

24. Kumar K, Toth C, Nath RK, Verma AK, Burgess JJ. Improvement of limb circulation in peripheral vascular disease using epidural spinal cord stimulation: a prospective study. J Neurosurg 1997; 86:662-669.

25. Ubbink DT, Spincemaille GH, HM, Prins MH, Reneman RS, Jacobs MJ. Microcirculatory investigations to determine the effect of spinal cord stimulation for critical leg ischemia: the Dutch multicenter randomized controlled trial. J Vasc Surg $1999 ; 30: 236-244$

26. Ubbink DT, Kitslaar PJ, Tordoir JH, Reneman RS, Jacobs MJ. Skin microcirculation in diabetic and non-diabetic patients at different stages of lower limb ischaemia. Eur J Vasc Surg 1993; 7: 659-666.

27. Kalani M, Brismar K, Fagrell B, Ostergren J, Jorneskog G. Transcutaneous oxygen tension and toe blood pressure as predictors for outcome of diabetic foot ulcers. Diab Care 1999; 22: 147-151. 


\section{General discussion}

The introduction gives an impression of the state of the art regarding critical limb ischemia and neuromodulation at the time the study was started. Besides neuromodulation, the only ways to help patients with non-reconstructable arterial disease are by means of conservative foot care and vasoactive drugs. Neuromodulation was presented as the therapy, which could relieve pain and probably enhance limb survival. The fact that expectation could not be fulfilled presented a serious draw back, resulting in criticism from those believing in SCS. Until now, no randomised clinical study could prove that SCS was statistically better than conservative treatment. Further work is required to elucidate why some patients are responders while others are not.

The actual state of the art has been discussed in several recent articles. The first one is a comment specifically targeted at SCS and CLI by Meyerson and Linderoth. The second is a large document/text/review recently published, which presents a general overview of the treatment of CLI. (Chronic critical limb ischemia 2000)

Meyerson stated in his review: "The Dutch multicentre, prospective study on spinal cord stimulation (SCS) in critical limb ischemia (Spincemaille $e t$ al., 2000) was planned and launched in the early nineties and the assessment algorithm was fixed at a time when several reviews from the eighties reported generally favourable outcomes of this treatment on various measures of ischemia in patients with peripheral vascular disease (PVD). Already at this time, however, the implantation rate in many European countries was decreasing and an effect of SCS on amputation frequency (a readily understandable measure for public health administrators) was asked for. At that time indications were merely based on crude staging of cases e.g. according to the Fontaine scale. The Dutch study provides valuable information, in that it clearly demonstrates that in a large unselected cohort of patients classified as corresponding to Fontaine stages IIIb-IVa (rest pain without or with slight tissue involvement), SCS does not produce significantly more pain relief or an improved quality of life than standard therapy. However, it should be noted that there was a significant reduction of analgesics and an improvement of mobility and energy in patients subjected to SCS as compared to the control group. 
In another report from the Dutch study the outcome regarding amputation rate was analysed in subdivisions of the entire material (Ubbink et al., 1999). On the basis of the skin microcirculatory data obtained immediately before therapy, the patient material was stratified in a poor, an intermediate and a good group. In these separate groups limb survival was related to treatment type after 18 months follow up. Neither in the entire material nor in the good and poor group was there any significant difference in survival rate between SCS and standard therapy but in the intermediate group, with pretreatment TcpO2 between $10-30 \mathrm{~mm} \mathrm{Hg}$, there was a marked separation of the Kaplan-Meier limb survival curves which, however, did not reach statistical significance $(\mathrm{P}=0.08)$.

Thus, by an ex post facto stratification of the material, the Dutch study group has provided data, which may be useful in selecting patients for future anti-ischemic therapy with SCS. During the last few years this issue has been discussed in several papers and attempts have been made to devise selection instruments in order to predict which type of patients could benefit from SCS. Gersbach et al. (1997) has proposed pretreatment evaluation of cases with TcpO2 measurement in the sitting and supine positions and based the selection on the difference between these two conditions. This measure proved to be reliable and enabled the prediction of a positive treatment outcome in $88 \%$ of the cases.

In the Dutch study, trial stimulation was not part of the protocol because it was considered that no scientific data substantiated that trial stimulation had a long-term predictive value. One of the members of the Dutch study group, however, recommended trial stimulation over about 2 weeks with regular assessment of pain and $\mathrm{TcpO}_{2}$, (MJ Jacobs. pers communication, 1998; see also Favre et al., 1995).

There are but a few other randomized, prospective studies on SCS for PVD. In an intention-to treat-study performed in Gothenburg, Sweden, 51 patients were included (Jivegard et al., 1995). There was a clear, though not significant, trend for a limb-saving effect of SCS. However, there were technical problems in the study protocol; $12 \%$ of patients randomized to SCS, for various reasons, never received implants. No percutaneous trial stimulation was performed. The authors observed a tendency for less satisfactory results in cases with arterial hypertension, an observation that has not been confirmed by others. If the hypertensive patients were excluded in the Gothenburg study, the remaining SCS group demonstrated a significantly lower amputation rate than the control patients.

Another controlled, randomized study is that of Horsch and Claeys (1994), comprising 86 Fontaine stage IV patients. Forty-five were subjected to SCS and the follow up was 12 months. The study was partly performed with the 
aim to evaluate the predictive power of $\mathrm{TcpO}_{2}$ measurements in the foot (see also Claeys and Horsch, 1996). The outcome of this study is partly at odds with the Dutch one, in that SCS together with i.v. prostaglandin $\mathrm{E}_{1}$ provided a significantly better foot ulcer healing and pain relief than did pharmacotherapy alone. However, no limb salvage effect was observed. Similar results have been reported from a Belgian controlled, randomized study (Suy et al., 1994). Out of 38 patients, 20 were randomized for SCS, and the mean follow up was 20 months. The outcome regarding pain relief, ability to walk and quality of life favoured the SCS group. It should be noted that percutaneous trials were not performed in any of the aforementioned studies.

Considering the outcome of previous studies, including the three controlled, randomized ones referred to above, it is difficult to explain the failure of SCS to ameliorate pain and improve quality of life as reported by the Dutch group. One possible reason might be that no effort was made to differentially assess the various types of pain components which exist in parallel in an ischemic leg: the deep aching ischemic pain; the pain from an ischemic ulcer and from the borders of gangrene; neuropathic pain components resulting from defective, nutritional nerve circulation etc. Identification and assessment of the 'true ischemic pain' would have been more relevant since this component is the first to respond when ischemia is reduced, the others following much later - or not at all. Another point of concern is the fact that the consumption of analgesics, including opioids, was significantly less in the SCS group, a fact which is difficult to reconcile with the conclusion that pain relief did not differ from the control group. This somewhat unexpected finding could perhaps be at least partly due to the fact that $13 \%$ of the patients for technical reasons had suboptimal stimulation.

It would also have been of considerable interest if the outcome had been discussed with reference to a stratification of the material according to the principles described in the report by Ubbink et al. (1999), which is not even cited in the text.

The mechanisms of pain relief in ischemia by SCS are still obscure, but several groups have proposed different mechanisms based on inhibition of sympathetic activity and/or antidromic release of vasoactive substances. The present study illustrates that the lack of knowledge has hampered the development of stringent criteria for selecting cases that may benefit from the treatment. The Dutch study was well designed and conducted but it cannot be considered to be the 'final' one. In order to optimize the utilization of the possible favourable effects of SCS, specific and sensitive tools for assessing microcirculation, both for patient selection and for screening, during trial stimulation have to be employed. 
During the last decade the technical development in vascular surgery has enabled longer by-pass grafting procedures, endovascular interventions. The patients eligible for SCS are often elderly, suffering from advanced atherosclerosis, with concurrent diseases such as diabetes, and in a stage of rapid decline towards critical, limb threatening ischemia. In some countries the use of SCS for PVD was almost stopped and in others it decreased considerably. It is with hope of a sound, evidence-based utilization of selection principles that we look forward to a steady - but possibly slow - revival of SCS for ischemic limb disease."

The second review is an extensive high quality document with recommendations for definition, investigation and treatment of CLI given by key opinion leaders. (chronic CLI 2000) It lacks, however, breakthrough propositions for investigation of CLI. This is understandable because there is no complete evidence for the value of some investigations. These recommendations reduce the uncertainty in selecting a circumscribed set of tools for investigation and outcome measures.

More information on the epidemiology of CLI is needed, simply because it is of value in planning and organizing the treatment of these patients. There is, however, very little information on the epidemiology of peripheral vascular disease compared to coronary and cerebral vessel disease. Balkau looked at the prevalence of PVD, taking the Ankle Brachial Index (ABI) of less than 0.9 as a criterion; this value is much higher than that seen in critical limb ischaemia and is more indicative of claudication. It appears that the lowest prevalence is $0.4 \%$ in $40-59$-year-old men in Odense, and ranges to more than $14 \%$ in American men and women aged 65 years and over, and to $35 \%$ in Italian men and 33\% in Italian women aged 80 years and over. (Balkau et al 1994) Apart from the difference in prevalence depending on the country, there is, as expected, an important increase related to age. The national Audit Committee of the Vascular Surgical Society of Great Britain estimates the incidence of CLI to be between 30 and 80 per 100,000 per year. (The a.c.a.i. group 1996)

In recommendation 100 it is stated that on current evidence SCS cannot be recommended in the treatment of CLI. Although this is a correct conclusion on the basis of actual knowledge, it is true for more treatments of CLI and points to the urgent need for better selection criteria. Neurostimulation was used as a last resource therapy but what if SCS could preserve limbs just as well as surgery in a defined condition of CLI? Guarnera proposed a prospective randomised study with as the main question: could SCS represent an efficacious and alternative therapy to bypass in the treatment planning of critical limb ischemia? He presented preliminary results that were in favour 
of SCS. (Guarnera et al 1994) Certainly a provocative question, which perhaps needs consideration if one looks at the functional outcome in limb salvage.

If the selection of patients with critical ischemia is a critical factor in the decision about further treatment, are all vascular departments sufficiently skilled to make that selection? Have the vascular laboratories people skilled to perform accurate Doppler, $\mathrm{TcpO}_{2}$ and perhaps capillary microscopy? What are the best strategies for the evaluation of the microcirculation? Can vascular surgeons agree on this, because if there is actually not a gold standard in diagnosing a patient as being critical or not, a consensus may be better than nothing? If only a few departments have a vascular laboratory, should patients not be centralized and sent to the departments fulfilling these criteria of quality? Are physicians willing to refer their patients with the aim of giving the patient the best treatment he deserves, or will they consider referring patients as a recognition of a lack of quality of their departments, although they may be very skilled in other areas of vascular surgery?

It seems clear that the condition of the microcirculation will play an important role in the selection criteria. But it is not clear how it will be measured. There are several possibilities as outlined in the last chapter of this thesis. Recently Ubbink stated that the optimal cut-off point for detecting patients requiring invasive treatment is a toe blood pressure (TBP) of $38 \mathrm{~mm} \mathrm{Hg}$ and a $\mathrm{TcpO}_{2}$ of $35 \mathrm{~mm} \mathrm{Hg}$. He added that measurements in the sitting position did not enhance diagnostic power. (Ubbink et al 2000) Gersbach and Galley, however, found that the difference between sitting and supine $\mathrm{TcpO}_{2}$ had a prognostic value.(Gersbach et al 1997, Galley et al 1992) It would seem, therefore, of utmost importance that experts in the field get together, compare their results and come up with a proposition that can be used as a guideline for the future/next few years.

In the same document on critical limb ischemia there is extensive discussion concerning definition, diagnosis and treatment options. In recommendation 74 , the document repeats the reported standards for CLI, but although criticizing the earlier definitions, goes no further than the SECD does with one addition: reduced $\mathrm{TcpO}_{2}(30-50 \mathrm{~mm} \mathrm{Hg})$. In a paragraph on microcirculatory pathophysiology the authors differentiate between nutritive and thermoregulatory flow. They give the impression that the impact of the nutritive flow is only minor because it represents only $15 \%$ of the flow to the foot. In the paragraph on investigation of CLI they discuss the various existing techniques for measuring blood flow. The practical problem in using the microcirculatory measurements is more a question of feasibility. 
Which tests can be used by most departments and how reliable are the results? Although as a neurosurgeon I should leave that discussion to vascular surgeons, it would be very helpful if the key opinion leaders in this field would try to come to a practical consensus and a standard for future research. The last chapter of this thesis discusses the available data. The algorithm is a proposal open to discussion. More complex investigations such as radionuclide perfusion scans and capillary microscopy are probably difficult to implement in daily practice at this point in time.

Remaining specific questions on the effect of neuromodulation on CLI.: The fact that more than $10 \%$ of the patients in the Dutch trial were not optimally followed for their stimulation could be argued to be not critical, as the assumption is that the same would happen once the therapy is free in general practice. However it undermines the effect of stimulation and one should try to use the therapy at its best. An explanation for this problem of undertreatment is the quite complex nature of the therapy as a whole compared to drug administration where the discipline of the patients to take the drug is the only possible bias. Another problem is also addressed in the document under the heading " operator variability". In a multicentre study there will inevitably be operators with unequal skills. The consequence is probably a less than optimal result when comparing treatments. The fact that initial results are usually far superior to those reported in randomised studies, is simply due to the biases present in non-randomized reports and the probably higher expertise of people reporting initial cohort studies.

There are several possible drawbacks to SCS during the follow-up, which might compromise the positive effect of stimulation on pain and limb salvage.

Trial stimulation, stimulation parameters, the influence of hypertension and diabetes, are all possible factors, which could influence the outcome results. Today the impact of the different factors remains unclear. In our study an analysis was made of diabetes, hypertension and smoking. All factors had a hazard ratio below or just above 1 . Only for ulcerations and gangrene was a hazard ratio of 2.5 and greater found with a p-value of 0.016 and $<0.001$. Petrakis studied the outcome of patients with critical limb ischemia and diabetes. He described 60 diabetic patients. The stage of neuropathy was inversely related to the success of SCS, independent of the stage of the vascular disease. (Petrakis et al 2000) Hoofwijk stressed in his thesis that sex, diabetes and condition of health, defined by a scoring system comparable to the SIP and NHP had an influence on the outcome.(Hoofwijk 1990) 
Ubbink stated that the influence of diabetes on the microcirculation is outweighed by the effect of atherosclerosis when vascular disease becomes severe. (Ubbink et al 1993) In none of the articles reporting more specifically on patients with diabetes is neuropathy considered as an important criterion for patient stratification.

Reporting on pain is, as stated not only scoring a visual analogue scale (VAS), but looking at the effects of pain on the various dimensions of health perception. Therefore the McGill questionnaire, the NHP, the Euroqol and part of the SIP were used in our study to evaluate the changes in quality of life of patients with CLI. Chetter presents an extensive overview of the use of different quality of life questionnaires and discusses their validity, responsiveness and reliability. (Chetter et al 1997)

From the studies available, we had insufficiently uniform data to undertake a metanalysis. If in the future the recommendations of the CLI document are followed and even more detailed propositions are formulated related to both the investigation and the outcome measures, pooling of different studies will be justified and it may be easier to prove the effectiveness of SCS in CLI. The ongoing European study, SCS-EPOS - Medtronic, which is not randomised and includes patients with CLI with criteria comparable to the Dutch randomised study stratifies patients according the proposal of Ubbink in different $\mathrm{TcPO}_{2}$ categories.(Ubbink et al 1999) Another study was mentioned in the article from the i.c.a.i. group as a collaborative clinical trial aiming to recruit 2000 patients. If this study is conducted as proposed by the recent Document on CLI, one might expect a conclusive statement on a number of the questions mentioned above.

\section{REFERENCES}

1. Claeys L, Horsch S. Transcutaneous oxygen pressure as predictive parameter for ulcer healing in endstage vascular patients treated with spinal cord stimulation. Int Angiol 1996; 15:344-349.

2. Favre JP, Richard A, Gournier JP, Barral X. Value of spinal cord stimulation for limb salvage in patients with graft failure. In: Horsch S, Claeys L. Spinal cord stimulation II. An innovative method in the treatment of PVD. and angina. Darmstadt: Steinkopff-Verlag, 1995; 137-145.

3. Jivegard L, Augustinsson LE, Holm J, Risberg B, Ortenwall P Efhects of spinal cord stimulayion (SCS) in patients with inoperable severe lower limb ischemia: a prospective randomized controlled study. Eur J Vasc Surg 1995; 9: 421-425.

4. Spincemaille GH, Klomp HM, Steyerberg EW, Habbema JDR Pain and quality of life in patients with critical limb ischaemia: results of a randomized controlled multicentre study on the effect of spinal cord stimulation. Eur J Pain 2000; 4:173-184. 
5. Suy R, Gybels J, Van Damme H, Martin D, van Maele R, Delaporte C. Spinal cord stimulation for ischemic rest pain. The Belgian randomized study. In: Horsch S, Claeys L eds. Spinal cord stimulation: An innovative method in the treatment of PVD, Darmstadt: Steinkopff-Verlag, 1994: 197-202.

6. Ubbink DTh, Spincemaille GH, Prins MH, Reneman RS, Jacobs MJ. Microcirculatory investigations to determine the effect of spinal cord stimulation for critical limb ischemia: The Dutch multicenter randomized controlled trial. J Vasc Surg 1999; 30: 236-244.

7. Balkau B, Vray M, Eschwege E. Epidemiology of peripheral arterial disease. J Cardiovasc Pharmacology 1994,23:S8-S16

8. Guarnera G, Furgiuele S, Camilli S. [Spinal cord electric stimulation vs. femoro-distal bypass in critical ischemia of the legs. Preliminary results in a randomized prospective study. Minerva Cardioangiol 1994,42:223-227.

9. The a.c.a.i. group. A prospective epidemiological survey of the natural history of chronic critical leg ischaemia. Eur J Vasc Endovasc Surg 1996,11:112-120.

10. Ubbink DT, Kitslaar PJEHM, Tordoir JHM, Reneman RS, Jacobs MJHM. Skin microcirculation in diabetic and non-diabetic patients at different stages of lower limb ischaemia. Eur J Vasc Surg 1993, 7:659-666.

11. Galley D, Rettori R, Boccalon H, Medvedowsky A, Lefebvre JM, Sellier F, Chauvreau C, Serise JM, Pieronne A. La stimulation électrique médullaire dans les artériopathies des membres inférieurs: une étude multicentrique chez 244 patients. J Mal Vasc 1992; 17:208-213

12. Gersbach P, Hasdemir MG, Stevens RD, Nachbur B, Mahler F. Discriminative microcirculatory screening of patients with refractory limb ischaemia for dorsal column stimulation. Eur J Vasc Endovasc Surg 1997; 13:464-471.

13. Ubbink DTh, Tulevski II, de Graaff JC, Legemate DA, Jacobs MJHM. Optimisation of the non-invasive assessment of critical limb ischaemia requiring invasive treatment. Eur J Vasc Endovasc Surg. 2000, 19: 131-137.

14. Linderoth B, Meyerson BA. Spinal cord stimulation in limb ischemia - time for revival. Eur J Pain. 2000,4:317-319.

15. Petrakis IE, Sciacca V. Does autonomic neuropathy influence spinal cord stimulation therapy success in diabetic patients with critical lower limb ischemia? Surg Neurol. 2000,53:182-188.

16. Hoofwijk AGM. Kritieke ischaemie van het been. Severe lower limb ischemia. Thesis 1990

17. Chetter IC, Spark JI, Dolan P, Scott DJA, Kester RC. Quality of life analysis in patients with lower limb ischaemia: suggestions for European standardisation. Eur J Vasc Endovasc Surg. 1997,13:597-604. 


\section{Summary}

The Dutch randomised trial was conducted between 1991 and 1996, intake period $2 \frac{1}{2}$ years and follow-up $2 \frac{1}{2}$ years. Data necessary were sampled for limb salvage, pain relief, the use of medication and health perception as defined by the WHO. As stated by Humphreys: "It is obvious that patients are not interested in the patency of the graft or the cost. Their main criterion for success is quality of life after the procedure". (Humphreys et al 1994) Cost-effectiveness was another important issue assessed by the Department of Epidemiology of the University of Rotterdam. The results of their study are not part of this report. Klomp published the overall results of the Dutch study in 1999 and stated: "We did not find that spinal cord stimulation was of benefit above that of best medical treatment. Amputation free survival was not improved nor was the risk of major amputation significantly reduced. The rates of amputation were similar in both groups and were particularly high during the first 3 months, which shows both the nature of critical ischemia and the limited potential of current treatments. However, a surprisingly high number of patients with critical ischemia can, temporarily, be stable or improve with conservative methods: in the standard group, limb survival was $46 \%$ after 1 year." (Klomp et al 1999- Chapter II) This straightforward conclusion, as expected, was the subject of discussion.

The other chapters of this manuscript give an impression of the problem as we tried to clarify the effect of SCS in patients with critical ischemia of the lower limbs. The inclusion of the microcirculatory measurements was done explicitly because we could not imagine that macro circulation would play an important role in these patients with sclerosis and occlusion of the larger vessels supplying the distal areas of lower limb and foot. These data were sampled in a unique way as one of the participants, highly skilled in these laboratory investigations, traveled around the country to perform the measurements throughout the study period.

A chapter on pain and quality of life is included, because the quality of life is what is important for the patients. There are a number of questionnaires which deal with quality of life. We used generic questionnaires including the Nottingham Health profile (NHP), part of the Sickness Impact profile (SIP) and the Euroqol. Main topics were pain and mobility, which were the domains most specific for patients with CLI. In addition to these question- 
naires, some specific measures were used including the visual analogue score, the McGill pain questionnaire and the medication quantification scale.

In the last chapter we discuss how to improve the selection of patients at risk of amputation who have a peripheral vascular bed which could still respond to a technique like SCS. This chapter focuses especially on microcirculation, which may not be the gold standard for screening these patients for their capacity to react to treatments like SCS, but in our opinion is certainly the best method currently available. 


\section{Samenvatting (Summary in Dutch)}

Ruggenmergstimulatie - Spinal Cord Stimulation (SCS) - werd het eerst verricht door Shealy in 1967, twee jaar na de publicatie van de Gate theorie van Wall and Melzack. De eerste 10 jaar werd het vooral gebruikt om pijn te behandelen bij patiënten met neurologische aandoeningen. Toen Cook in 1973 opmerkte dat behalve vermindering van pijn er ook een mogelijke invloed was op de perifere vaten, volgden case reports en patiënten series waarin werd aangetoond dat in geval van ischemie, SCS een aanzienlijke verbetering van de doorbloeding kon teweeg brengen. Tussen 1985 en het begin der jaren negentig verschenen artikelen vanuit Zweden, Italië en Spanje die deze preliminaire resultaten bevestigden en de indruk gaven dat deze behandeling niet alleen de pijn die gepaard gaat met de ischemie maar ook de ischemie zelf positief kon beïnvloeden. Op meerdere congressen werd uitgebreid gediscussieerd aan de hand van vooral de onderzoeken die in Italië en Spanje werden verricht. Men hield zich echter vooral aan het effect op pijn maar wees terzijde op de normalisatie van de doorbloeding in de onderste ledematen wat vast te stellen was aan de hand van een klassiek onderzoek als de Doppler. Men was van mening dat patiënten in een dergelijk stadium nagenoeg allen binnen enkele maanden een amputatie zouden ondergaan. In het licht van die redenering sprak het resultaat dat Augustinsson neerzette duidelijke taal. Augustinsson kwam in 1985 met een artikel getiteld: Evidences of pain relief, increased blood flow and a possible limb saving effect. Hij vergeleek een historische reeks patiënten met een opeenvolgende reeks patiënten behandeld met SCS. Van de behandelde patiënten waren er na 12 maanden follow-up nog $70 \%$ niet geamputeerd terwijl de niet behandelde groep een amputatie vrije percentage van $10 \%$ had. Dit gegeven is een belangrijke impuls geweest om de techniek te adviseren bij patiënten met kritieke ischemie van de onderste ledematen. Aangezien er geen gerandomiseerde studies beschikbaar waren, is het initiatief genomen om via de ontwikkelingsgeneeskunde een dergelijk project op te starten. De patiënten die in aanmerking kwamen voor de Nederlandse studie, waren allen uitbehandeld voor vasculaire chirurgie of endovasculaire therapie zoals het dotteren. Zij dienden bovendien te voldoen aan de criteria van kritieke ischemie als opgesteld in de Europese consensus. 
Hoofdstuk 2 geeft het resultaat van de pilot-studie. De resultaten wezen op een minder uitgesproken verschil tussen de beide behandelingen, maar maakten duidelijk dat men als organisatie klaar was voor het grote werk. Hoofdstuk 3 geeft de globale resultaten van de gerandomiseerde studie die plaats vond tussen 1991 en 1996. Er werd geen statistisch verschil gevonden tussen beide behandelingen. De kosten waren in de aanvang hoger voor de stimulatie dan voor de conservatieve behandeling. Dit leidde tot een negatief advies van de Ziekenfondsraad, waarbij voorlopig de behandeling als niet relevant werd aangemerkt.

Wanneer de resultaten verder werden geanalyseerd, Hoofdstuk 4, werd het accent verlegd naar de reductie van pijn en de kwaliteit van leven. Alhoewel op onderdelen er wel verschillen waren in het voordeel van de stimulatie waren deze te klein om de behandeling zonder meer aan te bevelen.

In Hoofdstuk 5 wordt ingegaan op de complicaties en de technische resultaten van de stimulatie. Het adagio "do not harm" is hier op zijn plaats. Als men al een winst boekt blijft het van belang na te gaan ten koste waarvan. Het moge duidelijk zijn dat een voldoende expertise in het gebruik van deze techniek niet een randvoorwaarde maar een voorwaarde sine qua non is, bij het verrichten van deze ingrepen.

Hoofdstuk 6 en 7 geven het belang weer van de microcirculatie. In de literatuur van de jaren 80 en het begin van de jaren 90 werd aangegeven dat de macrocirculatie kon beïnvloed worden door ruggenmergstimulatie. Het hoeft geen groot betoog dat verkalkte vaten niet meer reageren op welke behandeling dan ook tenzij in het eindstadium dotteren dan wel bypass procedures. Het distale vaatbed daarentegen heeft wel nog mogelijkheden om de doorbloeding aan te passen onder de vorm van een herverdeling van de flow. Dit wordt prachtig geïllustreerd door het werk van Ubbink, die in beide artikelen laat zien wat de gevolgen zijn wanneer men de zuurstofdruk van de huidcapillairen $\left(\mathrm{TcpO}_{2}\right)$ als parameter neemt voor de hoeveelheid flow in het distale vaatbed. Alhoewel niet eenduidig kon worden aangetoond dat deze methode de responders van de niet responders kan onderscheiden, is het toch de moeite om dit verder te onderzoeken. Het onderzoek leerde dat patiënten die in de middengroep zitten (matige $\mathrm{TcpO}_{2}$ ) nog kunnen reageren en de grootste kans maken om te verbeteren wanneer men SCS toepast. De goede groep met een nagenoeg normale $\mathrm{TcpO}_{2}$ hoeft geen SCS want loopt weinig risico's, tenzij in het natuurlijke beloop er een verslechtering optreedt en ze in de midden groep komen. De patiënten met een slechte $\mathrm{TcpO}_{2}$ hebben een aanzienlijk risico op amputatie.

In het laatste hoofdstuk wordt in de literatuur gezocht naar andere criter: voor de evaluatie van de microcirculatie. Wanneer enkele technieke 
gecombineerd worden zal voor een beperktere groep patiënten door de strengere selectie, de therapie wel zinvol blijken en ook economisch verantwoord zijn. Dit vraagt echter dat de vaatchirurgen tot een consensus komen om deze technieken toe te passen en alsnog op basis van deze kennis een laatste gerandomiseerde studie verrichten. 



\section{Dankwoord}

Hoe ouder men wordt hoe moeilijker het is om dit stukje kort en bondig te houden. Ik neem dan ook de vrijheid een en ander te verwoorden zoals ik het persoonlijk heb ervaren.

Hans Sier, Nanno Lambooy en Hans van der Aa. Jaren geleden hadden we enkele bijeenkomsten in het zuiden van Frankrijk. Het protocol dat aanvankelijk op de hotelkamer werd geschreven was meer dan een stuk papier. Het maakte duidelijk dat we iets met elkaar wilden realiseren en was tevens een commitment. Jullie, tezamen met anderen vermeld aan het einde van dit manuscript, waren na het succesvol doorlopen van de pilotstudie, bereid om deel te nemen aan het ontwikkelingsgeneeskundig project OG-90/053. Het eindverslag gerapporteerd aan de Ziekenfondsraad, nu College voor Zorgverzekeringen, resulteerde in een uitgave van de Raad getiteld "Epidurale elektrische ruggenmergstimulatie bij kritieke ischemie van de onderste ledematen". De studie is nu bekend in de literatuur als "the Dutch Randomized Trial of SCS in critical limb ischemia.

De onverwoestbare en creatieve inzet van Yvonne Keereweer, heeft het mogelijk gemaakt alle hindernissen op te ruimen die een dergelijk project op zijn weg vindt en die zijn niet gering.

De onvoorwaardelijke steun van Jo Merkun heeft er niet alleen toe geleid dat deze studie kon plaatsvinden, maar ook dat alle deelnemers aan de studie indien nodig steeds op hulp konden rekenen. Door de veelvuldige contacten ontstond een warme vriendschappelijke band. Niettegenstaande zijn stijgende belangrijkheid binnen Medtronic, blijft hij zijn bakermat trouw en geïnteresseerd in ons doen en laten. Een betere mentor kan men niet hebben.

Het bovengenoemde duo, Yvonne en Jo, zijn in belangrijke mate de motor geweest om het enthousiasme, niet alleen bij mij maar tevens in de groep, levendig te houden.

De inzet van Houke Klomp en Hero van Urk hebben het mogelijk gemaakt dat de studie goed opgevolgd werd, waarbij tijdens de tussentijdse bijeenkomsten zorgvuldig gekeken werd na de afgelegde weg, terwijl de blik 
steevast gericht was op het einddoel: binnen de afgesproken tijd de studie afronden. Dit lukt niet iedereen.

Achter de schermen gebeurt het verzamelen en analyseren van de data. Dik Habbema en Ewout Steyerberg hebben dat voortreffelijk gedaan. Tijdens de bijeenkomsten gaven ze blijk van grote betrokkenheid. De derde "geïnteresseerde" partij leidde ons naar het de eindstreep voor verschillende van de voorliggende publicaties. Mijn oprechte dank.

Door het jarenlange contact met het $\mathrm{CvZ}$ heb ik deze instantie leren waarderen als een terecht strenge bewaker van innovatieve technieken. Dank aan Remy Langenberg en Harry Janssen voor hun begrip in moeilijke tijden van voorbereiding en uitwerking van projecten. Niet in het minst voor de inzet van beiden voor het kwaliteitsproject pijn dat eind dit jaar afgerond wordt.

Michel Jacobs, je retourtje Amsterdam is de periode waarin dit alles zich heeft voorgedaan. In de periode voor je vertrek hebben we uitgebreid overleg gehad hoe deze studie er zou uitzien. De impact van de microcirculatie was voor mij duidelijk en zorgde ervoor dat wij vanaf het begin een gemeenschappelijk doel hadden. Mede in je kielzog had je Dirk Ubbink die van onschatbare waarde bleek voor het op een unieke manier verzamelen van de data over de microcirculatie. In de eindstrijd van mijn manuscript reageerde hij nog sneller dan Overtoom op mijn vragen. Hij kon naast zijn drukke werkzaamheden je verrassen door zo snel te reageren dat het leek alsof hij steeds voor het computerscherm zat.

Andries Bosch, op zoek naar een promotor binnen het terrein van de neurochirurgie, heb ik je gevraagd die taak op je te nemen. Je brede interesse voor pijn en functionele neurochirurgie speelt daar een belangrijke rol in. Je weet dat ik het jammer vind dat neurochirurgen te weinig met dit probleem begaan zijn. Ik wil je danken voor de openheid en de voortreffelijke manier waarop je mij hebt geholpen in deze voor mij niet zo makkelijke periode.

De leden van de beoordelingscommsisie dank ik voor de snelheid waarmee ze hun werk hebben gedaan, mede daardoor heb ik geen excuus om nog langer de verdediging van dit proefschrift uit te stellen.

Peter Theuvenet, jou wil ik bedanken niet alleen omwille van je participatie aan de vatenstudie waar wij min of meer onbekenden voor elkaar waren. In de periode nadien zorgde jij ervoor dat de werkgroep neuromodulatie zijn 
plaats kreeg waar ze nu staat: de eindfase van het kwaliteitsproject neuromodulatie voor pijn. Zonder jou was dit niet mogelijk geweest. Als ik even niet oplette, en ook op andere momenten, was je er steeds weer om te overleggen. Je onverdroten inzet voor dit kwaliteitsproject heeft ervoor gezorgd dat we als een van de eersten een prachtig project hebben gerealiseerd. Niet minder dank aan de leden van de werkgroep die onmisbaar zijn om het doel, kwaliteitszorg in de neuromodulatie voor pijn, te bereiken

In een dankwoord hoort tevens dat je de ouders betrekt. Ik doe dit met een persoonlijke attentie die verschillend is voor mijn ouders en schoonouders. Beiden hebben hun kinderen door alle perikelen, die de jeugd kan meebrengen, geloodst. Alhoewel de tijden veranderd zijn denk ik dat die inspanning niet te onderschatten is.

Mijn vader was als huisarts enorm begaan met de mensen en zijn vak. Van hem leerde ik hoe mooi dit vak kan zijn, maar anderzijds ook dat het je volledig kan opslorpen. Hij heeft gedurende jaren het woord "vakantie" vrijwillig geschrapt. Later heeft hij als adviserend geneeskundige in Leuven, een medisch minder hectische periode gekend. De kinderen kregen daardoor toch wat meer aandacht. Mijn moeder verstond de kunst om 7 kinderen groot te brengen zonder ons de indruk te geven dat het haar een grote last was. Altijd stond ze klaar en de periode voor de examens werd iedereen à la carte bediend. Dat is een kwestie van je thuis te voelen. Haar artistieke gaven resulteerden in menig expositie en later in het voorzitterschap van Arte, de kunstkring in Leuven. Een voorbeeld van haar creativiteit is de illustratie op het omslag van dit proefschrift. Je kan er naar kijken maar het duurt even vooraleer je ziet wat ermee bedoeld wordt. Zo hoort het ook, je moet niet alles meteen prijsgeven.

Mijn schoonouders dank ik op een andere manier. Niet alleen omdat een van hun dochters mij nu reeds jaren terzijde staat, maar om hun gedrevenheid eenieder zonder onderscheid te helpen. Wij hebben allen een goede verstandhouding en kunnen uitstekend met elkaar opschieten getuige daarvan de jaarlijkse vakanties. Het is dus echt niet te generaliseren wat men over schoonmoeders zegt.

Tenslotte mijn gezin, waarbij in eerste instantie Rita. Jij hebt het niet gemakkelijk in een mannenhuis. Door buitenstaanders wordt je bij herhaling gezien als de zus van onze zonen, niet alleen daardoor tref ik het. Alhoewel je ook carrière hebt willen maken heb je je toch op het "andere" plan als huismoeder waar gemaakt. Daarnaast spoorde je mij onafgebroken 
aan om dit proefschrift tot een goed einde te brengen. Excuses om het niet te doen had ik genoeg. Dan was het mijn functie als penningmeester van het wereldcongres, het stafvoorzitterschap of het kwaliteitsproject, laat staan de afdeling neurochirurgie. Uiteindelijk is het toch gelukt.

Als laatste de kinderen. Jullie zijn altijd erg zelfstandig geweest wat dit ook als gevolgen voor ons mocht hebben. Geregeld hadden we het over het medisch vak. Ik kan het mij goed voorstellen dat na drie generaties artsen, we er nu eentje overslaan. Misschien kan de volgende generatie het vaandel overnemen, wanneer de turbulentie verdwijnt die om het vak zit en die meer kwaad dan goed doet. Er zijn zoveel andere gebieden waar men goed werk kan doen en zich ten dienste kan stellen van anderen.

Bovenal is het van belang creatief te zijn. Wat stond er ook weer op de muur van een van de paviljoenen in Epcot? What you can dream, you can do! Die woorden verwijzen naar wat ik meen echt een boodschap is: de toekomst is aan hen die durven.

Het gaat jullie allen goed! 


\section{Curriculum}

Geboren lang geleden in Rumbeke, West Vlaanderen (B). Negen jaar op internaat bij de Jezuïeten in Gent (St Barbara).

1964 aanvang van de medische studies in Namen en Leuven alwaar hij in 1971 de graad van doctor in de Genees- Heel en Verloskunde behaalde met onderscheiding. Opleiding tot neurochirurg in Leuven van 1971 tot 1976. Drie maanden verblijf in Brazilië, Belo Horizonte bij Professor Crabral, vervolgens 1 jaar in de afdeling neurochirurgie te Homburg Saar (D) (Professor Loew).

1977 en 1978 neurochirurg te Genk (B).

Van 1979 tot 1995 neurochirurg verbonden aan het ziekenhuis De Wever Heerlen nu Atrium Heerlen.

1992 tot heden deeltijdse aanstelling in Maastricht en vanaf 1995 voltijds werkzaam in Maastricht.

\section{Belangrijkste activiteiten}

1989-1991 voorzitter beroepsbelangencommissie neurochirurgie 1993-1997 penningmeester van het $11^{\mathrm{e}}$ wereldcongres voor neurochirurgie te Amsterdam

1993-1995 voorzitter medische staf Heerlen 1994- voorzitter Nederlandse werkgroep neuromodulatie 1995- waarnemend hoofd afdeling neurochirurgie Maastricht 



\section{Acknowledgements}

\section{ESES STUDY GROUP}

- University Hospital Groningen: van den Dungen JJAM, Staal MJ

- Medisch spectrum Twente, Enschede: van Det RJ, van der Aa HE.

- De Weezenlanden Hospital, Zwolle: Kole EA

- St Antonius Hospital, Nieuwegein: Moll FL, Scholten E, Liem AL

- Medisch Centrum Alkmaar: van Dijk HA, Theuvenet PJ.

- Leyenburg Hospital, Den Haag: Sier JC, Lambooy N.

- St. Clara Hospital, Rotterdam: Yo TI, Kazemier G.

- St. Franciscus Gasthuis, Rotterdam: Wittens CHA.

- University Hospital Rotterdam-Dijkzigt: duBois NAJJ,Veeger AI, Hoedt MTC.

- Catharina Hospital, Eindhoven: Buth J.

- Atrium Medical Center, Heerlen: Bollen ECM, van Houtte HPJKM, Lens J.

- Maasland Hospital, Sittard: Hoofwijk AGM.

- University Hospital, Maastricht: Tordoir JHM.

- Lievensberg Hospital, Bergen op Zoom: Bikkers THA.

- St Geertruiden Hospital, Deventer: van Lent D, van Elk PJ

- University Medical Center, Amsterdam: Jacobs MJHM, Ubbink DTh.

- St. Jansdal Hospital, Harderwijk: van der Ham AC.

Grant: Sickness Funds Council (Health Insurance Executive Board), The Netherlands.

Grant: Medtronic BV, The Netherlands, Microcirculatory Investigation. 